A PROCEDURE FOR USING MULTIVARIATE NORMAL TOLERANCE REGIONS FOR THE CERTIFICATION OF RELATED CHARACTERISTICS

C. W. Holland 


\section{DISCLAIMER}

This report was prepared as an account of work sponsored by an agency of the United States Government. Neither the United States Government nor any agency Thereof, nor any of their employees, makes any warranty, express or implied, or assumes any legal liability or responsibility for the accuracy, completeness, or usefulness of any information, apparatus, product, or process disclosed, or represents that its use would not infringe privately owned rights. Reference herein to any specific commercial product, process, or service by trade name, trademark, manufacturer, or otherwise does not necessarily constitute or imply its endorsement, recommendation, or favoring by the United States Government or any agency thereof. The views and opinions of authors expressed herein do not necessarily state or reflect those of the United States Government or any agency thereof. 


\section{DISCLAIMER}

Portions of this document may be illegible in electronic image products. Images are produced from the best available original document. 
Reference to a company or product name does not imply approval or recommendation of the product by Union Carbide Corporation or the U.S. Atomic Energy Commission to the exclusion of others that may meet specifications.

\author{
Printed in the United States of America. Available from \\ National Technical Information Service \\ U.S. Department of Commerce \\ 5285 Port Royal Road, Springfield, Virginia 22151 \\ Price: Printed Copy $\$ 5.45$; Microfiche $\$ 2.25$
}

This report was prepared as an account of work sponsored by the United States Government. Neither the United States nor the United States Atomic Energy Commission, nor any of their employees, nor any of their contractors, subcontractors, or their employees, makes any warranty, express or implied, or assumes any legal liability or responsibility for the accuracy, completeness or usefulness of any information, apparatus, product or process disclosed, or represents that its use would not infringe privately owned rights. 


\title{
A PROCEDURE FOR USING MULTIVARIATE NORMAL TOLERANCE REGIONS FOR THE CERTIFICATION OF RELATED CHARACTERISTICS
}

\author{
C. W. Holland \\ Statistical Services Department \\ Y-12 Technical Division
}

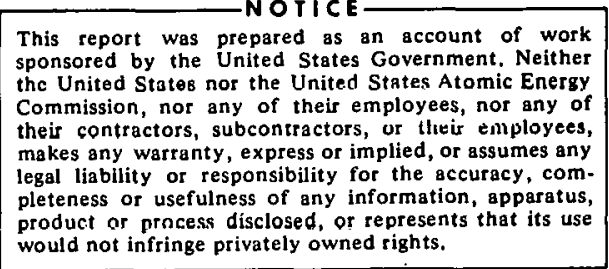

would not infringe privately owned rights.

Adapted from a dissertation that was submitted to The University of Tennessee in partial fulfillment of the requirements for the Degree Doctor of Philosophy.

\section{Oak Ridge Y-12 Plant}

P.O. Box Y, Oak Ridge, Tennessee 37830

Prepared for the U.S. Atomic Energy Commission Under U.S. Government "Contract W-7405trly-28 


\section{ABSTRACT}

The purpose of this investigation was to develop a complete procedure for the use of multivariate normal tolerance regions for the simultaneous certification of up to 30 related characteristics. A Monte Carlo integration technique was developed to investigate the accuracy of an approximation to the multivariate normal tolerance region. The results indicated that the approximation is sufficiently accurate for relatively small sample sizes. 


\section{CONTENTS}

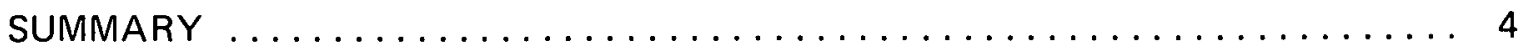

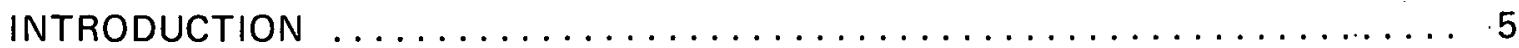

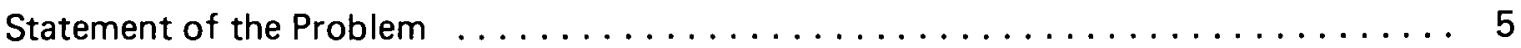

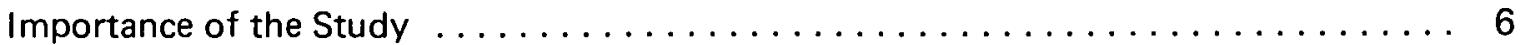

USING MULTIVARIATE NORMAL TOLERANCE REGIONS $\ldots \ldots \ldots \ldots \ldots \ldots$

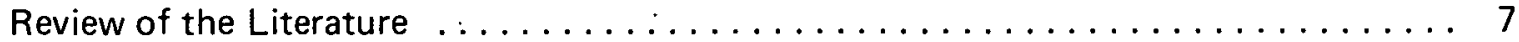

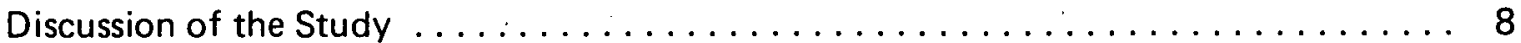

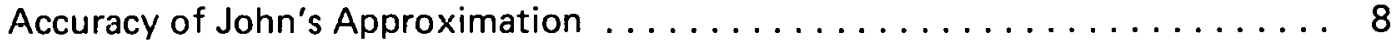

Procedure for Using Multivariate Normal Tolerance Regions . . . . . . . . . 12

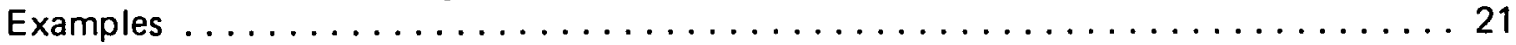

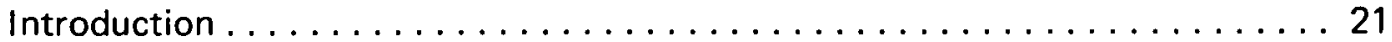

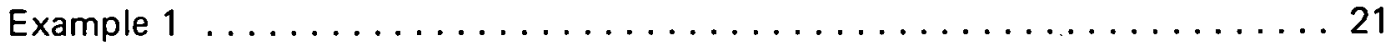

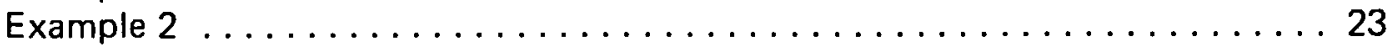

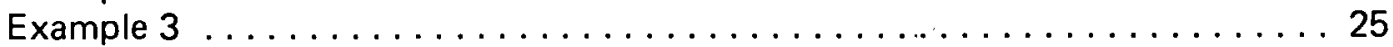

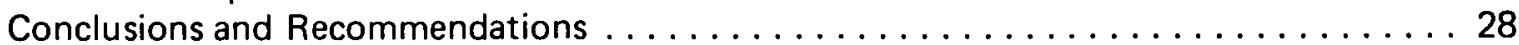

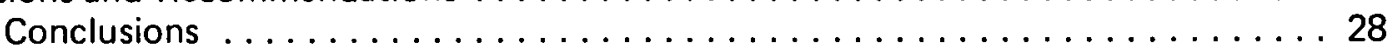

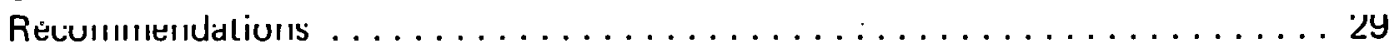

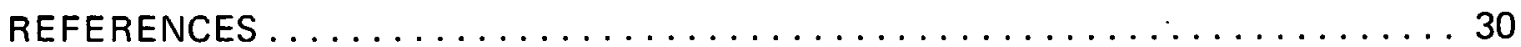

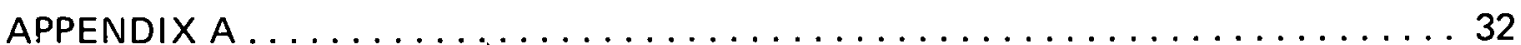

Program for Checking the Accuracy of John's Approximation . . . . . . . . . . . 32

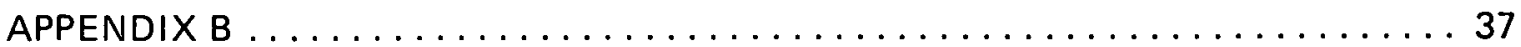

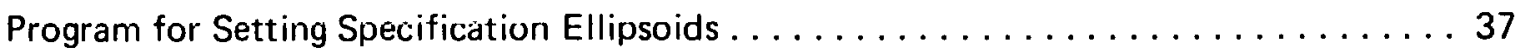

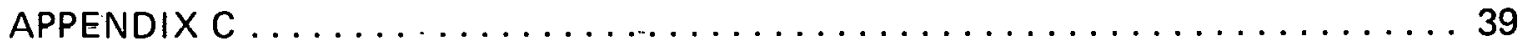

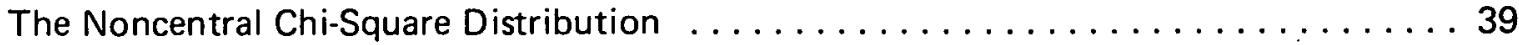

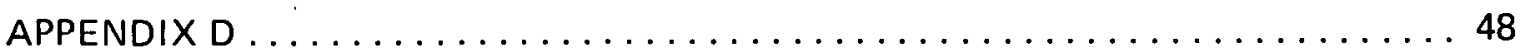

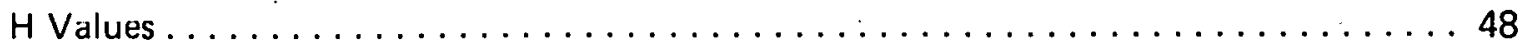

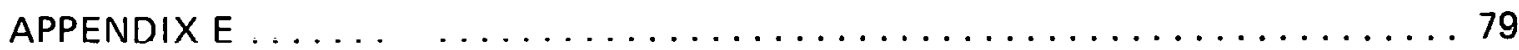

Program for Determining if the Tolerance Ellipsoid is is Within the Specification Ellipsoid . . . . . . . . . . . . . . . . 79

ACKNOWLEDGEMENTS $\ldots \ldots \ldots \ldots \ldots \ldots \ldots \ldots \ldots \ldots \ldots \ldots \ldots$ 


\section{SUMMARY}

The first step in the development of the procedure involved the determination of a method for setting specification regions. The method proposed involves using the univariate specification intervals to define a rectangular solid and using this rectangular solid in conjunction with an estimate of the variance-covariance matrix to inscribe a maximum-volume ellipsoid within the rectangular solid. This inscribed ellipsoid is the specification ellipsoid.

The second step in the development of the procedure involved generating a complete set of tables for determining the equation for the calculated tolerance ellipsoid that contains, with a certain $\gamma$ degree of confidence, a proportion, $P$, of the population of items. In generating these tables, the most complete set of noncentral Chi-Square tables in existence was generated.

The final step involved the development of a method for testing to see if the calculated tolerance ellipsoid is within the specification ellipsoid. If this test is positive, it can be said, with $100 \gamma \%$ degree of confidence, that at least $100 \mathrm{P} \%$ of the items meet the specification. 


\section{INTRODUCTION}

Manufactured items often have several continuous characteristics which must be measured to determine if the items conform to customer specifications. For example, a certain alloy part might have several metallurgical characteristics (such as tensile strength, elongation, and modulus of elasticity) and several chemical characteristics (such as major constituent content and various elemental impurity contents each of which must meet some specification). The procedure used to determine if the items conform to customer specification is often referred to as a "certification procedure". Sometimes the certification procedure involves $100 \%$ sampling or the measurement of each required characteristic on every item produced. Frequently, however, the quantities produced are so large that the time or cost involved prohibits measuring all characteristics on $100 \%$ of the items. In these situations, certification must be accomplished by using some form of sampling.

Methods commonly used to accomplish the certification in sampling situations involve the use of "univariate tolerance intervals" or "attribute acceptance plans". Univariate tolerance intervals are used to make confidence statements about a proportion of items from a population based on a random sample of items from the population; attribute acceptance sampling plans are used to make probability statements about the long-run average quality levels of the population of items based on random samples of items from fixed periods of production.

Both the univariate tolerance intervals and the attribute acceptance sampling plans offer advantages in that they are well documented, easy to use, and their properties have been extensively investigated. However, they also have some serious disadvantages: First, the confidence statements cannot be made about related characteristics simultaneously. Confidence statements must be made about each characteristic separately unless the characteristics are independent. (If the characteristics are statistically independent, the product rule of probability may be used to make statements about the probability that all characteristics meet the requirements simultaneously.) Also, the buyer cannot control the relationships between characteristics with the univariate tolerance intervals or the attribute acceptance sampling plans. Only the levels and variability of the individual characteristics can be controlled.

\section{STATEMENT OF THE PROBLEM}

Just as the univariate normal distribution is frequently assumed in industrial situations involving one variable, the multivariate normal distribution is frequently assumed in situations involving more than one variable. An approximation to the tolerance region for a multivariate normal distribution has been developed by John. (1)

The purpose of this study was to develop a complete systematic procedure for the use of multivariate normal tolerance regions in situations involving up to 30 variables. However, it was recognized that, for these regions to be of much practical value in industry, they must be reasonably accurate for relatively small. sample sizes. Consequently, before developing a procedure for their use, it was necessary to investigate the accuracy of John's approximation. Fortunately, this investigation indicated that the approximation is reasonably good even for small sample sizes. Based on this, a procedure for using these regions was developed. 
Facilities at the Oak Ridge National Laboratory,(a) Oak Ridge, Tennessee, were used in the pursuit of this study.

\section{IMPORTANCE OF THE STUDY}

Use of multivariate tolerance regions offers a solution to the problem of simultaneously certifying all characteristics of a production item. Through the use of these regions, legitimate confidence statements can be made about the entire set of characteristics rather than about each characteristic separately. A typical statement is: "We are $100 \gamma \%$ confident that at least $100 \mathrm{P} \%$ of the items meet the requirements for all characteristics." Also, use of multivariate tolerance regions allows a buyer to set his specifications so he can control the relationships between characteristics in addition to the levels and variabilities of the individual characteristics.

Despite the fact that multivariate tolerance regions offer some very worthwhile advantages, they are not used in industry. There are two principal reasons for this failure: First, very few people in industry are aware of the advantages of using the multivariate tolerance regions for certification purposes; further, even those who are aware of multivariate tolerance regions and their advantages cannot use them because a procedure for their use has not been developed.

Since the objective of this study is to produce a procedure for the use of multivariate normal tolernace regions for situations involving up to 30 variables; and, since the multivariate normal distribution can be assumed in a large proportion of cases, the results of this study should be extremely useful for certification purposes in industry and in other situations where it is desired to make confidence statements about multiple characteristics of a population of items based on a sample of the items.

(a) Operated for the USAEC by the Union Carbide Corporation's Nuclear Division. 


\section{USING MULTIVARIATE NORMAL TOLERANCE REGIONS}

\section{REVIEW OF THE LITERATURE}

Tolerance regions make it possible to make confidence statements about proportions of individuals of a population that are included within a given region. Tolerance regions differ from confidence regions in that confidence regions are confidence statements about certain parameters of a distribution. The earliest work on tolerance regions was by Wilks. (2) $\mathrm{He}$ considered the univariate case in which nothing was known about the probability density function except that it was continuous. He found a relatively simple method for determining a nonparametric tolerance interval for this situation. Wald (3) expanded Wilks' method to the multivaraite case, assuming that nothing was known about the joint probability density function except that it was continuous. Several authors have published later works on nonparametric tolerance regions. Nonparametric tolerance regions are very useful in situations where nothing is assumed to be known about the density function except that it is continous. However, the nonparametric regions have a disadvantage in that large sample sizes are required to make the desired confidence statements. Usually, if a specific density function can be assumed, a smaller sample size is required. In particular, Wald and Wolfowitz (4) have worked out a tolerance-interval solution for the univariate normal distribution which requires a much smaller sample size than the Wilks nonparametric interval solution. John(1) has extended their results to the multivariate normal distribution case. The tolerance region for the multivariate normal distribution developed by John is an ellipsoid.

If the sample mean, $m$, of an n number of observations is an unbiased estimate, $S$, of $\Sigma$ (the population variance-covariance matrix) distributed independently of $m$ as a Wishart variable with $f$ degrees of freedom, then the tolerance ellipsoid that has approximately $100 \gamma \%$ probability of containing at least $100 \mathrm{P} \%$ of the population has for its equation:

$$
H=(X-m)^{\prime} S^{-1}(X-m)=\frac{\chi^{\prime 2}(1-P, c, c / n)}{\left[\chi^{2}(\gamma, f c)\right] / f c}
$$

where:

C

n

$x=\left[x_{1}, x_{2}, \ldots, x_{c}\right]^{\prime}$

$m=\left(m_{1}, m_{2}, \ldots, m_{c}\right)^{\prime}$

$s=1$ represents the number of characteristics;

the number of items measured;

a c-dimensional random vector, where $X_{i}$ represents the ith characteristic;

the sample mean vector, where each $m_{i}$ term $=\left\langle X_{i l}+\ldots+\right.$ $\left.X_{\text {in }}\right) / n$, the sample mean of the ith characteristic;

the inverse of the sample covariance matrix of order, c; 


$$
\begin{aligned}
& \chi^{\prime 2}(a, f, \lambda) \quad \text { the upper } 100 a \% \text { point of } \chi^{\prime 2}(f, \lambda) \text {, the noncentral } \\
& \text { Chi-Square distribution with } f \text { degrees of freedom and } \\
& \text { noncentrality parameter, } \lambda \text {, defined by } P\left[\chi^{\prime} 2(f, \lambda)>\right. \\
& \left.\chi^{\prime 2}(a, f, \lambda)\right]=a \text {; } \\
& \chi^{2}(a, f) \\
& \text { the upper } 100 a \% \text { point of the Chi-Square distribution with } \\
& f \text { degrees of freedom; } \\
& \mathbf{P} \\
& \text { the proportion of population to be included in tolerance } \\
& \text { region, and } \\
& \gamma
\end{aligned}
$$

The main problem with John's work is that no tables of $H$ are given, and nothing is mentioned about the accuracy of the approximation.

Two very complete surveys of the tolerance region literature have been published in recent years. Chew (5) has surveyed the work done prior to 1965 and Guttman(6) has surveyed all work done prior to 1970, including a considerable amount of recent work in the area of Bayesian tolerance regions. Guttman also derives an approximation for the multivariate normal tolerance region using a different procedure from that of John. Both Guttman and Chew present tables for the multivariate normal case. However, these tables are very incomplete. Chew presents a table for $c=2$, with values of $n$ from 8 to 100; Guttman presents tables for $c=2,3$, and 4 , with $n$ greater than 100. Unfortunately, these tables are insufficient for most industrial applications.

Several additional articles have appeared in recent years concerning specific tolerance region problem areas, including such things as tolerance regions for censored distributions and the robustness of univariate normal tolerance regions. However, none of these documents consider the multivariate case.

\section{DISCUSSION OF THE STUDY}

\section{Accuracy of John's Approximation}

As mentioned earlier, the multivariate normal tolerance regions must be reasonably accurate for small sample sizes if they are to be of much practical value in industry. That is, if $g_{X}(\mu, \Sigma)$ denotes the multivariate normal density, the proportion of the multivariate normal population covered by regions, $R_{H}$, defines as all points satisfying the inequality:

$$
(X-m)^{\prime} S^{-1}(\dot{X}-m) \leqslant H
$$

must be such that:

$$
\text { prob }\left[\int \underset{\mathrm{R}_{\mathrm{H}}}{\ldots \int} \mathrm{g}_{\mathrm{X}}(\mu, \Sigma) \mathrm{dX} \mathrm{X}_{1} \ldots \mathrm{dX} \mathrm{C} \geqslant \mathrm{P}\right] \approx \gamma .
$$

Unfortunately, the integration of the multivariate normal distribution is extremely complicated when several variables are involved. Speck (7) has developed tables that can be used to integrate the trivariate normal distribution. Gupta(8) has summarized all 
multivariate normal integration work done prior to 1963, but all of it is confined to situations involving four or less variables. Milton $(9)$ has developed a computer program that obtains very accurate results, but his work indicates that the computer execution times would be prohibitive for situations involving up to 30 variables. Consequently, it appears that a practical method for integrating the multivariate normal distribution has not been described in the literature.

Kahn(10) suggested that Monte Carlo integration techniques were the most practical way to integrate multiple integrals involving a large number of variables. He stated that the major problem in performing the Monte Carlo multiple integration was that it required the generation of a large number of random points to achieve accurate results. However, there have been tremendous improvements in the computer execution speeds and in the quality of random-number generating techniques since 1954. Consequently, it was felt that the Monte Carlo technique might provide a solution to the problem of integrating the multivariate normal distribution for a large number of variables.

Based on Kahn's reasoning, a Monte Carlo procedure for performing the required integration was developed. The procedure consists of considering a given multivariate normal distribution, generating a very large sample of random points $(\mathrm{eg}, 25,000)$ from this distribution, and counting the number of points that fall on or inside the region of integration. The ratio of the number of points falling on or inside the region to the total number of points generated is an estimate of the value of the integral. The procedure can be repeated several times to obtain an estimate of the mean value of the integral and an estimate of the error associated with this mean value.

The success of the Monte Carlo integration procedure depends on the quality of the multivariate normal random number generator. The International Mathematical and Statistical Libraries (IMSL) statistical program library(11) contains a multivariate normal random number generator program that generates 247 random points before repeating itself. The quality of the numbers generated by this program was checked by comparing the integration results obtained using the program with some exact results. Twenty-five random samples of Size 1000 each were used to obtain the average value of each integral. The comparison is given in Table 1 for the case where $\mu=0, \Sigma=1$, and the region of integration is the positive $\mathrm{c}$-tant. The exact value of the integral is $2^{-} \mathrm{c}$.

This comparison indicated that the Monte Carlo integration technique gives reasonably accurate results using the original IMSL multivariate normal random number generator. Better accuracy could be obtained by increasing the number of random points used in the integration. However, the IBM 360-91 CPU execution time required to obtain the results in Table 1 was 24.97 seconds and it was felt that, for situations involving up to 30 variables, the execution time might be excessive. Consequently. ways to cut down on the execution time were investigated. It was felt that the

Table 1

COMPARISON OF MONTE CARLO INTEGRATION RESULTS WITH EXACT RESULTS FOR POSITIVE C-TANT

\begin{tabular}{ccll}
\hline $\begin{array}{c}\text { Number of } \\
\text { Variables }\end{array}$ & $\begin{array}{c}\text { Monte Carlo } \\
\text { Result }\end{array}$ & $\begin{array}{c}\text { Exact } \\
\text { Result }\end{array}$ & $\begin{array}{c}\text { Absolute } \\
\text { Difference }\end{array}$ \\
\hline 2 & 0.25308 & 0.250 & 0.00308 \\
3 & 0.12736 & 0.125 & 0.00236 \\
4 & 0.06412 & 0.0625 & 0.00162 \\
5 & 0.03224 & 0.03125 & 0.00099 \\
6 & 0.01552 & 0.015625 & 0.000105 \\
\hline
\end{tabular}


accuracy could be improved by improving the IMSL multivariate normal random number generator program. This program calculates $m$ multivariate normal random points by first calling a subroutine that calculates $m \times c$ univariate uniform random numbers and then calling another subroutine that transforms each of these uniform random numbers to a univariate normal random number. The univariate normal random numbers are transformed to an $\mathrm{m} \times \mathrm{c}$ matrix of multivariate normal deviates. The procedures used by the univariate normal and multivariate normal programs are described by Strecok(12) and Hurst and Knop, (13) respectively. These procedures appear to be the best available. However, the Oak Ridge National Laboratory Computer Library has a uniform random number subroutine developed by Coveyou(14) that is acknowledged by many numerical analysts to be the best in existence. Consequently, it was inserted into the IMSL multivariate normal random point generator program to see if the integration accuracy could be improved. The resulting program will be referred to hereafter as the "modified IMSL program".

In order to check out the modified IMSL program, it was felt that several known multivariate normal integrals should be evaluated. Anis and Lloyd (15) show that when the inverse of the covariance matrix has twos on the main diagonal, ones on the two adjacent diagonals, and zeros elsewhere, the value of the integral over the positive $c$-tant is $1 /(1+c)$. A comparison between the Monte Carlo results obtained using the modified IMSL program and the exact results is given in Table 2 for $\mu=0, R=\left\{X: 0 \leqslant X_{1}<\infty\right\}$, and two types of covariance matrices. The first type is $\Sigma=1$ and the second is the special matrix of Anis and Lloyd.

Titsle 2

COMPARISON OF MONTE CARLO INTEGRATION RESULTS OBTAINED USING THE MODIFIED IMSL PROGRAM WITH EXACT RESULTS FOR POSITIVE C-TANT

\begin{tabular}{|c|c|c|c|c|}
\hline $\begin{array}{l}\text { Number of } \\
\text { Variables }\end{array}$ & $\begin{array}{c}\text { Type Variance- } \\
\text { Covariance Matrix }\end{array}$ & $\begin{array}{l}\text { Exact } \\
\text { Result }\end{array}$ & $\begin{array}{c}\text { Monte Carlō } \\
\text { Result }\end{array}$ & $\begin{array}{l}\text { Absolute } \\
\text { Difference }\end{array}$ \\
\hline \multirow[t]{2}{*}{2} & $\Sigma=1$ & 0.2500 & 0.25066 & 0.00066 \\
\hline & Anis and Lloyd & U.3333 & U.333/8 & 0.00048 \\
\hline \multirow[t]{2}{*}{3} & $\Sigma=1$ & 0.1250 & 0.12573 & 0.00073 \\
\hline & Anis and Lloyd & 0.2500 & 0.25048 & 0.00048 \\
\hline \multirow[t]{2}{*}{4} & $\Sigma=1$ & 0.0625 & 0.06147 & 0.00103 \\
\hline & Anis and Lloyd & 0.20000 & 0.19972 & 0.00028 \\
\hline \multirow[t]{2}{*}{5} & $\Sigma=1$ & 0.03125 & 0.03146 & 0.00021 \\
\hline & Anis and Lloyd & 0.16667 & 0.16592 & 0.00075 \\
\hline \multirow[t]{2}{*}{6} & $\Sigma=1$ & 0.01562 & 0.01559 & 0.00003 \\
\hline & Anis and Lloyd & 0.14286 & 0.14181 & 0.00105 \\
\hline 30 & Anis and Lloyd & 0.03226 & 0.03291 & 0.00065 \\
\hline
\end{tabular}


As indicated in the table, the approximation is considerably better than that obtained using the original program and is good enough for the purposes of this study. Also, the IBM 360-91 CPU execution time required to obtain the result for $c=30$ was only 4.7 seconds. This reasonable time lapse indicates that Monte Carlo integration is a practical and reasonably accurate technique for integrating the multivariate normal distribution on high-speed computers.

The accuracy of John's approximation for a given number of characteristics was investigated by the following procedure:

1. A random sample of $n$ points was generated from the $c$-variate normal distribution with density $g_{X}(\mu, \Sigma)$.

2. A tolerance ellipsoid was calculated from the sample data.

3. The c-variate normal density was integrated over the calculated tolerance ellipsoid region by the previously described Monte Carlo integration technique using 25 random samples of size 1000 each.

4. Steps 1 - 3 were repeated one hundred times to obtain a frequency distribution of the proportion of the population covered.

A computer program that performs the four steps just enumerated is given in Appendix A. The program also calculates the standard error for each integral value obtained in Step 3 . The standard errors obtained were approximately equal to $\sqrt{P(1-P) / 25,000}$. All 1000 random points in a sample are obtained by a single call of the modified IMSL program in order to cut down on computer execution time.

Perhaps the procedure can best be understood by considering the analogous one-variable problem. Given a univariate normal distribution with mean, $\mu$, and a variance, $\sigma^{2}$ (as noted in Figure 1), a sample of size, $n$, is generated from this distribution and the univariate tolerance limits, $S_{1}$ and $S_{2}$, are calculated using these sample data. Then, the normal

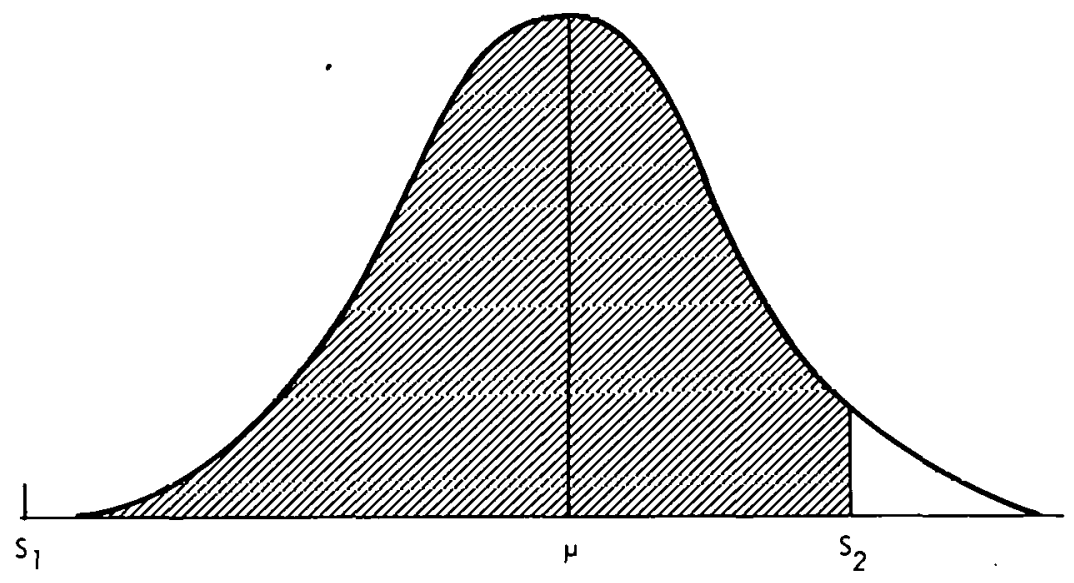

Figure 1. COVERAge OF $N(\mu, \sigma)$ DISTRIBUTION BY INTERNAL $\left(S_{1} S_{2}\right)$. (Ghaded Alud Rupresents the Coverage) 
distribution with mean, $\mu$, and variance, $\sigma 2$, is integrated from $S_{1}$ to $S_{2}$ by generating 1000 random numbers from this distribution and counting the ones that fall within the calculated region. The ratio of the ones that fall within the region to the total number generated yields an estimate of the proportion of the population covered by the region. This procedure is repeated 25 times and the estimated value of the integral is the average of the 25 proportions. A frequency distribution of the coverage is obtained by generating one hundred estimated values of the integral.

The procedure yields an estimate of the distribution of the proportion of the population covered by tolerance ellipsoids obtained using John's approximation for a fixed sample size, a fixed number of characteristics, a given variance-covariance matrix, and fixed $\gamma$ and $P$. For example, Figure 2 shows for $n$ values of 5, 10,20, and 40, frequency distributions of the proportion of the population covered by the calculated tolerance ellipsoids for $c=2$, $\gamma=P=0.95$ and the variance-covariance matrix obtained for the first two characteristics of Table A-1, Appendix A. An estimate of the sample size required for the approximation to be accurate for any number of characteristics can be obtained by repeating the procedure for varying sample sizes and a varying number of characteristics. Figures A-1 through A-6 in Appendix $A$ show the average proportion of the population covered for varying sample sizes with $\mathrm{c}=5,10,20$, and 30 characteristics, respectively, where the characteristics involved are the first characteristics of Tables A-1 through A-6 of Appendix A.

As indicated in Figure 2 and in Figures 3 through 6, John's approximation is valid for small sample sizes and appears to be conservative for large sample sizes. That is, for large samples the probability that the proportion of the population covered will be at least $P$ is larger than $\gamma$. For example, when $n=40, c=2$, and $\gamma=P=0.95$, the estimate of the probability is 0.97 that the proportion of the population covered is at least 0.95 ; for $c=5$ and $n=100$, the estimated probability is 0.99 that the proportion of the population covered is at least 0.95 . When $c=30$, a sample size of 30 is not nearly sufficient. Based on the results shown in Figures 2 through 6, it appears that a good rule of thumb is that the approximation is sufficiently accurate for $n \geqslant c^{2}$ for $c$ less than 10 , for $n \geqslant c 2 / 2$ for $c$ between 10 and 20 , and for $n \geqslant c 2 / 3$ for $c \geqslant 20$.

Similar studies could be performed for other variance-covariance matrices, and it is possible that different sample sizes would be required for vastly different variance-covariance matrices. However, it is felt that the matrix, which is based on actual data obtained from a preproduction process described more fully the section that follows, entitled EXAMPLES, is fairly representative of most situations involving multiple characteristics. Also, similar studies could be performed for other values of $P$ and $\gamma$.

\section{Procedure for Using Multivariate Normal Tolerance Regions}

Introduction - The procedure for using the multivariate normal tolerance regions is as follows:

1. A specification region is established. This specification region is in the form of an ellipsoid.

2. A random sample of $n$ items is taken over a given time period of production. Each specified characteristic is measured on each sampled item. 

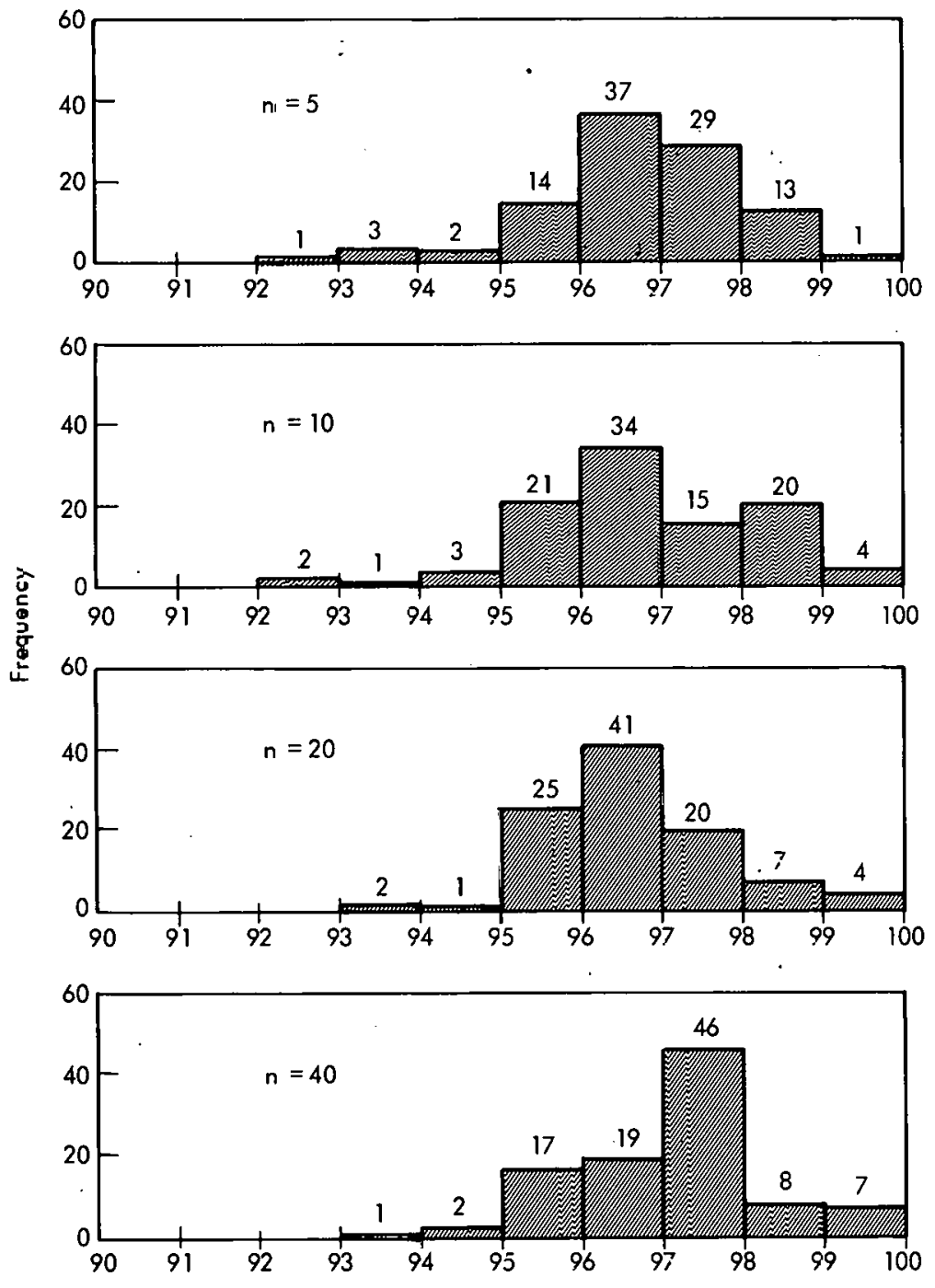

Figure 2. FREQUENCY DISTRIBUTIONS OF THE PROPORTION COVERED FOR $\mathrm{c}=2, \gamma=0.95$, AND $\mathrm{P}=0.95$.
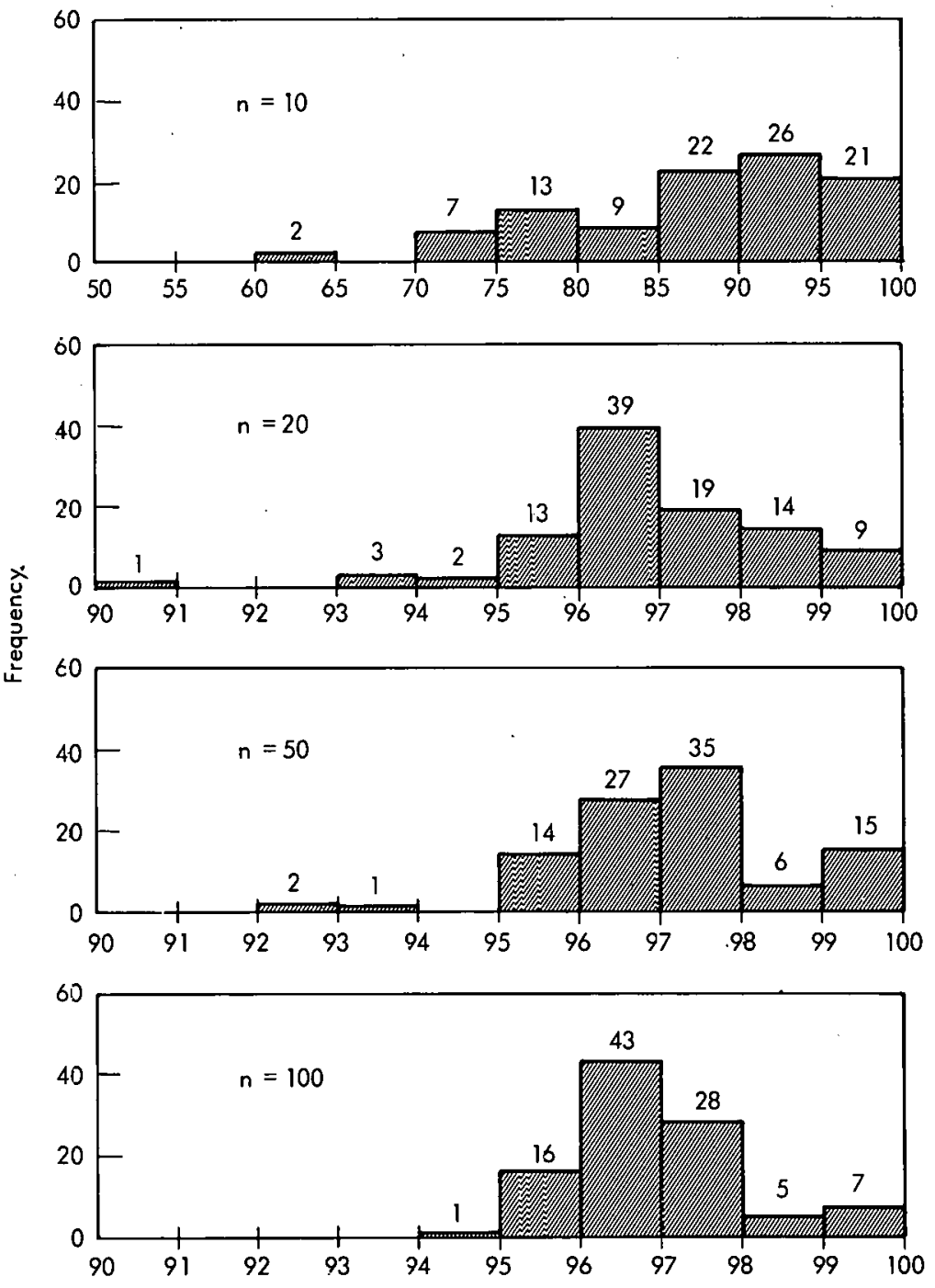

Figure 3. FREQUENCY DISTRIBUTIONS. OF THE PROPORTION COVERED FOR $\mathrm{c}=5, \gamma=0.95$, AND $\mathrm{P}=0.95$. 

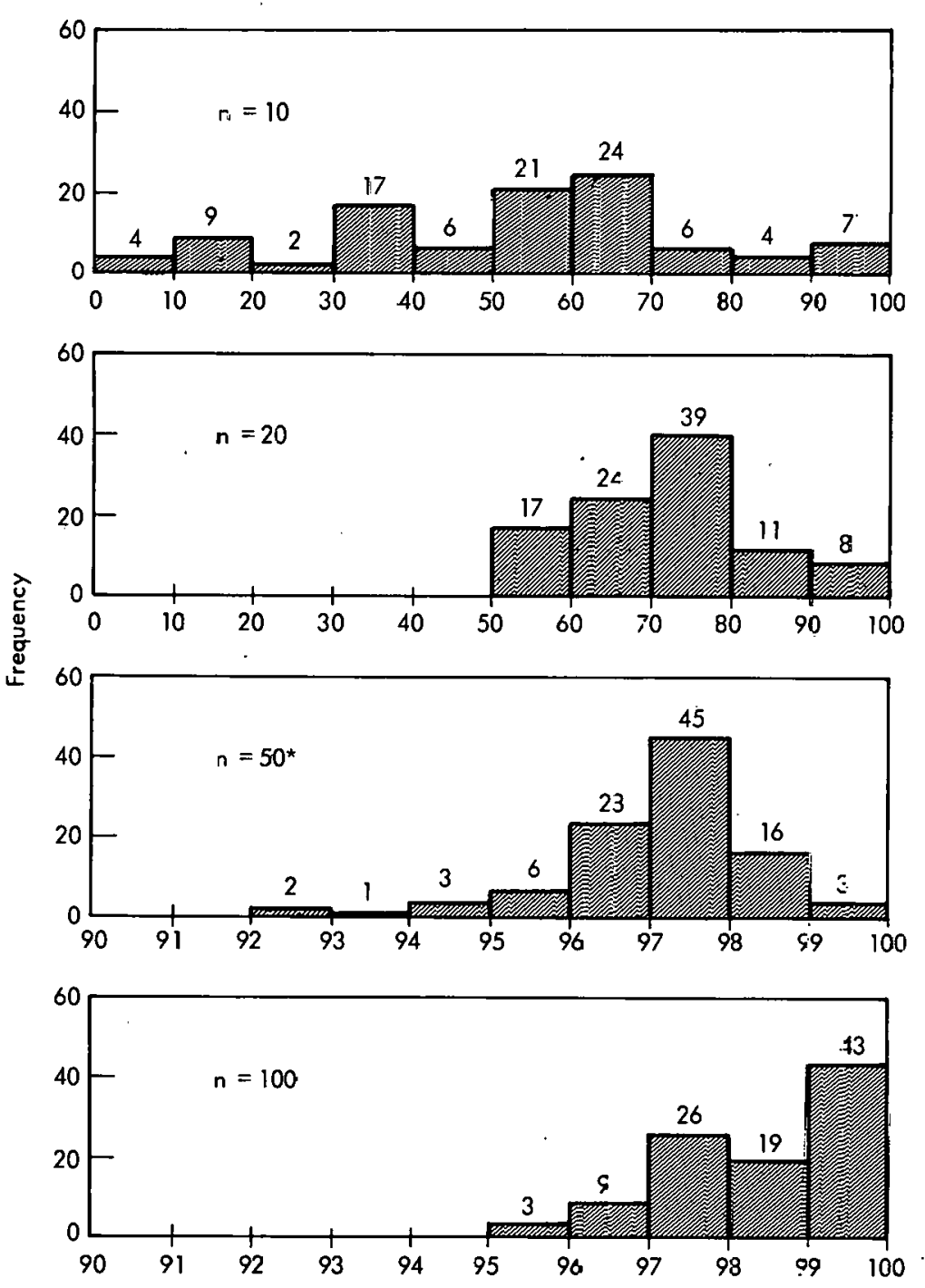

*One value of 88.7 not shown.

Figure 4. FREQUENCY DISTRABUTIONS OF THE PROPORTION COVERED FOR $c=10, \gamma=0.95$, AND $P=0.95$.
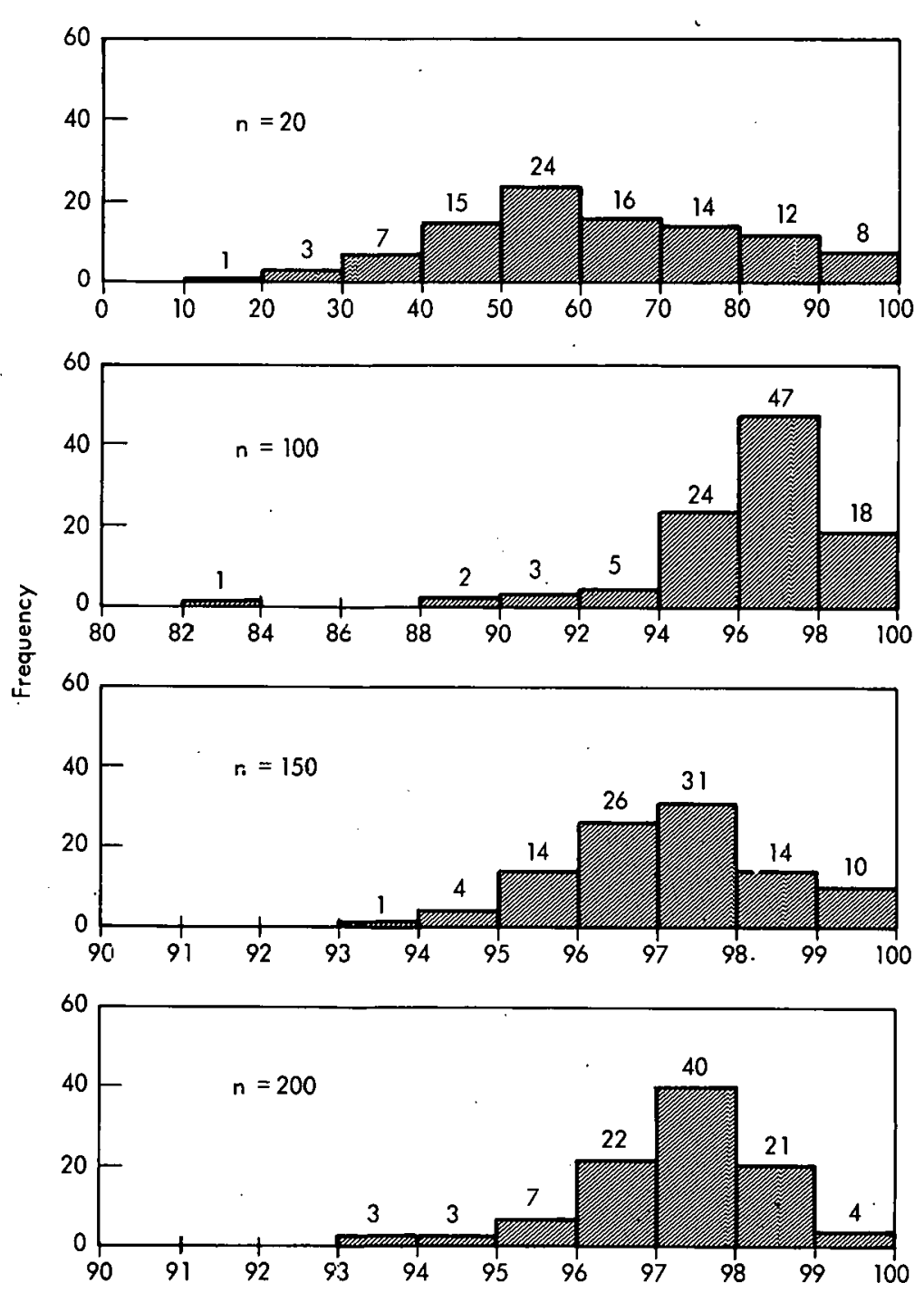

Figure 5. FREQUENCY DISTRIBUTIONS OF THE PROPORTION COVERED FOR $\mathrm{c}=20, \gamma=0.95$, AND $P=0.95$. 
3. The data generated in Step 2 are used to calculate a tolerance ellipsoid within which it can be said, with $\gamma$ degree of confidence, that at least a proportion, $P$, of the population of items fall.

4. If the calculated tolerance ellipsoid is completely within the specification ellipsoid, the items produced during the given production period are acceptable. Otherwise, they are - not acceptable.

Method for Constructing the Specification Ellipsoid-Using ellipsoids for specification regions allows the buyer to control the relationship among characteristics as well as the level and variability of each characteristic. However, the question arises of what method should be used to construct the specification ellipsoid. One possible method suggested by Bradley and Jackson(16) is to start with a rectangular solid defined by the univariate specification limits, use an estimate of the variance-covariance matrix, and inscribe a maximum-area ellipsoid within the rectangular solid. Of course, this method results in a smaller specification region than the rectangular region, and offers the intuitive appeal to the buyer that the resulting acceptance region will not contain any points outside the rectangular solid.

Bradley and Jackson's procedure for inscribing a maximum ellipsoid within a rectangular solid is as follows for this situation: Suppose the upper and luwer speciflcation limits for characteristic, i, is $\mathrm{S}_{i u}$ and $\mathrm{Sil}_{\mathrm{i}}$, then shift the center of the specification to the origin by the transformation $L_{i u}=S_{i u}-\left(S_{i u}+S_{i l}\right) / 2, i=1$, $2, \ldots$, c. First, consider the side Llu, the transformed upper specification limit for the first characteristic. It is desirable to find the equation for an ellip. soid that is symmetric about the center of the solid which will just touch this side. To do this, first form the equation:
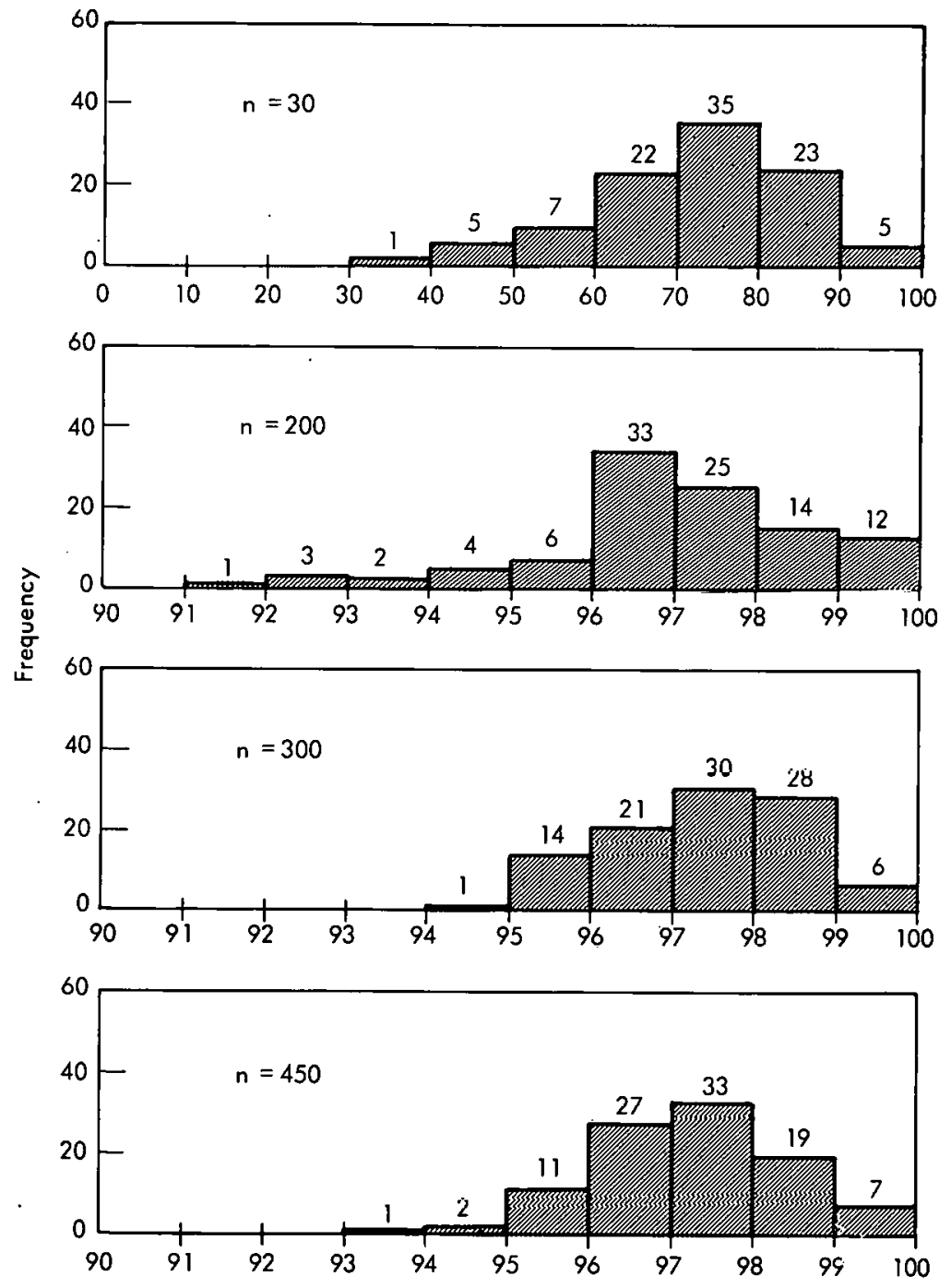

Figure 6. FREQUENCY DISTRIBUTIONS OF THE PROPORTION CUVERED FOR $\mathrm{s}=30, \gamma=0.95$, AND $\mathrm{P}=0.05$. 


$$
\lambda 2=\left[L_{l u}, X_{2}, X_{3}, \ldots, X_{c}\right] \widehat{\Sigma}-1\left[L_{l u}, X_{2}, X_{3}, \ldots, X_{c}\right]^{\prime},
$$

in which $\widehat{\Sigma}$ represents a sufficiently good estimate of the variance-covariance matrix. The desired ellipsoid is then obtained by solving the following system of equations for $X_{2}, X_{3}$, $\ldots, \mathrm{X}_{\mathrm{c}}$ :

$$
\begin{aligned}
& \frac{\partial \lambda^{2}}{\partial X_{2}}=\frac{\partial}{\partial X_{2}}\left[L_{l u}, X_{2}, X_{3}, \ldots, X_{c}\right] \hat{\Sigma}^{-1}\left[L_{l u}, X_{2}, X_{3}, \ldots, X_{c}\right]^{\prime}=0 \\
& \frac{\partial \lambda 2}{\partial X_{3}}=\frac{\partial}{\partial X_{3}}\left[L_{l u}, X_{2}, X_{3}, \ldots, X_{c}\right] \cdot \widehat{\Sigma}^{-1}\left[L_{u}, X_{2}, X_{3}, \ldots, X_{c}\right]^{\prime}=0, \ldots \\
& \frac{\partial \lambda 2}{\partial X_{c}}=\frac{\partial}{\partial X_{c}}\left[L_{l u}, X_{2}, X_{3}, \ldots, X_{c}\right] \hat{\Sigma}^{-1}\left[L_{l u}, X_{2}, X_{3}, \ldots, X_{c}\right]^{\prime}=0
\end{aligned}
$$

The values of $x_{2}, x_{3}, \ldots, x_{c}$ can be substituted back into the original expression for $\lambda 2$. This procedure can then be repeated for the remaining surfaces: $X_{2}=L_{2} u, X_{3}=L_{3} u, \ldots$, $X_{c}=L_{c u}$. The minimum value of $\lambda 2$ obtained from these $c$ determinates will define the

\begin{tabular}{|c|c|c|c|c|}
\hline \multirow[b]{2}{*}{ Characteristic } & \multicolumn{2}{|c|}{ Specification Limits } & \multicolumn{2}{|c|}{$\begin{array}{c}\text { Transformed } \\
\text { Specification Limits }\end{array}$} \\
\hline & Upper & Lower & Upper & Lower \\
\hline$x_{1}$ & +12 & +8 & +2 & -2 \\
\hline$x_{2}$ & +15 & +9 & +3 & -3 \\
\hline
\end{tabular}
largest ellipsoid that can be inscribed in the rectangular solid.

The procedure can be illustrated by an example. Suppose a two-characteristic situation is present with the following specification limits:

Further, suppose that the following estimate of the variance-covariance matrix has been obtained:

$$
\hat{\Sigma}=\left[\begin{array}{ll}
\frac{2}{3} & \frac{1}{2} \\
\frac{1}{2} & 1
\end{array}\right] \text {. }
$$


Then:

$$
\begin{aligned}
& \lambda 2=\left[x_{1}, x_{2}\right]\left[\begin{array}{cc}
\frac{12}{5}-\frac{6}{5} \\
-\frac{6}{5} & \frac{8}{5}
\end{array}\right]\left[\begin{array}{l}
x_{1} \\
x_{2}
\end{array}\right] \text {, or } \\
& \lambda^{2}=\frac{12}{5} x_{1}^{2}-\frac{12}{5} x_{1} x_{2}+\frac{8}{5} x_{2}^{2} .
\end{aligned}
$$

Hence, if $X_{1}=+2$ :

$$
\begin{aligned}
& \lambda_{2}=\frac{8}{5} x_{2}^{2}-\frac{24}{5} x_{2}+\frac{48}{5}, \text { and } \\
& \frac{\partial \lambda^{2}}{\partial x_{2}}=\frac{16}{5} x_{2}-\frac{24}{5}=0 x_{2}=1.5
\end{aligned}
$$

Substituting $X_{2}=1.5$ into this equation, and solving for $\lambda 2$, yields:

$$
\lambda 2=\frac{8}{5}\left[\frac{3}{2}\right]^{2}-\frac{24}{5}\left[\frac{3}{2}\right]+\frac{48}{5}=6 \text {. }
$$

Repeating the procedure for the $X_{2}=+3$ side yields $\lambda 2=9$. Hence, the equation for the maximum area ellipse that can be inscribed within the rectangle defined by $X_{1}= \pm 2$ and $X_{2}= \pm 3$ is:

$$
\frac{12}{5} x_{1}^{2}-\frac{12}{5} x_{1} x_{2}+\frac{8}{5} x_{2}^{2}=6
$$

The rectangle and the inscribed ellipse are illustrated in Figure 7.

The method can be used for a problem involving any number of characteristics. A computer program that uses this procedure to find the equation for the specification ellipsoid is given in Appendix B.

Determination of $\mathbf{H}$ Values - To evaluate $H$ requires the percentage points of the noncentral Chi-Square distribution. Haynam and Leone(17) have developed the most complete set of tables available. Also, Fix, (18) Patnaik, (19) and Siotani(20) have published limited tables and graphs. Unfortunately, not one of these tables is nearly complete enough to satisfy the needs of this study.

Consequently, a computer program was developed to calculate the percentage points of the noncentral Chi-Square distribution. The program makes use of the following equation from the National Bureau of Standards Handbook of Mathematical Functions (1964)(21): 


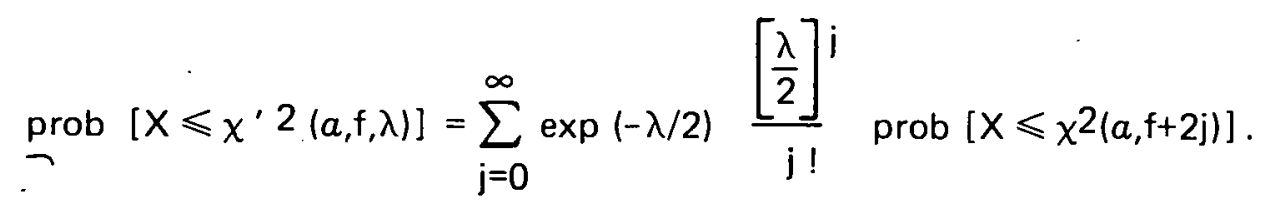

The proqram utilizes the IMSL statistical subroutine to obtain the probabilities for the central Chi-Square distribution. The indicated summation is then pertormed until the summation converges. The result is the probability that a noncentral Chi-Square distributed

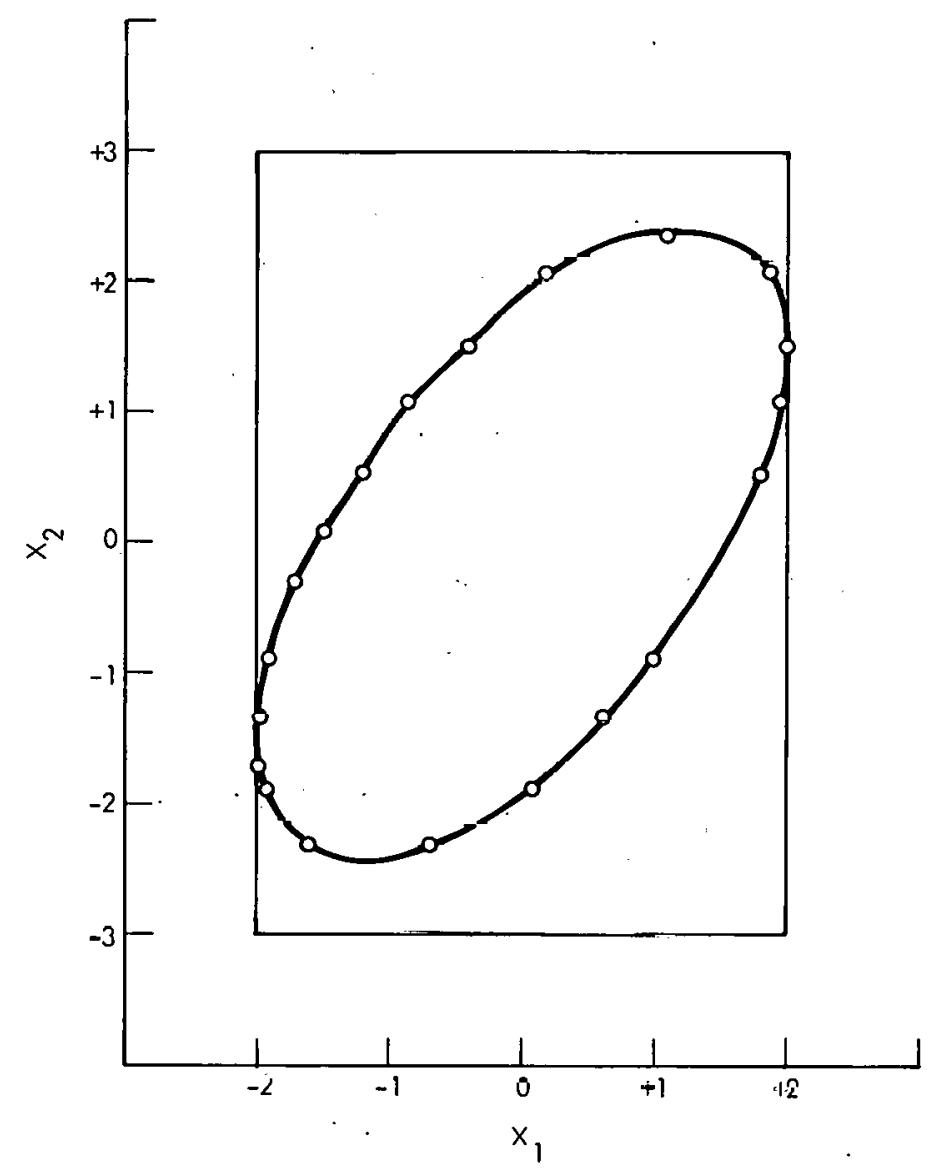

Figure 7. SPECIFICATION ELLIPSE INSCRIBED WITHIN THE RECTANGLE GENERATED BY UNIVARIATE SPECIFICATION LIMITS.

random variable is less than some particular value. Therefore, if $f_{Z}(f, \lambda)$ is the density function of the noncentral Chi-Square variable with $f$ degrees of freedom and noncentrality parameter, $\lambda$, the percentage points are then obtained by solving for $\chi^{\prime 2}(a, f, \lambda)$ in the equation:

$$
\text { prob }\left[X \geqslant \chi^{\prime 2}(a, f, \lambda)\right]=1-\int_{0}^{\chi^{\prime 2(a, f, \lambda)}} f_{z}(f, \lambda) d z=a
$$


This equation was solved for $\chi^{\prime 2}(a, f, \lambda)$ by using the guaranteed convergence technique given in Brent ${ }^{(22)}$. The complete program is given in Appendix $C$. The results obtained using the program are compared in Table 3 with some of the exact published results given by Patnaik.

Based on these results it appears that this computer program yields very accurate percentage points of the noncentral Chi-Square distribution. Tabulated values of the noncentral Chi-Square distribution for various values of $\lambda$ and $a$ are given in Tables C-1 through C-6 of Appendix C. Another more complete set of tables has been prepared and will be published in a subsequent report. This noncentral Chi-Square table is more complete than any of those known to have been previously published. The IBM 360-91 time required to produce the entire table was less than 30 seconds.

The program for the percentage points of the noncentral Chi-Square distribution was used in conjunction with the IMSL inverse-central Chi-Square subroutine to produce a set of tables . for $H$. These values with $\lambda=0.90,0.95$, and $0.99 ; P=0.90,0.95$, and 0.99 , and $c=2$ to 30 for selected values of $n$ are given in Tables D-1 through D-29 of Appendix D. The tables for $c=2$ agree closely with those given by Chew and should be more accurate than Chew's values since more accurate noncentral Chi-Square values have been used.

Method to Determine if the Tolerance Ellipsoid is Within the Specification Ellipsoid - The equation for the tolerance ellipsoid is:

$$
(X-m)^{\prime} S^{-1}(X-m)=H
$$

and the equation for the specification ellipsoid is:

$$
x^{\prime} \Sigma-1 X=\lambda^{2}
$$

These equations can be normalized to obtain:

$$
\begin{gathered}
(X-m)^{\prime} B(X-m)=1 \text { where } B=S^{-1 / H, \text { and }} \\
X^{\prime} A X=1 \text { where } A=\Sigma^{-1 / \lambda 2} .
\end{gathered}
$$

The following procedure can be used to determine if the tolerance ellipsoid is within the specification ellipsoid:

1. Maximize:

$$
f(X)=(X-m)^{\prime} B(X-m),
$$

subject to:

$$
g(X)=X^{\prime} A X-1=0 .
$$


2. Substitute the solution of Step 1 (say $X^{*}$ ) into $f(X)$ to obtain the maximum value of $f$.

3. If $f\left(X^{*}\right)<1$, the tolerance ellipsoid is partially outside the specification ellipsoid; if $f\left(X^{*}\right)$ $>1$, the tolerance ellipsoid is completely within or outside of the specification ellipsoid; if $f\left(X^{*}\right)=1$, the tolerance ellipsoid just touches the specification ellipsoid.

4. If $f\left(X^{*}\right) \geqslant 1$, compute $m^{\prime}$ Am. If this quadratic form is $>1$, the tolerance ellipsoid is outside the specification ellipsoid, otherwise it is within the specification ellipsoid.

The procedure can be illustrated by an example. Consider the problem of determining if the specification ellipse illustrated in Figure 7 contains the tolerance ellipse:

$$
\left[\left(x_{1}-1, x_{2}-1\right)\right]\left[\begin{array}{rr}
2.0 & -1.0 \\
-1.0 & 2.0
\end{array}\right]\left[\begin{array}{ll}
x_{1} & -1 \\
x_{2} & -1
\end{array}\right]=4
$$

The problem is to maximize: $f(x)=\frac{1}{2}\left(x_{1}^{2}+x_{2}^{2}-x_{1} x_{2}-x_{1}-x_{2}+1\right)$, subject to:

$$
\frac{12}{5} x_{1}^{2}-\frac{12}{5} x_{1} x_{2}+\frac{8}{5} x_{2}^{2}-6=0
$$

The Lagrange multiplier technique can be used to solve this problem when $\mathrm{c}$ is small. However, use of this technique results in a problem of solving $c+1$ nonlinear equations for $c+1$ unknowns, and this is extremely difficult for large c. The Oak Ridge National Laboratory Computer Library has a subroutine called GRADIENT that can be used to solve an optimization problem involving a nonlinear objective function and nonlinear constraints. (23) This subroutine uses a gradient technique to find the maximum of the function. Applications of this subroutine to this problem yielded a solution of $X_{1}^{*}=1.925$ and $X_{2}{ }^{*}=2.000$ for which $f\left(X^{*}\right)=0.461$. Since $f\left(X^{*}\right)$ is $<1$, the tolerance ellipse has to be reduced before it fits within the specification ellipse, as noted in Figure 8.

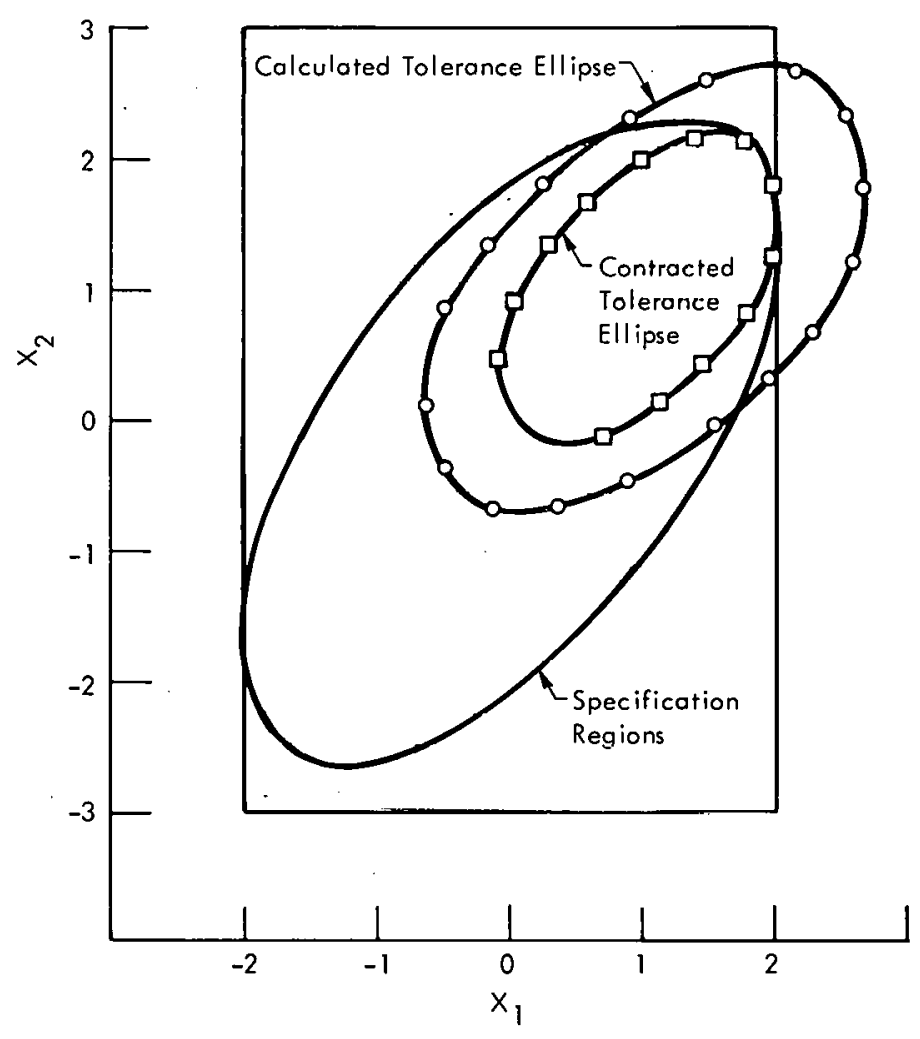

Figure 8. CONTRACTION OF A TOLERANCE ELLIPSOID If $\left.\left(X^{\prime \prime}\right)=0.461\right]$. 
The procedure will work in all instances except for the unlikely case where $m=0$, and $A=B$. A computer program that checks to see if the tolerance ellipsoid is within the specification ellipsoid is given in Appendix E. This program utilizes the subroutine GRADIENT. The program first checks to determine if $m=O$ and $A=B$. If both of these conditions exist, the tolerance ellipsoid is the same as the specification ellipsoid. Otherwise, the steps of the procedure are performed.

\section{EXAMPLES}

\section{Introduction}

This report section provides illustrations of the use of the multivariate normal tolerance regions through three examples. The items involved are machined uranium alloy parts. There are 30 characteristics that must be measured and certified: four metallurgical characteristics, three major chemical characteristics, and 23 chemical impurity characteristics. The metallurgical and chemical samples for each measured part are taken from the excess material that is removed during the machining process.

These examples utilize data from 106 preproduction parts used to construct the 30 characteristic variance-covariance matrix given in Tables A-1 through A-6. The first example illustrates each step of the procedure for using multivariate tolerance regions to certify product characteristics for a three-characteristic situation, the second example illustrates the case where the relationship between characteristics changes for a two-characteristic situation, the third example illustrates the use of the procedure for 13 of the characteristics.

\section{Example 1}

This example illustrates each step of the procedure for using the multivariate normal tolerance regions. The characteristics involved are the first three in Table A-1. The assumed population variance-covariance matrix and its inverse are:

$$
\begin{aligned}
\hat{\Sigma} & =\left[\begin{array}{rrr}
0.0563 & -0.0194 & -0.0057 \\
-0.0194 & 0.0167 & 0.0038 \\
-0.0057 & 0.0038 & 0.0014
\end{array}\right], \text { and } \\
\hat{\Sigma}^{-1} & =\left[\begin{array}{rrr}
32.59 & 20.05 & 78.28 \\
20.05 & 168.93 & -376.89 \\
78.28 & -376.89 & 2056.02
\end{array}\right]
\end{aligned}
$$


Hence, the equation for the specification ellipsoid is:

$$
\left(x_{1}, x_{2}, x_{3}\right)\left[\begin{array}{rrr}
32.59 & 20.05 & 78.28 \\
20.05 & 168.93 & -376.89 \\
78.28 & -376.89 & 2056.02
\end{array}\right]\left[\begin{array}{l}
x_{1} \\
x_{2} \\
x_{3}
\end{array}\right]=\lambda^{2}
$$

The original and transformed univariate specification intervals are:

\begin{tabular}{cccccc}
\hline & \multicolumn{2}{c}{$\begin{array}{c}\text { Original Univariate } \\
\text { Specification Limits }\end{array}$} & & \multicolumn{2}{c}{$\begin{array}{c}\text { Transformed Univariate } \\
\text { Specification Limits }\end{array}$} \\
\cline { 2 - 4 } Variable & Upper & Lower & & Upper & Luvver \\
\hline$X_{1}$ & 91.0 & 89.0 & 1.0 & -1.0 \\
$X_{2}$ & 8.20 & 6.80 & 0.7 & -0.7 \\
$X_{3}$ & 2.75 & 2.25 & 0.25 & -0.25 \\
\hline
\end{tabular}

An application of the computer program for inscribing an ellipsoid within a rectangular solid, given in Appendix B, yields the specification ellipsoid:

$$
\left(x_{1}, x_{2}, x_{3}\right)\left[\begin{array}{rrr}
32.59 & 20.05 & 78.28 \\
20.05 & 168.93 & -376.89 \\
78.28 & -376.89 & 2056.02
\end{array}\right]\left[\begin{array}{l}
x_{1} \\
x_{2} \\
x_{3}
\end{array}\right]=17.76
$$

The data in Table 4 were obtained from a recent month's production of parts. Estimates of the mean vector, variance-covariance matrix, and its inverse calculated from these data are:

$$
\begin{aligned}
& \mathrm{m}=\left[\begin{array}{c}
90.06 \\
7.50 \\
2.51
\end{array}\right] \quad \mathrm{s}=\left[\begin{array}{ccc}
0.0892 & -0.0271 & -0.0066 \\
-0.0271 & 0.0139 & 0.0028 \\
-0.0066 & 0.0028 & 0.0010
\end{array}\right], \text { and } \\
& \mathrm{s}^{-1}=\left[\begin{array}{ccc}
29.404 & 43.119 & 69.987 \\
43.119 & 227.043 & -350.750 \\
68.987 & -350.750 & 2379.120
\end{array}\right]
\end{aligned}
$$


The $H$ value for $n=20, c=3$, and $\gamma=P=0.95$, obtained from Table $D-2$ is 11.50 . Hence, the tolerance ellipsoid is:

$$
\left[\begin{array}{rr}
x_{1}-90.05 \\
x_{2}-7.50 \\
x_{3}-2.51
\end{array}\right]\left[\begin{array}{rrr}
29.404 & 43.119 & 68.987 \\
43.119 & 227.043 & -350.750 \\
68.987 & -350.750 & 2379.120
\end{array}\right]\left[\begin{array}{l}
x_{1}-90.05 \\
x_{2}-7.50 \\
x_{3}-2.51
\end{array}\right]=11.50
$$

Application of the program for determining if the tolerance ellipsoid is within the specification ellipsoid given in Appendix $E$ yields $f\left(X^{*}\right)=1.312$, indicating that the tolerance ellipsoid is completely within the specification ellipsoid. Consequently, the given month's production can be certified with $95 \%$ confidence that at least $95 \%$ of the parts met the specification for the three characteristics.

\section{Example 2}

A plot of the tensile strength versus elongation data for the 106 previously produced parts is given in Figure 9. As indicated in the figure, the two characteristics are highly correlated. The univariate specification region is represented by the rectangular region. Application of the method for constructing the specification ellipsoid discussed earlier (page 19) yields the solid-line elliptical specification region shown in the figure.
Table 4

DATA FROM A SAMPLE OF 20 PARTS REPRESENTING A RECENT ONE-MONTH PRODUCTION

\begin{tabular}{cccc}
\hline \multirow{2}{*}{$\begin{array}{c}\text { Sample } \\
\text { Number }\end{array}$} & \multicolumn{3}{c}{ Characteristic Number } \\
\cline { 2 - 4 } 1 & & 2 & 3 \\
\hline & 89.9184 & 7.4638 & 2.4873 \\
2 & 90.0035 & 7.5150 & 2.4895 \\
3 & 89.6112 & 7.6345 & 2.5248 \\
4 & 90.1172 & 7.4023 & 2.5245 \\
5 & 89.8161 & 7.5153 & 2.4825 \\
6 & 90.8547 & 7.2611 & 2.4122 \\
7 & 89.9658 & 7.5355 & 2.5108 \\
8 & 90.1151 & 7.4772 & 2.5093 \\
9 & 90.4272 & 7.4088 & 2.5035 \\
10 & 90.3279 & 7.3822 & 2.4770 \\
11 & 90.3406 & 7.3129 & 2.4840 \\
12 & 90.0317 & 7.5559 & 2.5486 \\
13 & 90.3154 & 7.4735 & 2.5040 \\
14 & 89.8750 & 7.5185 & 2.5353 \\
15 & 89.5985 & 7.5914 & 2.5379 \\
16 & 89.8737 & 7.5840 & 2.5026 \\
17 & 90.1442 & 7.6998 & 2.5283 \\
18 & 89.7869 & 7.6548 & 2.5406 \\
19 & 90.1513 & 7.4117 & 2.4654 \\
20 & 89.8524 & 7.6687 & 2.5289 \\
& & &
\end{tabular}

Figure 10 contains a plot of the data from 19 randomly sampled routine production parts measured during a recent month. The ellipsoid represented by the connected dots represents the tolerance region within which it can be stated with $95 \%$ confidence that the characteristic values of at least $95 \%$ of the items produced during the month are contained. Application of the computer program given in Appendix $E$ confirms that the certification ellipse is completely contairied within the specification. Consequently, it can be stated with $95 \%$ confidence that at least $95 \%$ of the items produced during the month met the elongation and tensile strength specification.

To illustrate how the relationship among characteristics can be controlled by using the multivariate normal tolerance regions, suppose that the correlation between tensile strength and elongation changed from -0.82 to -0.40 during the month, but that the levels and variability remained the same. The resulting data are given in Figure 11. 


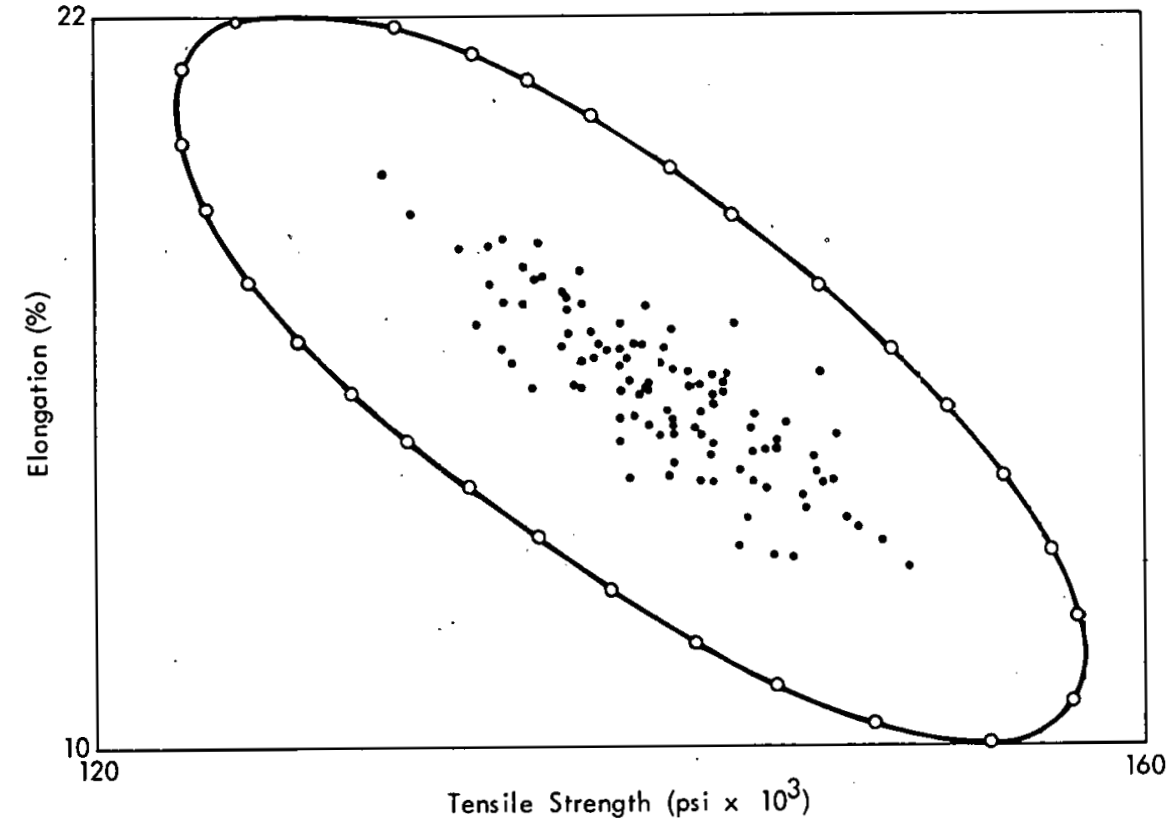

Figure 9. TENSILE STRENGTH AS A FUNCTION OF ELONGATION WITH AN INSCRIBED SPECIFICATION ELLIPSOID.

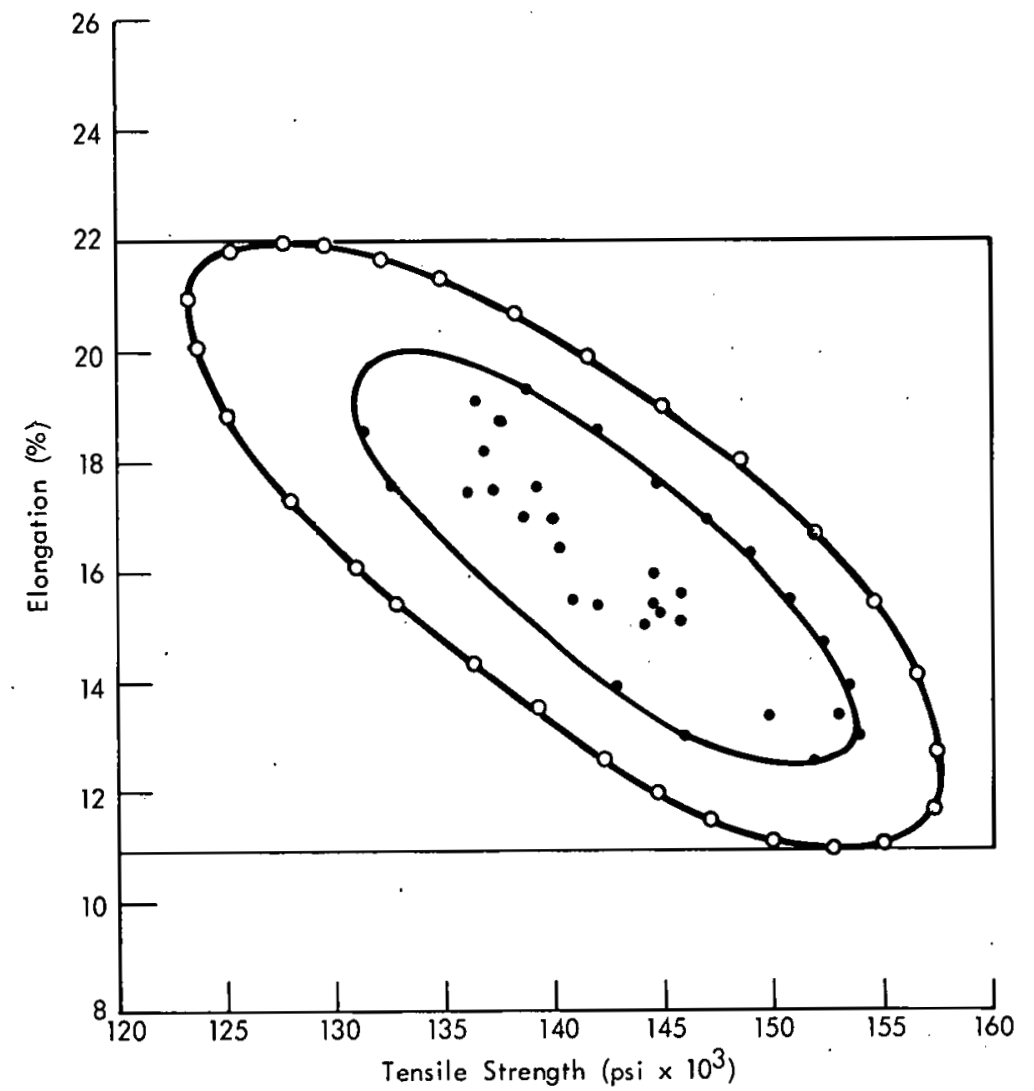

Figure 10. CALCULATEd tOleRANCE ELLIPSE For A RECENT ONE-MONTH SAMPLE DATA WITH A CORRELATION COEFFICIENT OF -0.82 . 
The calculated tolerance ellipsoid, within which it can be stated with $95 \%$ confidence that the elongation and tensile-strength values of at least $95 \%$ of the items produced during the month are contained, is represented by the connected-dot ellipsoid in the figure. Portions of this calculated ellipsoid fall outside the specification ellipsoid. This fact was confirmed by applying the program in Appendix $E$. An $f\left(X^{*}\right)$ value of 0.893 was obtained. Consequently, it cannot be stated with $95 \%$ confidence that $95 \%$ of the items produced during the month met the elongation and tensile-strength specification.

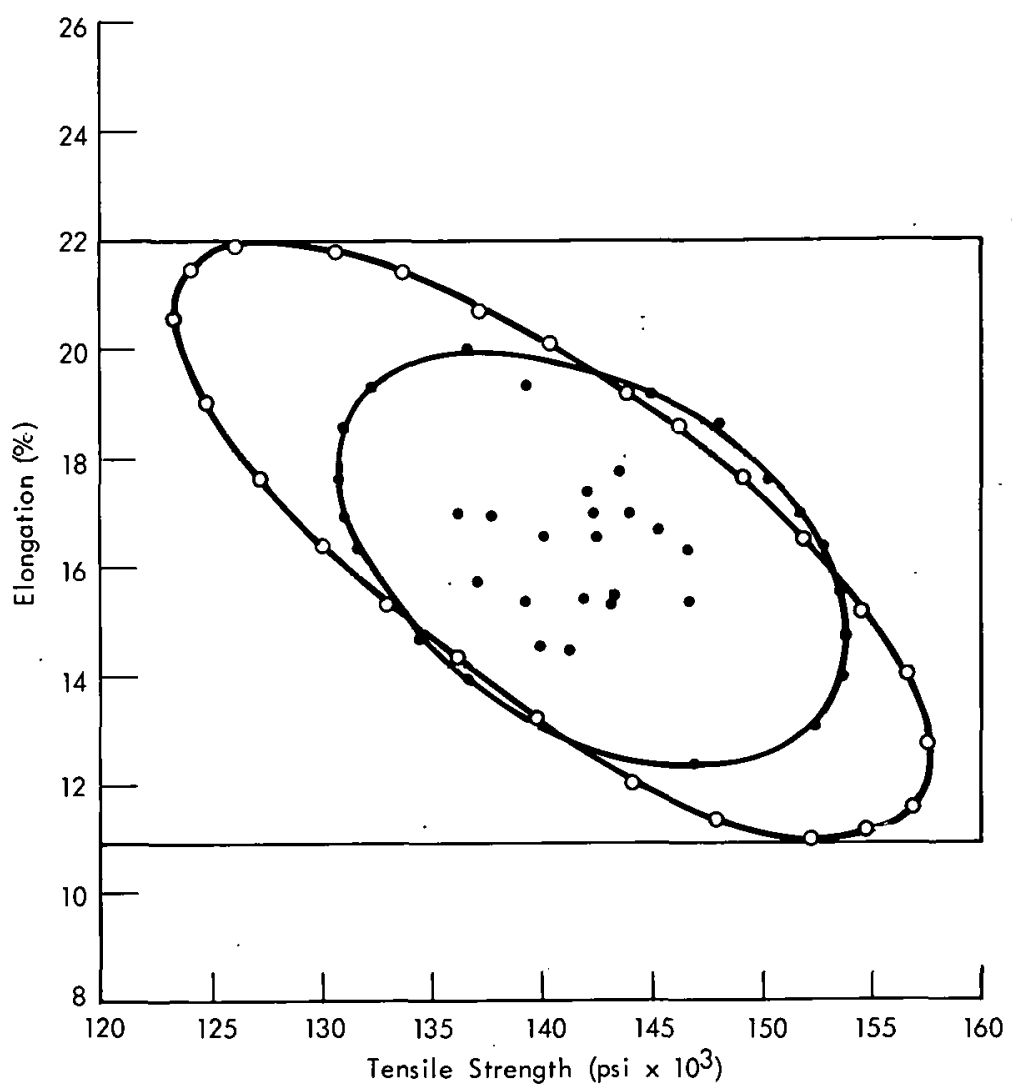

Figure 11. CALCULATED TOLERANCE ELLIPSE FROM HYPOTHETICAL DATA WITH A CORRELATION COEFFICIENT OF -0.40 .

\section{Example 3}

The procedure for using the multivariate normal tolerance regions was used to see if it could be stated with $95 \%$ confidence that at least $95 \%$ of the parts produced during a recent month met a given 13-characteristic specification. Data representing all 13 characteristics from 28 routine production parts measured during the month are reported, along with the univariate specification limits in Table 5 . The covariance matrix calculated from these data are listed in Table 6. This covariance matrix was used to construct a tolerance ellipsoid representing the entire month's production.

A 13-characteristic specification ellipsoid was constructed from the univariate specification limits of Table 5 and from the 106 data points used to obtain the variance-covariance matrix given in Table A-1 through A-6. Application of the program given in Appendix $E$ indicated that the calculated tolerance ellipsoid was completely within the specification ellipsoid, since an $f\left(X^{*}\right)$ value of 1.153 was obtained. Consequently, it was possible to make the desired certification statement. (This example is given to demonstrate the feasibility of using the multivariate normal tolerance regions for a large number of characteristics. A sample size of $n \geqslant c 2 / 2$ would normally be necessary in order to assure adequate coverage.) 
Table 5

OBSERVATIONS FROM VARIATE NORMIAL DISTRIBUTION AND UNIVARIATE SPECIFICATION LIMITS

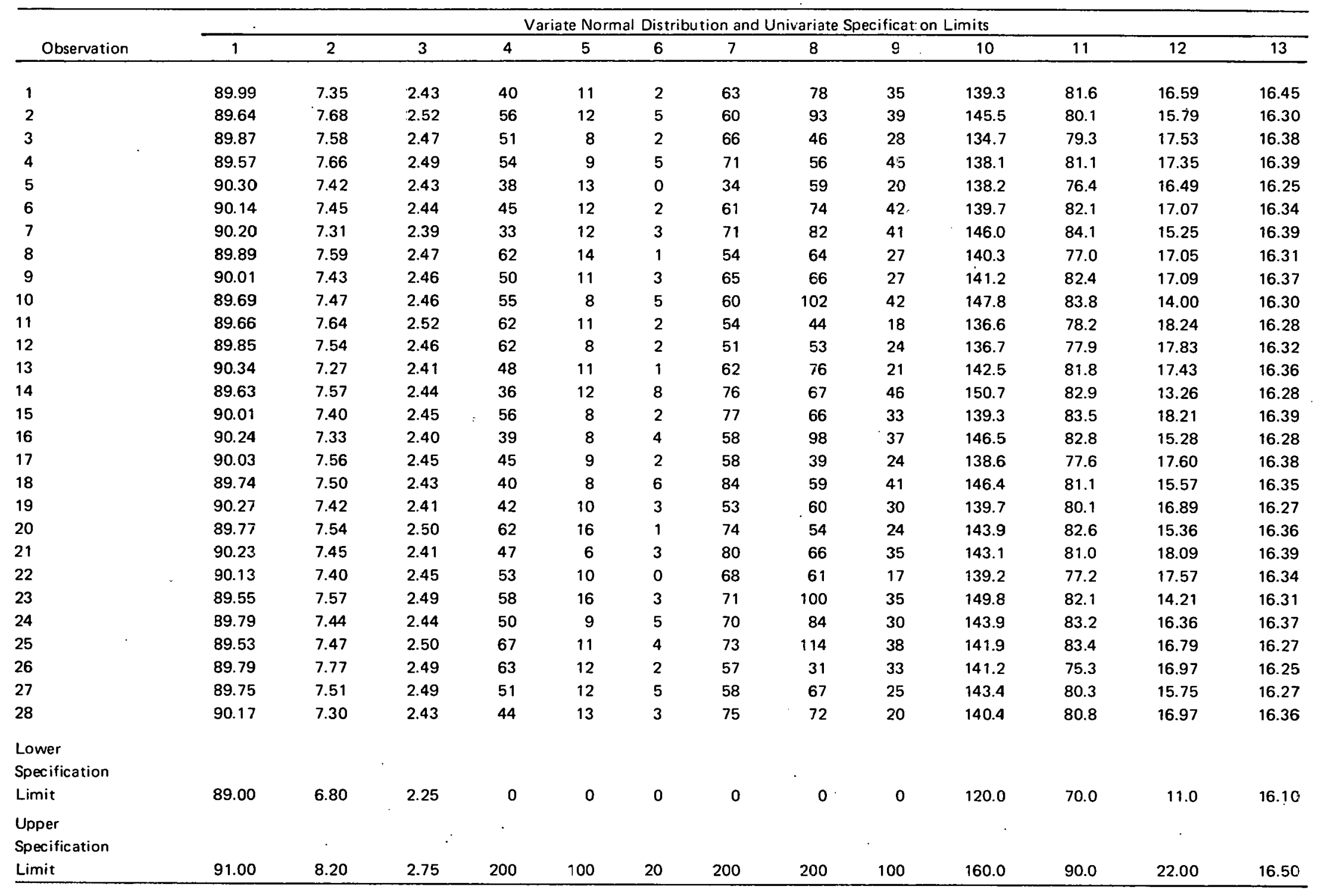


Table 6

COVARIANCE MATRIX CALCULATED FROM THE DATA OF TABLE 5

\begin{tabular}{|c|c|c|c|c|c|c|c|c|c|c|c|c|c|}
\hline \multirow{2}{*}{$\begin{array}{l}\text { Characteristic } \\
\text { Number }\end{array}$} & \multicolumn{13}{|c|}{ Variate Normal Distribution and Univariate Specification Limits } \\
\hline & 1 & 2 & 3 & 4 & 5 & 6 & 7 & 8 & 9 & 10 & 11 & 12 & 13 \\
\hline 1 & 0.087 & & & & & & & & & & & & \\
\hline 2 & -0.026 & 0.018 & & & & & & & & & & & \\
\hline 3 & -0.001 & 0.001 & 0.001 & & & & & & & & &. & \\
\hline 4 & -3.342 & 0.958 & 0.075 & $4,123.00$ & & & & & & & & & \\
\hline 5 & -0.879 & 0.415 & 0.027 & 312.77 & 59.830 & & & & & & & & \\
\hline 6 & 0.208 & -0.141 & -0.008 & -205.15 & -30.200 & 25.295 & & & & & & & \\
\hline 7 & 4.943 & -3.118 & -0.200 & 582.91 & -47.519 & 3.993 & $11,244.00$ & & & & & & \\
\hline 8 & -4.626 & 6.120 & 0.244 & $11,032.00$ & 689.470 & -452.010 & $-14,466.00$ & $149,680.0$ & & & & & \\
\hline 9 & 4.335 & 1.649 & -0.023 & $1,290.40$ & 57.663 & -69.820 & 175.94 & $25,031.0$ & $9,520.2$ & & & & \\
\hline 10 & 0.439 & 0.596 & -0.021 & 479.06 & 43.931 & -21.830 & 175.94 & $10,735.0$ & $3,130.2$ & $1,248.7$ & & & \\
\hline 11 & 0.718 & 0.239 & 0.000 & 457.70 & 30.162 & -29.278 & 182.42 & $7,129.8$ & $2,003.4$ & 744.3 & 511.4 & & \\
\hline 12 & -0.234 & -0.246 & -0.007 & -223.18 & -22.318 & -14.758 & 405.25 & $-4,582.9$ & $-1,184.1$ & -462.9 & -282.8 & 189.4 & \\
\hline 13 & -0.015 & -0.007 & 0.000 & -14.48 & $=1.034$ & 0.563 & 19.03 & -147.1 & $-\quad 26.3$ & -11.2 & -6.9 & 4.9 & 0.162 \\
\hline
\end{tabular}




\section{CONCLUSIONS AND RECOMMENDATIONS}

\section{Conclusions}

A complete procedure for the use of multivariate normal tolerance regions for the certification of related characteristics has been developed. The procedure is as follows:

1. A specification region is established. This specification region is in the form of an ellipsoid.

2. A random sample of $\mathrm{n}$ items is taken over a given time period of production. Each specified characteristic is measured on each sampled item.

3. The data generated in Step 2 are used to calculate a tolerance ellipsoid within which it can. be said with $\gamma$ confidence that at least a proportion, $P$, of the population of items fall. The equation for this ellipsoid is:

$$
(X-m)^{\prime} S^{-1}(X-m)=H
$$

4. If the calculated tolerance ellipsoid is completely within the specification ellipsoid, the items produced during the given production period are acceptable. Otherwise, they are not acceptable.

This procedure should be extremely useful in industry. It is the only method available in which controlled probability statements can be made about several characteristics simultaneously. Also, it is the only method that allows the buyer to control the relationship between the characteristics. It can be used in any situation where an underlying multivariate normal distribution can be assumed.

In mass production situations, the procedure can be used to make probability statements about production for a day or a week. In low-production situations, the certification period might be a month or longer. The procedure can also be used as a lot-acceptance criterion for large lots of items.

The procedure is quick and easy to use. All that is required is the use of the $H$ values given in Appendix $D$ and the two computer programs given in Appendixes B and $E$. A large computer is not required. However, a small computer would be a necessity when a large number of characteristics is involved.

In obtaining the procedure, the most complete set of noncentral Chi-Square tables known to be in existence have been produced. These noncentral Chi-Square values have been used to produce a set of tables of $\mathrm{H}$ values that are required for use in constructing the tolerance ellipsoid. Also, methods for constructing specification ellipsoids and for testing to see if the calculated tolerance ellipsoid is completely within the specification ellipsoid have been developed. 
The procedure utilizes an approximation to the multivariate normal tolerance region developed by John. It has been shown that John's approximation is sufficiently accurate for use with small sample sizes.

In investigating the accuracy of John's approximation, a procedure for integrating the multivariate normal distribution was developed. This procedure appears to be the only practical method in existence for integrating the multivariate normal distribution for as many as 30 variables.

\section{Recommendations}

The study has revealed several promising areas for possible further work. Guttman(6) has developed an approximation to the multivariate normal tolerance region that differs from John's. The accuracy of his approximation could be investigated in a manner similar to the investigation of the accuracy of John's approximation performed in this study. The two approximations could then be compared to see if one is superior to the other. Also, the investigation of the accuracy of John's approximation could be extended to several types of variance-covariance matrices not considered in this study. Also, the accuracy for other values of $\gamma$ and $P$ not considered in this study could be investigated.

Another possible future research topic would be the study of the robustness of multivariate normal tolerance regions. Skewed and censored distributions are common in industry, and a study of the effect of this lack of normality on $\gamma$ and $P$ would be worthwhile.

A considerable amount of work has been done by Guttman on the power of tolerance regions. A study of the power of John's multivariate normal tolerance regions would also be beneficial. 


\section{REFERENCES}

(1) John, S.; "A Tolerance Region for Multivariate Normal Distributions", Sankhya, 25, pp $363 \cdot 368$ (1963).

(2) Wilks, S. S.; "Statistical Prediction with Special Reference to the Problem of Tolerance Limits", Annals of Mathematical Statistics, 13, pp 400 - 409 (1942).

(3) Wald, A.; "An Extension of Wilks' Method for Setting Tolerance Limits", Annals of Mathematical Statistics, 14, pp $45-55$ (1943).

(4) Wald, A. and Wolfowitz, J.; "Tolerance Limits for a Normal Distribution", Annals of Mathematical Statistics, 17, pp 208 - 215 (1946).

(5) Chew, V.; “Confidence, Prediction, and Tolerance Regions for the Multivariate Normal Distribution", Journal of American Statistical Association, 61, pp 605 - 617 (1966).

(6) Guttman, I.; Statistical Tolerance Regions: Classical and Bayesian; Hafner Publishing Company, Connecticut (1970).

(7) Speck, G.P.; "A Table for Computing Trivariate Normal Probabilities", Annals of Mathematical Statistics, 29, pp $780-800$ (1958).

(8) Gupta, S. S.; "Probability Integrals of Multivaraite Normal and Multivariate t", Anna/s of Mathematical Statistics, 34, pp 792 - 828 (1963).

(9) Milton, R. C.; "Computer Evaluationn of the Multivariate Normal Integral", Technometrics, 14, pp 881 -889 (1972).

(10) Kahn, H.; Applications of Monte Carlo, The Rand Corporation, California (1954).

(11) IMSL Library, (3rd Edition); International Mathematical and Statistical Libraries, Incorporated, Houston (1974).

(12) Strecok, A. J.; "On the Calculation of the Inverse of the Error Function", Mathematics of Computation, 22, pp 144 - 158 (1968).

(13) Hurst, R. L. and Knop, R. E.; "Generation of Random Correlated Random Variables", Collected Algorithms from CACM, p 425 (1972).

(14) Coveyou, R. R.; "FLTRN-A Double Precision, Uniform Random Number Generator", The Computing Technology Center Numerical Analysis Library; p 415 (1970).

(15) Anis, A. A. and Lloyd, E. H.; "On the Range of the Partial Sums of a Finite Number of Independent Normal Variates", Biometrika, 44, pp 35 - 42 (1953). 
(16) Bradley, R. A. and Jackson, J. E.; "Sequential $\chi^{2}$ and T2 Tests and Their Application to an Acceptance Sampling Problem", Technometrics, 3, pp 519 - 534 (1961).

(17) Haynam, G. E. and Leone, F. C.; Tables of the Non-Central Chi-Square Distribution, 1060; Case Institute of Technology, Computing Center and Statistics Laboratory (1962).

(18) Fix, E.; "Tables of Noncentral Chi-Square", University of California Publications in Statistics, 1, pp $15-19$ (1949).

(19) Patnaik, R. B.; "The Non-Central Chi-Square and F-Distribution and Their Applications", Biometrika, 36, pp 202 - 232 (1949).

(20) Siotani, M.; "Tolerance Regions for a Multivariate Normal Population", Annals of the Institute of Statistical Mathematics, 16, pp 135 - 153 (1964).

(21) Abramowitz, M. and Stegun, I. A:; Handbook of Mathematical Functions; National Bureau of Standards, Washington, (1964).

(22) Brent, R. P.; Algorithms for Minimization Without Derivatives; Prentice-Hall, New Jersey (1973).

(23) Cross, K.; GRADIENT-An Optimization Program, K-1427; Union Carbide Corporation-Nuclear Division, Oak Ridge Gaseous Diffusion Plant, Oak Ridge, Tennessee (1968). 


\section{APPENDIX A}

PROGRAM FOR CHECKING THE ACCURACY OF JOHN'S APPROXIMATION

C

C

C

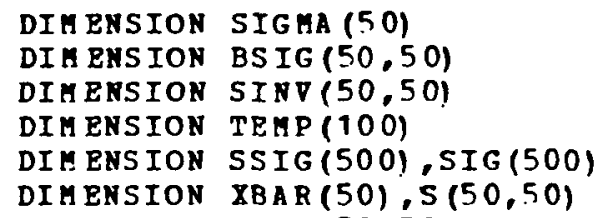


RRITE $(6,3017)$

IDG $T=0$

CALI L INV 1P (BSIG, C, 50, SINV; TDGT, RKAREA, IER)

301.7 PORHAT (1RO,' SIGHA IRVERSE'/1X)

DO $29 I=1, C$

$\operatorname{RRITE}(6,3003)(\operatorname{SIRV}(I, J), J=1, C)$

29

CON TIN UB

IP (IS IG. EQ.0) GO TO 21

DO $17 I=1,80 \mathrm{BB}$

17 SIG (I) $=$ SS IG (I)

SEE $D=0.01368854963220356 D 0$

CALL GGHRA (SEED,H,C,SIG ,IR,RVEC, RKVEC, IER)

21 CONTINOE

CALL GGNRI1 (SEED, NST ,C,SIG,IR, RVEC, RKVEC, IRR)

QR I TE $(6,77)$

77 PORHAT (1H0,45X, 's CO-VARIARCE'/1X)

Dก $19 \quad T T \equiv 1, \pi$

DO $19 \mathrm{JJ}=1, \mathrm{C}$

19

$\operatorname{RPEC}(I I, J J)=\operatorname{RVEC}(I I, J J)+A B O(J J)$

RO $=\mathrm{C}$

$\mathbf{X}=\mathbf{H}$

DO $10 \mathrm{~J}=1$, 80

SOH $=0.0$

DO $5 I=1, N$

$S O B=S O M+\operatorname{RVEC}(I, J)$

$22 \operatorname{RVEC}(I I, J J)=\operatorname{RVEC}(I I, J J)+\operatorname{ABO}(J J)$

IV A L $=0$

C

SOBTRACT SAMPLE MEAN

C

DO $45 \mathrm{~J}=1$, RST RT

D) $45 \mathrm{mH}=1, \mathrm{C}$

$45 \operatorname{RVBC}(J, M H)=\operatorname{RVEC}(J, M M) \quad-X B A R(M H)$

C

C

C

$$
\text { CALCdCate }(X-B) * S^{\prime *}(X-B) \cdot
$$

DO $65 \mathrm{~J}=1$, RSTRT

DO 53 II $=1, C$

SOH $=0$

DO $51 \mathrm{JJ}=1, \mathrm{C}$

$51 S \operatorname{SOH}=50 \mathrm{SOSINV(II,JJ)*R \nabla EC} \mathrm{(J,} \mathrm{JJ)}$

53 TE UP (II) $=S O B$

C

TOT $S=0$

DO $55 \mathrm{II}=1, \mathrm{C}$

55 TOT S=TOTS +RVEC (J,II) *TEHP (II)

IF (TOTS. L E. HA H) IV AL $=I \nabla A L+1$

3000 PORHAT $(1 X, \cdot X 1=+$, PP2E15.4,5X, SOH $=1, E 15.4,5 x, I 5)$

65 CONTIROE

$\triangle A=$ FLOAT (IVAL)/FLOAT (NSTRT)

$\triangle V G E=A \nabla G E+A A * * 2$

$A \nabla G=A \nabla G+A A$

MR I TE $(6,60) I, A A$

60 PORMAT $(1 X, 15,1 P E 15.5)$

100 CONTINOE

AVG =AVG/PLOAT (NBATS)

AVGE=A VGE PLOAT (NBATS)

AVGE=DSQRT (DABS (AVGE-AVG**2)/DFLOAT(NBATS-1))

URI TE $(6,105)$ A VG, A VGE 


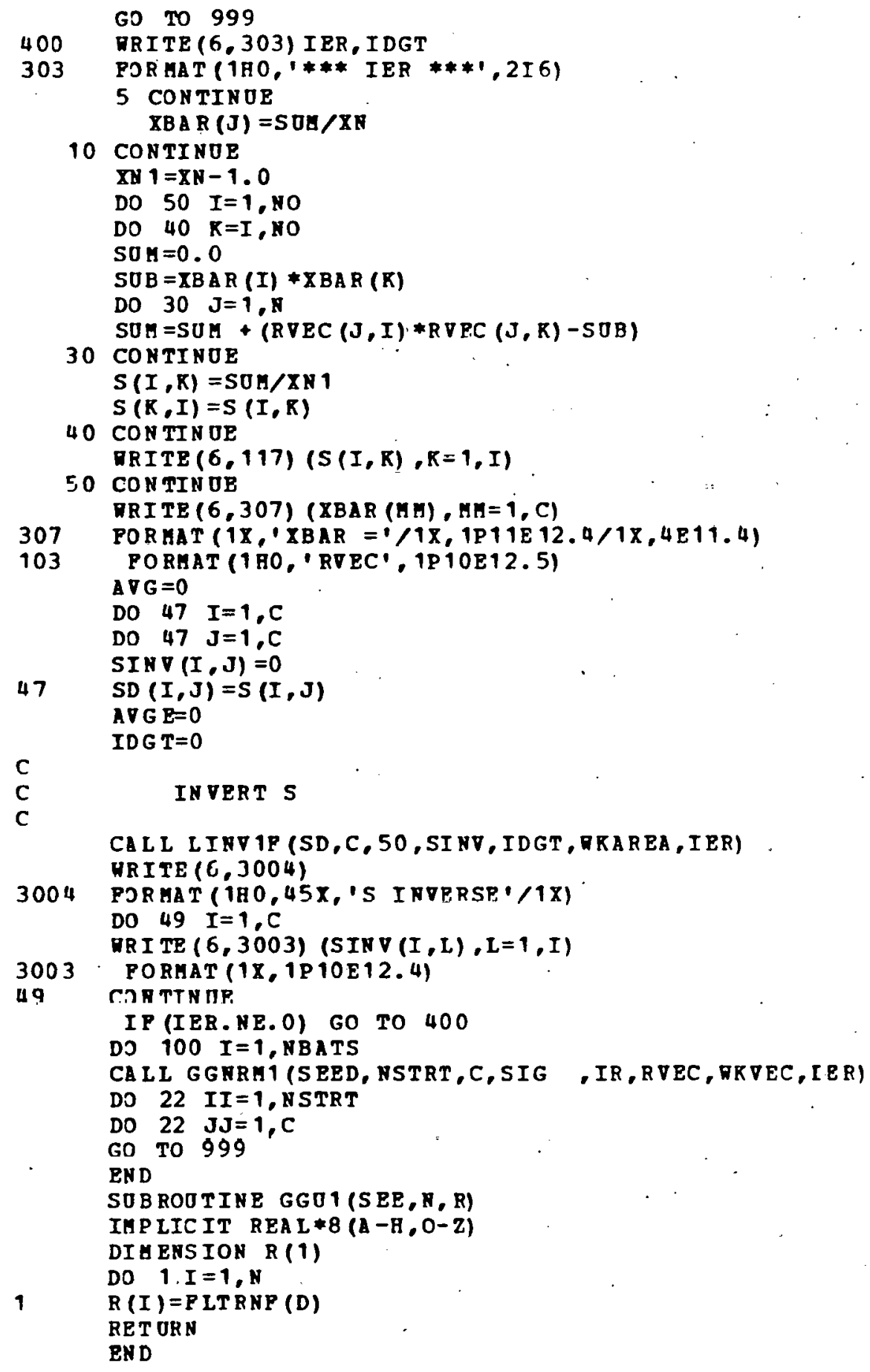


Table A-1

COLUMNS 1.5 OF THE 30 .CHARACTERISTIC
VARIANCE-COVARIANCE MATRIX

\begin{tabular}{|c|c|c|c|c|c|}
\hline$c$ & 1 & 2 & 3 & 4 & 5 \\
\hline & 0.0563 & -0.0194 & -0.0057 & 1.5633 & -0.1126 \\
\hline & 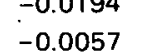 & $\begin{array}{l}0.006767 \\
0.0038\end{array}$ & $\begin{array}{l}0.0038 \\
0.038\end{array}$ & 0.62333 & \\
\hline & & 0.6233 & $\begin{array}{l}0.0014 \\
0.2391\end{array}$ & $\begin{array}{r}0.32391 \\
94251\end{array}$ & $\begin{array}{l}0.003099 \\
5388\end{array}$ \\
\hline & -0.1126 & 0.0469 & 0.0309 & 5 & $\begin{array}{l}5.2866 \\
7.1637\end{array}$ \\
\hline & & & -0.0028 & -3.8947 & -1.3684 \\
\hline & $\begin{array}{l}0.101717 \\
-13727\end{array}$ & -0.05549 & -0.0455 & -12.4999 & 3.1111 \\
\hline & $\begin{array}{l}-1.3 .325 \\
-0.8492\end{array}$ & $\begin{array}{r}-0.033032 \\
0.032\end{array}$ & $\begin{array}{l}0.0 .030 \\
0.038\end{array}$ & $\begin{aligned} 292076 \\
5\end{aligned}$ & $\begin{array}{l}3.53222 \\
7,14323\end{array}$ \\
\hline 10 & & & -0.0082 & -30178 & $\begin{array}{l}7.1 .1433 \\
2.2477\end{array}$ \\
\hline & 0.0101 & -0.1488 & -0.0268 & - 4.9661 & 1.3206 \\
\hline 12 & 0.1206 & 0.0085 & 0.0011 & 0.2753 & -1.0277 \\
\hline & $\begin{array}{l}0.036 \\
0.0528\end{array}$ & $\begin{array}{l}-0.0000 \\
{ }_{0.0285}\end{array}$ & -0.00050 & $\begin{array}{c}-0.1101 \\
7270\end{array}$ & $=0.0222$ \\
\hline 15 & $\begin{array}{l}0.0952 \\
0\end{array}$ & 0.0829 & 0.0011 & 3.6959 & $\begin{array}{l}0.608999 \\
0.691\end{array}$ \\
\hline & 1.6187 & 0.3591 & -0.2041 & -37.7864 & -11.7193 \\
\hline & 0.0120 & -0.0226 & -0.0026 & 0.2330 & 0.2351 \\
\hline 10 & $\begin{array}{l}0.18121 \\
0.72\end{array}$ & -0.05817 & -0.2363 & $-34,4590$ & $\begin{array}{c}6.53234 \\
.93097\end{array}$ \\
\hline & $\begin{array}{r}-3.02005 \\
-3.0\end{array}$ & 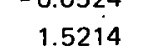 & $\begin{array}{l}0.3504 \\
0.3904\end{array}$ & $\begin{array}{l}1007060 \\
1070\end{array}$ & $\begin{array}{r}-0.4519 \\
19.4619\end{array}$ \\
\hline 2. & 0.2892 & -0.3579 & -0.0811 & -7.4824 & -2.2281 \\
\hline & 01141 & -0.1010 & -0.0268 & 1.5234 & 0.8070 \\
\hline${ }^{23}$ & 1.0809 & -1.0112 & -0.0558 & 7.04699 & -11.3304 \\
\hline & 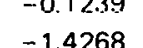 & $\begin{array}{l}0.0569 \\
0.544\end{array}$ & 01433 & $\begin{array}{l}0.60 \\
1505\end{array}$ & - \\
\hline & -0.2881 & 0.2538 & 0.0628 & & \\
\hline & -0.8911 & 0.5536 & 0.1358 & 54,1052 & -0.9795 \\
\hline & 0.7435 & -0.4788 & -0.1711 & -45.8996 & -3.3684 \\
\hline . & $\begin{array}{l}2.5,1510 \\
-0.110\end{array}$ & $\begin{array}{l}-0.0240 \\
-0.2464\end{array}$ & $\begin{array}{l}-0.00303 \\
-0.133\end{array}$ & 8 & $\begin{array}{l}0.2103 \\
0.2027\end{array}$ \\
\hline
\end{tabular}

COLUMNS 6 - 10 OF THE 30-CHARACTERISTIC

\begin{tabular}{|c|c|c|c|c|}
\hline $\bar{c}$ & 7 & 8 & 9 & 10 \\
\hline-0.1222 & 0.1017 &. .1 .3725 & -0.8492 & \\
\hline 0.0390 & $\begin{array}{r}-0.2554 \\
-\end{array}$ & $-\quad 0.5300$ & 0.2328 & -0.0182 \\
\hline $\begin{array}{l}-0.0028 \\
-30947\end{array}$ & $\begin{array}{r}0.0455 \\
-120999\end{array}$ & $\begin{array}{l}0.0416 \\
209076\end{array}$ & $\begin{array}{l}0.0038 \\
=0 ? 0\end{array}$ & -0.0082 \\
\hline $\begin{array}{r}3.8947 \\
-1.3684\end{array}$ & 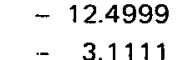 & $\begin{array}{l}29.2076 \\
3.5322\end{array}$ & & $\begin{array}{l}-3.01018 \\
-1077\end{array}$ \\
\hline $\begin{array}{l}2.090423 \\
2.9123\end{array}$ & 5 & 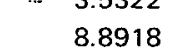 & 8.8918 & $\begin{array}{l}2.247 \\
3.0570\end{array}$ \\
\hline 5.3333 & 115.3331 & $\begin{array}{l}.0 .99404 \\
19.944\end{array}$ & 19.5554 & 15.0933 \\
\hline 8.8918 & 19.9444 & 401.2559 & 87.6459 & 38.5981 \\
\hline $\begin{array}{l}8.8918 \\
3.50570\end{array}$ & $\begin{array}{l}19.5554 \\
1.50933\end{array}$ & $\begin{array}{r}87.6459 \\
38.591\end{array}$ & $\begin{array}{l}71.701016 \\
71027\end{array}$ & $\begin{array}{l}14.1433 \\
1.7435\end{array}$ \\
\hline $\begin{array}{l}3.0 .070 \\
.3837 \\
\end{array}$ & $\begin{array}{l}15.0933 \\
96583\end{array}$ & $\begin{array}{l}38.5981 \\
24.985\end{array}$ & $\begin{array}{l}14.1433 \\
8.0214\end{array}$ & $\begin{array}{l}13.7445 \\
3.5904 \\
3\end{array}$ \\
\hline $\begin{array}{r}-1.0837 \\
-0.8106\end{array}$ & $\begin{array}{r}9.6583 \\
. . \quad 1.2350\end{array}$ & $\begin{array}{r}24.9855 \\
-\quad 14.2991\end{array}$ & $\begin{array}{r}.802014 \\
-4.9502 \\
\end{array}$ & $\begin{array}{r}3.50944 \\
-3.7263 \\
\end{array}$ \\
\hline-0.0314 & 0.0252 & -0.3492 & -0.0417 & \\
\hline & 1.8889 & 21.8011 & -24.3011 & 0.7621 \\
\hline $\begin{array}{l}1.7836 \\
1.7572\end{array}$ & 5.6667 & 6.7368 & 1.7076 & 2.1211 \\
\hline $\begin{array}{l}1.2573 \\
0.0855\end{array}$ & 73.77776 & $\begin{array}{l}2577.6338 \\
2380\end{array}$ & $\begin{array}{l}-18.41222 \\
-1202\end{array}$ & \\
\hline $\begin{array}{l}-.009315 \\
1.0945\end{array}$ & 1. & $05 \approx 57$ & A1.2503 & 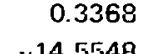 \\
\hline $\begin{array}{l}2.7988 \\
2.7982\end{array}$ & 6055 & 9.0356 & 10.053 & 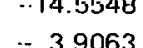 \\
\hline 0.5439 & 33.8333 & 60.5293 & 192485 & $\begin{array}{l}9.0851 \\
9\end{array}$ \\
\hline 0.1520 & 1.11111 & 13.6024 & 4.0643 & 2.1120 \\
\hline $\begin{array}{l}2.0936 \\
2.036\end{array}$ & 0.0555 & 6.5117 & 6.2339 & 1.2834 \\
\hline $\begin{array}{l}10.1462 \\
0.71933\end{array}$ & 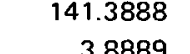 & 52.0321 & -54.534343 & 25.0464 \\
\hline 14.8655 & $\begin{array}{l}\text { 2.586778 } \\
2.478\end{array}$ & 年 & $\begin{array}{l}10.19649 \\
78968\end{array}$ & \\
\hline & $\begin{array}{l}1.46111 \\
\end{array}$ & 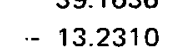 & $\begin{array}{l}0.43906 \\
0.1397\end{array}$ & $\begin{array}{l}5.2897 \\
\beta_{02515}\end{array}$ \\
\hline 2.9211 & 30.5555 & 0.7807 & .10.2193 & 0 \\
\hline 5.1901 & 25.27777 & .57 .1694 & 11.8917 & 12.2821 \\
\hline 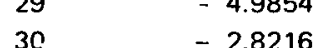 & $\begin{array}{l}-228.8351 \\
-20943\end{array}$ & 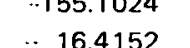 & 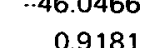 & $\begin{array}{l}-65.8439 \\
6.6757\end{array}$ \\
\hline
\end{tabular}

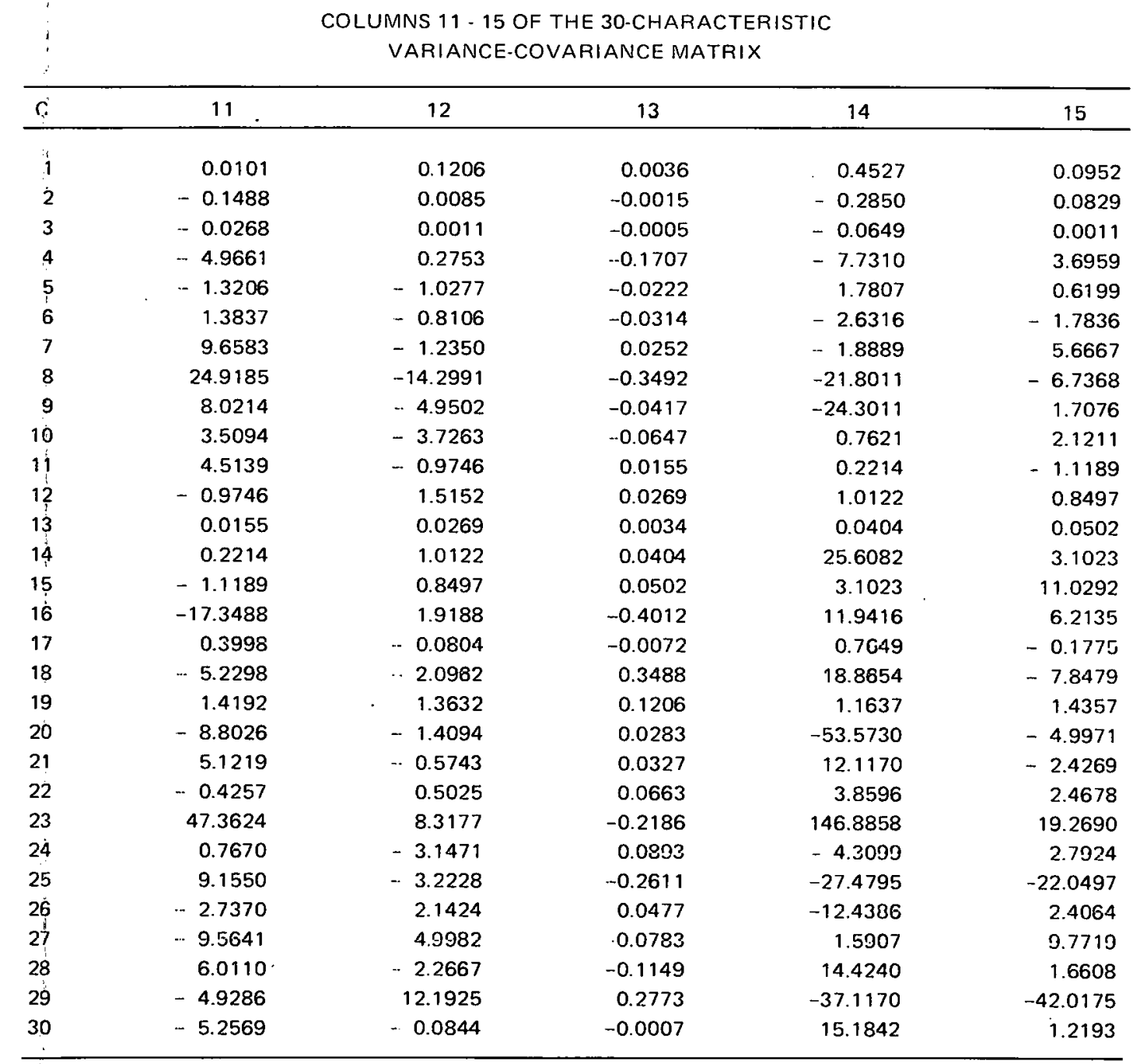


Table A.4.
COLUMNS 16 - 20 OF THE 30.CHARACTERISTIC
VARIANCE-COVABIANCEMATRIX

\begin{tabular}{|c|c|c|c|c|c|}
\hline$c$ & 16 & 17 & 18 & 19 & 20 \\
\hline & 1.6187 & 0.0120 & 0.1812 & 0.2268 & 3.0206 \\
\hline 2 & 0.3591 & -0.0226 & $\begin{array}{r}-0.5817 \\
\end{array}$ & $\begin{array}{rl}-0.0524 & 0.024\end{array}$ & $\begin{array}{l}1.52214 \\
032004\end{array}$ \\
\hline & $\begin{aligned} 0.2041 \\
-37.7864\end{aligned}$ & $\begin{array}{l}-0.0026 \\
-0.02330\end{array}$ & $\begin{array}{r}-0.2363 \\
-34.4590\end{array}$ & $\begin{array}{l}0.0153 \\
0.0468\end{array}$ & $\begin{array}{c}0.3904 \\
100.7250\end{array}$ \\
\hline 4 & $\begin{array}{r}-37.7764 \\
111.793\end{array}$ & $\begin{array}{r}-0.2330 \\
0.2351\end{array}$ & $\begin{array}{r}r 34.4590 \\
6.5234\end{array}$ & $\begin{array}{r}0.0 .0688 \\
-0.4971\end{array}$ & $\begin{array}{r}100.7250 \\
19.4619\end{array}$ \\
\hline 6 & $1.25 \% 3$ & $\begin{array}{l}.035055 \\
0.0655\end{array}$ & $\begin{array}{l}6.52534 \\
10.9415\end{array}$ & $\begin{array}{l}-0.49 / 2 \\
-2.7982\end{array}$ & $\begin{array}{r}9.44619 \\
0.5439\end{array}$ \\
\hline & 73.7776 & 1.2833 & - 22.2221 & -6.0555 & - 33.8333 \\
\hline & $\begin{array}{r}257.6339 \\
\quad 21040\end{array}$ & $\begin{array}{r}2.1693 \\
0.0 .090\end{array}$ & - 95.85377 & $\begin{array}{l}-9.2456 \\
-105529\end{array}$ & 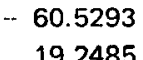 \\
\hline 10 & 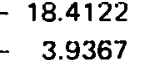 & $\begin{array}{r}-0.2196 \\
0.3368\end{array}$ & $\begin{array}{l}-41.3538 \\
-14.5548\end{array}$ & $\begin{array}{r}-10.5234 \\
-3.2003\end{array}$ & $\begin{array}{r}19.24855 \\
-9.0851\end{array}$ \\
\hline & $\begin{array}{r}37.9687 \\
-17.3488\end{array}$ & $\begin{array}{l}0.3598 \\
0.3998\end{array}$ & $\begin{array}{l}4.53298 \\
-5.2298\end{array}$ & $\begin{array}{r}3.0503 \\
1.4192\end{array}$ & $\begin{array}{l}-5.050 \\
-\quad 8.026\end{array}$ \\
\hline 12 & 1.9188 & -0.0844 & 2.0962 & 1.3632 & -1.4094 \\
\hline & $\begin{array}{r}0.4012 \\
1109012\end{array}$ & -0.0072 & $\begin{array}{l}0.3488 \\
0\end{array}$ & $\begin{array}{l}0.12206 \\
1200\end{array}$ & $\begin{array}{c}0.0283 \\
555720\end{array}$ \\
\hline & $\begin{array}{l}11.9416 \\
6,21313\end{array}$ & $\begin{array}{r}0.7649 \\
-0.1777\end{array}$ & $\begin{array}{r}18.86549 \\
-788479\end{array}$ & $\begin{array}{l}1.1637 \\
1.4357\end{array}$ & 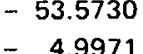 \\
\hline $\begin{array}{l}15 \\
16\end{array}$ & $\begin{array}{r}6.2 .135 \\
785.7173\end{array}$ & $\begin{array}{l}-0.113 \\
-2.3184\end{array}$ & 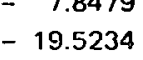 & $\begin{array}{r}-31.44373 \\
\end{array}$ & $\begin{array}{c}-107.2397 \\
-107\end{array}$ \\
\hline & 2.3184 & 0.1845 & 0.8082 & 0.0316 & -2.7328 \\
\hline 10 & $\begin{array}{l}10.5294 \\
-2\end{array}$ & $\begin{array}{l}0.0002 \\
0.0013\end{array}$ & $\begin{array}{r}42.05034 \\
1.5649\end{array}$ & $\begin{array}{r}13.8988 \\
15.968\end{array}$ & 38.1374 \\
\hline & & 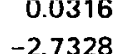 & $\begin{array}{l}2 \\
3\end{array}$ & $\begin{array}{r}15.6082 \\
43717\end{array}$ & $\begin{array}{l}4.47313 \\
3680282\end{array}$ \\
\hline 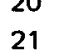 & $\begin{array}{rlrl} & -12.2937 \\
-12.2719\end{array}$ & $\begin{array}{r}2.27328 \\
1.0368\end{array}$ & $\begin{array}{r}88.71744 \\
5.7134\end{array}$ & $\begin{array}{l}4.37110 \\
4.610\end{array}$ & 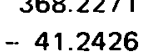 \\
\hline 22 & $\begin{array}{l}-13.1959 \\
\end{array}$ & -0.0342 & 21.9327 & 1.8596 & -0.7866 \\
\hline 23 & - 33.9470 & 17.6593 & - 2.69901 & 63.2277 & -336.73933 \\
\hline 24 & 甚 & $\begin{array}{l}0.5529 \\
.90299\end{array}$ & 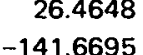 & $\begin{aligned}-1.5688 \\
-15000\end{aligned}$ & $\begin{array}{r}-3.91537 \\
2211227\end{array}$ \\
\hline & 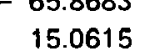 & 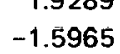 & -26.7.7503 & $\begin{array}{l}6.5058 \\
6.505\end{array}$ & $\begin{array}{l}58,3127 \\
58\end{array}$ \\
\hline 27 & - 87.4093 & -0.8567 & - 33.8859 & - 9.9649 & 4663216 \\
\hline 28 & 8.4093 & 1.8433 & 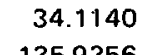 & -7.6316 & -102.253388 \\
\hline $\begin{array}{l}29 \\
30\end{array}$ & $\begin{array}{l}18.672525 \\
13.9619\end{array}$ & $\begin{array}{l}-2.1702 \\
-0.0395\end{array}$ & $\begin{array}{r}-33.93966 \\
40.2514\end{array}$ & $\begin{array}{r}63.2 .2162 \\
-211.1824\end{array}$ & $\begin{array}{r}45.59095 \\
-31.2280\end{array}$ \\
\hline
\end{tabular}

COUUMUS 21.25 OF THE 30 CHARACTERISTIC

\begin{tabular}{|c|c|c|c|c|c|}
\hline c & 21 & 22 & 23 & 24 & 25 \\
\hline & 0.2092 & 0.1141 & 1.0009 & 0.1239 & 1.4288 \\
\hline 2 & -0.3579 & 0.1010 & 1.0112 & -0.0489 & 0.5144 \\
\hline 3 & -0.0814 & $\begin{array}{l}0.0268 \\
0.5728\end{array}$ & 0.0558 & $\begin{array}{l}-0.0411 \\
\end{array}$ & $\begin{array}{l}0.1433 \\
1.5000\end{array}$ \\
\hline & $\begin{array}{r}-7.48211 \\
-2.2281\end{array}$ & $\begin{array}{l}1.5234 \\
0.08070\end{array}$ & $\begin{array}{r}7.0469 \\
1.13304\end{array}$ & 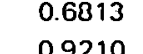 & $\begin{array}{l}1.5059 \\
1102037\end{array}$ \\
\hline $\begin{array}{l}5 \\
6\end{array}$ & 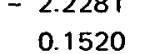 & $\begin{array}{l}2.80906 \\
2.0936\end{array}$ & $\begin{array}{l}\begin{array}{l}11.32304 \\
1.014622\end{array}\end{array}$ & $\begin{array}{l}0.9710 \\
0.7193\end{array}$ & $\begin{array}{r}-12.22427 \\
14.8655\end{array}$ \\
\hline & $\begin{array}{l}-1.1111 \\
-2\end{array}$ & 0.0555 & 141.3888 & 3.88099 & -24.7778 \\
\hline 8 & $\begin{array}{r}13.6024 \\
-400944\end{array}$ & 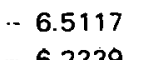 & $\begin{array}{r}52.0321 \\
5.4201\end{array}$ & $\begin{array}{r}20.0759 \\
1100006\end{array}$ & $\begin{array}{r}39.1636 \\
70.0000\end{array}$ \\
\hline & 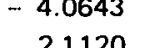 & $\begin{aligned}-6.2339 \\
\end{aligned}$ & $\begin{aligned}-5.463343 \\
250303\end{aligned}$ & 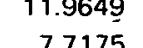 & $\begin{array}{l}87.4698 \\
5.9287\end{array}$ \\
\hline 10 & $\begin{array}{l}2.1720120 \\
5.1219\end{array}$ & $\begin{array}{l}1.2834 \\
0.4257\end{array}$ & $\begin{array}{l}25.540464 \\
47.3624\end{array}$ & 0.7670 & $\begin{array}{l}5.289 / \\
\text { 9.1550 }\end{array}$ \\
\hline 12 & -0.5743 & 0.5025 & 8.3177 & -3.1471 & 3.2228 \\
\hline & 0.0327 & $\begin{array}{l}0.0663 \\
0.0605\end{array}$ & $\begin{array}{r}-0.2186 \\
\end{array}$ & $\cdot 0.0893$ & $\begin{array}{c}0.2611 \\
07070\end{array}$ \\
\hline $\begin{array}{l}14 \\
15\end{array}$ & $\begin{array}{r}12.11700 \\
-242669\end{array}$ & $\begin{array}{l}3.8596 \\
2.4678\end{array}$ & $\begin{array}{r}146.88588 \\
19.26909\end{array}$ & $\begin{array}{r}-4.3099 \\
372094\end{array}$ & $\begin{array}{l}\begin{array}{l}27.4795 \\
220497\end{array}\end{array}$ \\
\hline & $\begin{array}{l}-2.46969 \\
-12.2719\end{array}$ & $\begin{array}{r}2.4 .478 \\
-13.1959\end{array}$ & 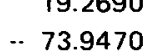 & 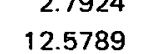 & 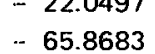 \\
\hline 17 & 1.0368 & -0.0342 & 17.6593 & 0.5029 & 1.9289 \\
\hline 10 & 5.77194 & $21:-9327$ & $\begin{array}{l}-2.0901 \\
0\end{array}$ & $\begin{array}{r}28.4048 \\
\end{array}$ & $-141.6669 y$ \\
\hline & 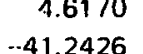 & $\begin{array}{r}1.53966 \\
-0.9766\end{array}$ & $\begin{array}{r}63.2747 \\
-33653939\end{array}$ & $\begin{array}{r}1-16988 \\
-3953\end{array}$ & $\begin{array}{r}-15.0906 \\
2111227\end{array}$ \\
\hline 21 & 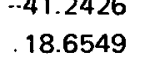 & $\begin{array}{r}0.87866 \\
1.5585\end{array}$ & $\begin{array}{r}-336.7393 \\
136.7835\end{array}$ & 2 & $\begin{array}{l}21.121287 \\
16.502\end{array}$ \\
\hline 22 & 1.5585 & 4.2632 & -14.1959 & 0.6784 & - 233.4619 \\
\hline 23 & 136.7835 & $\begin{array}{c}-14,1959 \\
-19\end{array}$ & 3065499399 & -10.3654 & 197.6313 \\
\hline & $\begin{array}{r}2.5643 \\
165702\end{array}$ & $\begin{array}{r}0.06784 \\
-324814\end{array}$ & $\begin{array}{r}-103654 \\
197631\end{array}$ & $\begin{array}{r}20.4994 \\
0.11906\end{array}$ & $\begin{array}{r}1.1696 \\
4042946\end{array}$ \\
\hline & $\begin{array}{l}0.628925 \\
-6.2895\end{array}$ & 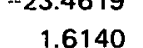 & 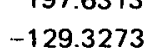 & $\begin{array}{r}-4.10950 \\
-4\end{array}$ & $\begin{array}{l}-1 \\
-1\end{array}$ \\
\hline 27 & $\begin{array}{r}-14.7924 \\
\end{array}$ & 1.8509 & -19.0204 & -11.5585 & $\begin{array}{l}1.1988 \\
1.1988\end{array}$ \\
\hline 28 & 6.8743 & 0.0176 & 183.7572 & 10.1082 & 41.4678 \\
\hline 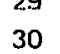 & $\begin{array}{l}37.678383 \\
4.2983\end{array}$ & ${ }_{9.4532}$ & -161.5932 & $\begin{array}{r}-26.5087 \\
5.1374\end{array}$ & $\begin{array}{r}-4.85717 \\
-\quad 4573\end{array}$ \\
\hline
\end{tabular}

COLUMNS 26 - 30 OF THE 30 CHARACTERISTIC

\begin{tabular}{|c|c|c|c|c|}
\hline 26 & 27 & 28 & 29 & 30 \\
\hline 0.2881 & - 0.89111 & 0.7435 & 2.3570 & 0.1102 \\
\hline $\begin{array}{l}0.2538 \\
0.0628\end{array}$ & $\begin{array}{l}0.05536 \\
0.0358\end{array}$ & $\begin{array}{c}-0.4788 \\
0.07111\end{array}$ & $\begin{array}{l}0.1544 \\
0.0632\end{array}$ & $\begin{array}{l}0.2462 \\
0.1023\end{array}$ \\
\hline $\begin{array}{r}0.0628 \\
32.5175\end{array}$ & $\begin{array}{r}0.15080 \\
54.1052\end{array}$ & $\begin{array}{l}-45.8994 \\
\end{array}$ & $\begin{array}{l}5.00732 \\
5.7073\end{array}$ & $\begin{array}{l}0.1033 \\
8.7193\end{array}$ \\
\hline & 0.9795 & $\begin{array}{r}-3.503084 \\
-\quad 3,364\end{array}$ & 11.2183 & $\begin{array}{l}8.2047 \\
0.07\end{array}$ \\
\hline 3.0146 & 2.9211 & 5.1901 & $\begin{array}{r}-4.9854 \\
\end{array}$ & 2.8216 \\
\hline $\begin{array}{l}-44.6111 \\
132310\end{array}$ & $\begin{array}{r}-30.55555 \\
0.7807\end{array}$ & $\begin{array}{l}25.27777 \\
5.71694\end{array}$ & $\begin{array}{l}-222838331 \\
-212530\end{array}$ & $\begin{array}{l}20.9443 \\
0.942\end{array}$ \\
\hline $\begin{array}{l}3.3977 \\
1.3977\end{array}$ & $\begin{array}{r}-0.20 .293 \\
-20\end{array}$ & $\begin{array}{l}51710949 \\
1119911\end{array}$ & 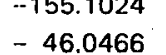 & $\begin{array}{l}16.4152 \\
0.9181\end{array}$ \\
\hline 8.0515 & -9.2657 & 12.2821 & $\begin{array}{l}-40.04040 \\
-65.8439\end{array}$ & $\begin{array}{l}0.9787 \\
4.757\end{array}$ \\
\hline 2.7370 & -9.5641 & 6.0110 & 4.9286 & $\begin{array}{l}5.22569 \\
\end{array}$ \\
\hline $\begin{array}{l}2.12424 \\
0.0477\end{array}$ & $\begin{array}{r}4.9982 \\
-0.0783\end{array}$ & $\begin{array}{l}-2.2667 \\
-0.011199\end{array}$ & $\begin{array}{l}12.1925 \\
1727\end{array}$ & \\
\hline 12.4386 & $\begin{array}{l}1.5907 \\
\end{array}$ & 14.4240 & $\begin{array}{l}3.711170 \\
\end{array}$ & 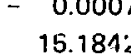 \\
\hline 2.4064 & 9.7719 & 1.6608 & 420175 & $\begin{array}{l}1.184 \\
1.19\end{array}$ \\
\hline 15.0615 & -87.4093 & 8.4093 & 18.6725 & 13.961 \\
\hline & & & & $0.13:$ \\
\hline 8.5058 & & 7.5216 & & $\begin{array}{l}40.25 \\
40.25\end{array}$ \\
\hline 58.3127 & 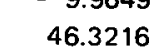 & -102.2338 & 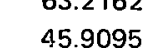 & $\begin{array}{l}211.48 \\
31.28\end{array}$ \\
\hline 6.2895 & $-14,7924$ & 6.8743 & 37.6782 & $\begin{array}{l}4.298 \\
4\end{array}$ \\
\hline & $\begin{array}{r}1.8509 \\
1.509\end{array}$ & & & \\
\hline${ }_{44912}$ & -115589 & 101098 & 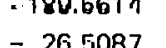 & $161.50:$ \\
\hline $\begin{array}{l}13.5965 \\
13.595\end{array}$ & 1.1988 & $\begin{array}{lll}414678 \\
\end{array}$ & 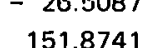 & $\begin{array}{l}5.13 \\
4.56\end{array}$ \\
\hline 35.09993 & 16.4853 & 38.2368 & 6.5.17178 & $\begin{array}{l}\text {.4567 } \\
7.312\end{array}$ \\
\hline 16.4853 & 116.4677 & 12.4210 & 68.0408 & \\
\hline 38.2368 & -12.4210 & 86.8011 & -1111.9297 & 4.122 \\
\hline 66.1783 & 68.0408 & 11.9297 & 1366.319191 & 99.242 \\
\hline 1.3129 & 14.6784 & 4.1228 & - 99.2426 & 103.561 \\
\hline
\end{tabular}




\section{APPENDIX B}

\section{PROGRAM FOR SETTING SPECIFICATION ELLIPSOIDS}

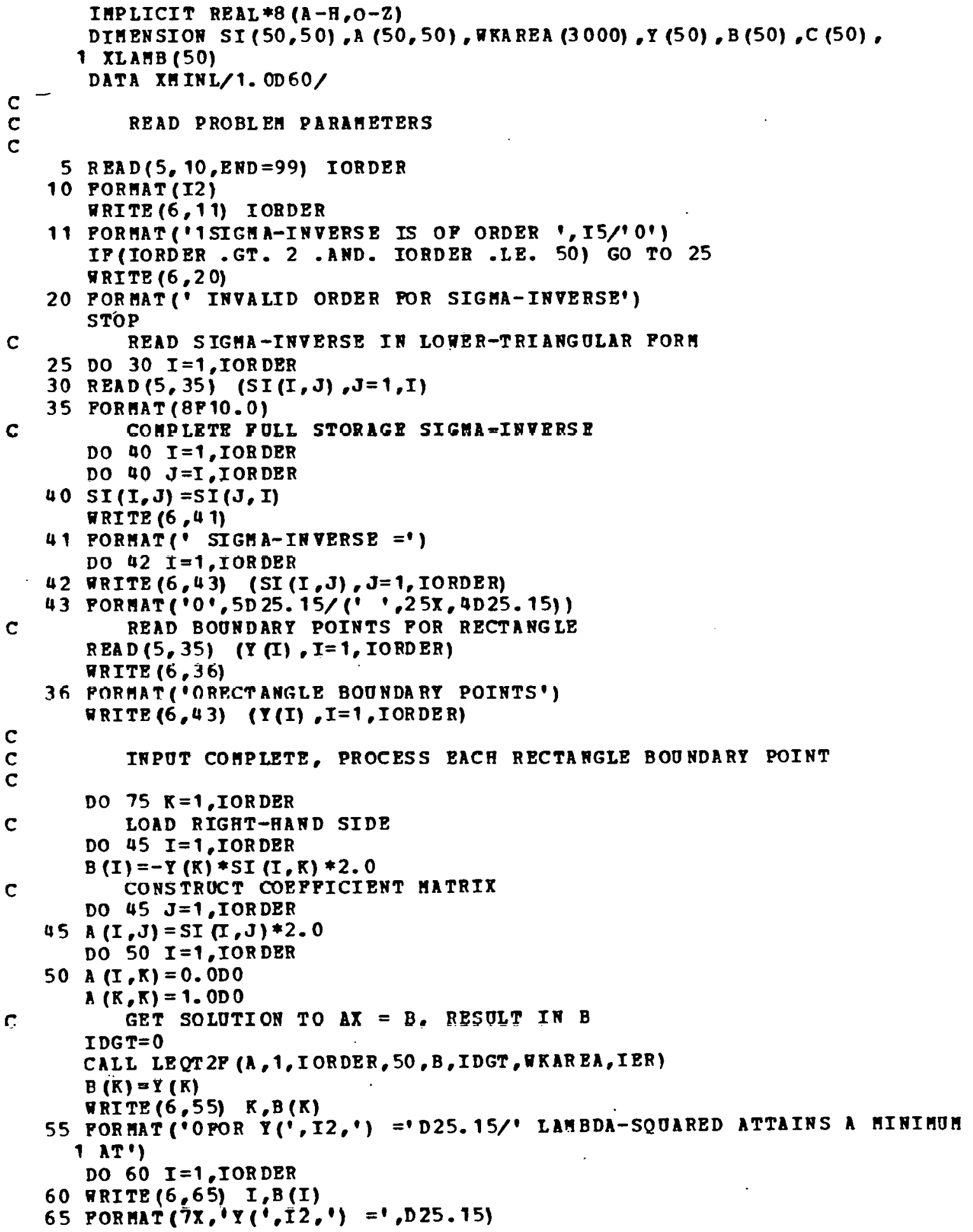


CALI VHUL PP (S I, B, IORDER, IORDER,1,50,50,C,50, IERV)

CALI VIPRPP (B,C, IORDER, 1, 1, SQLAHB)

WRITE $(6,70)$ SQLAAB

70 PORAAT (8X, LABBDA-SQUARED $=$. D25.15)

$X L A B B(K)=S Q L A$ AB

IP (XAINL ILT. SQLAHB) GO TO 75

$X H I N L=S Q L A H B$

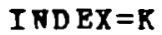

75 CONTIROE

URITE $(6,80)$ (I, Y (I), XLAMB (I), I=1, IORDER)

80 POR AAT ('1SUMAARY OF CALCULATIONS \% OI NDEX', T30, BOOND', T55, 1 'LA ABDA-SQOAR ED' ( (1X,I4,2D25.15) )

VRITE $(6,85)$ I NDEX, I DGT, IER, IBRV

85 PORMAT ('OAINIMOM LABBDA-SQOARED OCCORS AT I HDEX = , I3/

1 . SIGNIPICANT DIGITS IN RESULTS $=1, \mathrm{I} 3 \%$

2' LEQT2F ERROR CODE $=$. I $3 /$

3. VHOLPF ERROR CODE $=$..I 3 )

GO TO 5

99 STOP

END 


\section{APPENDIX C}

\section{THE NONCENTRAL CHI-SQUARE DISTRIBUTION}

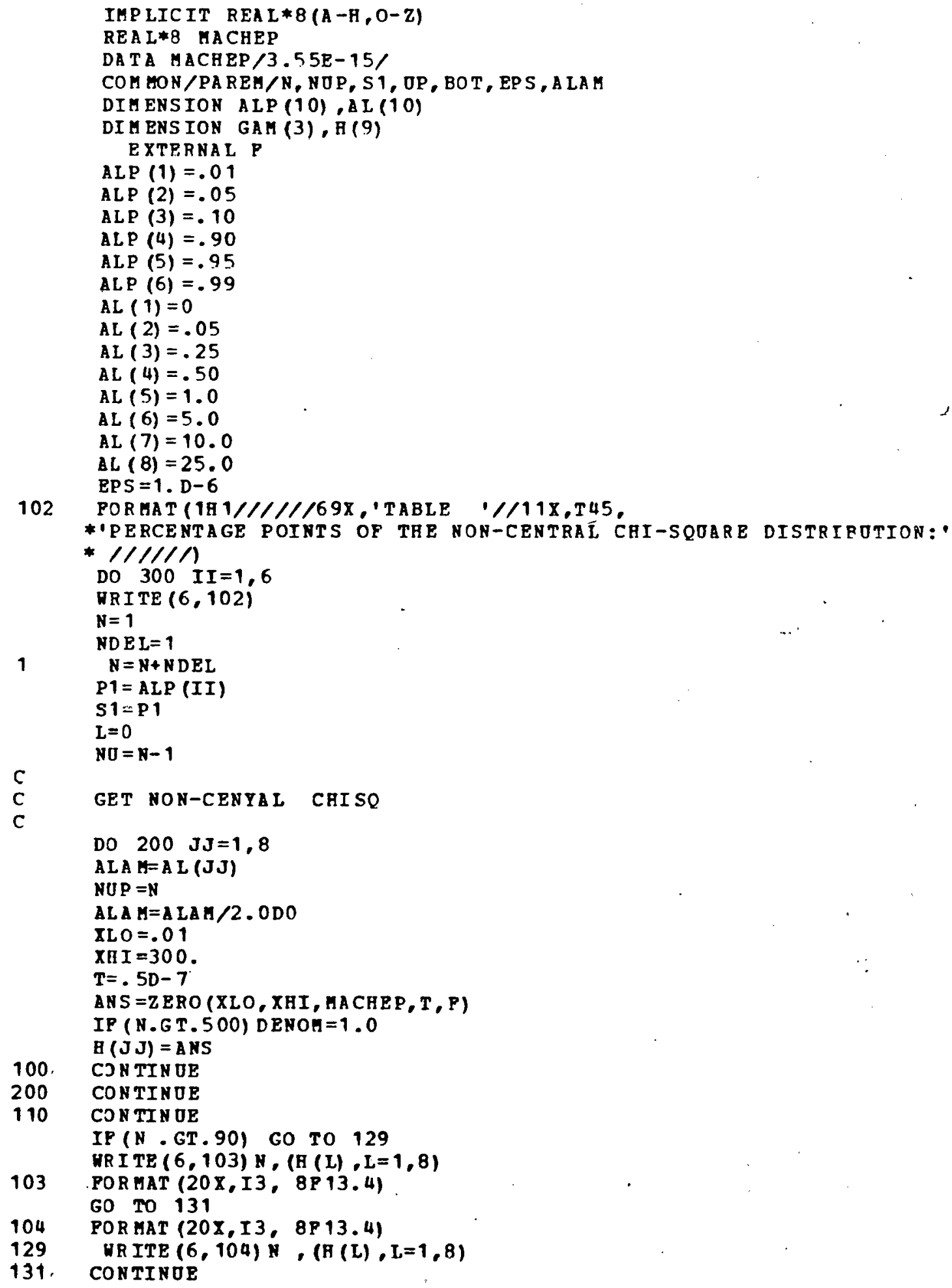




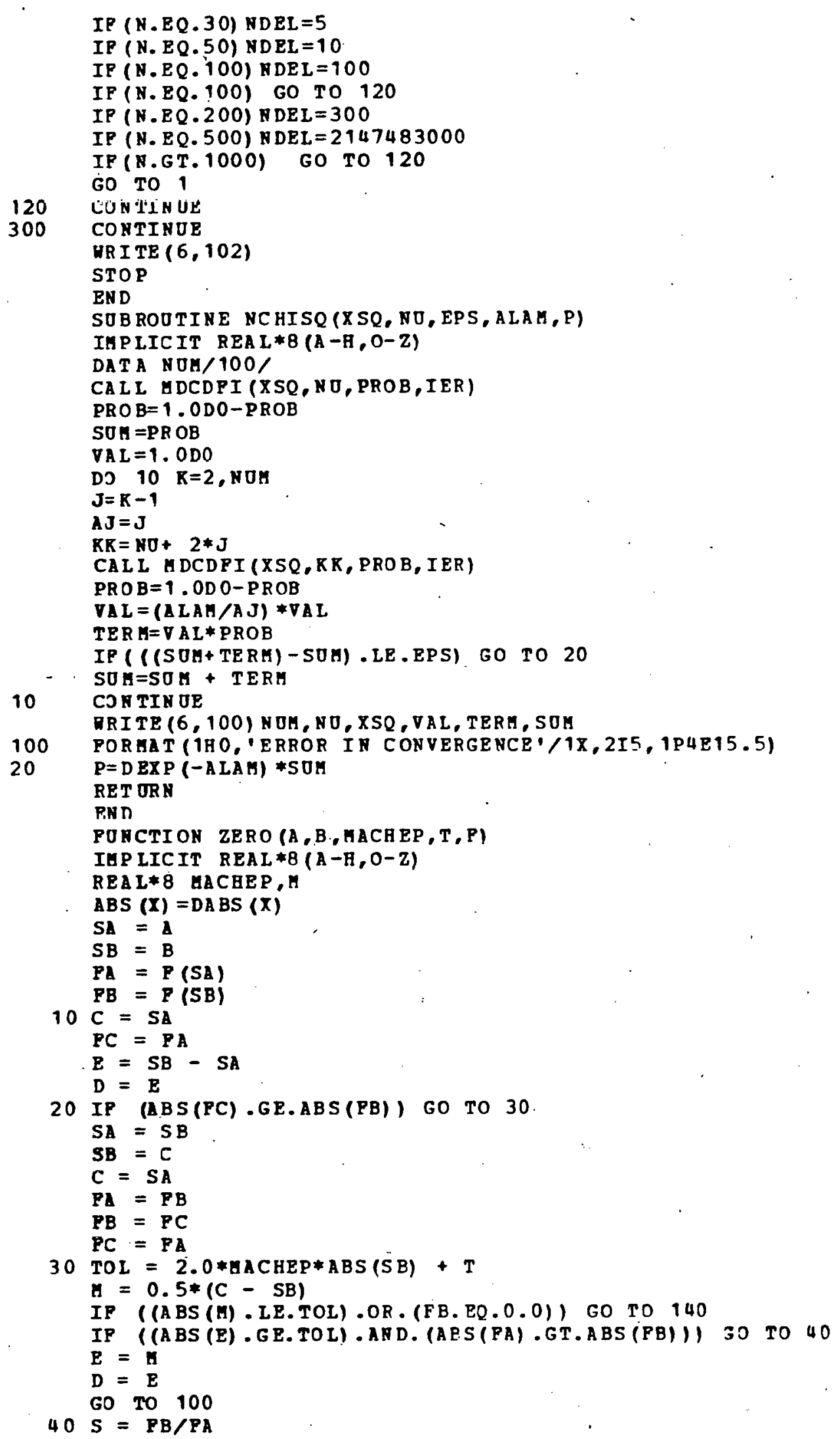




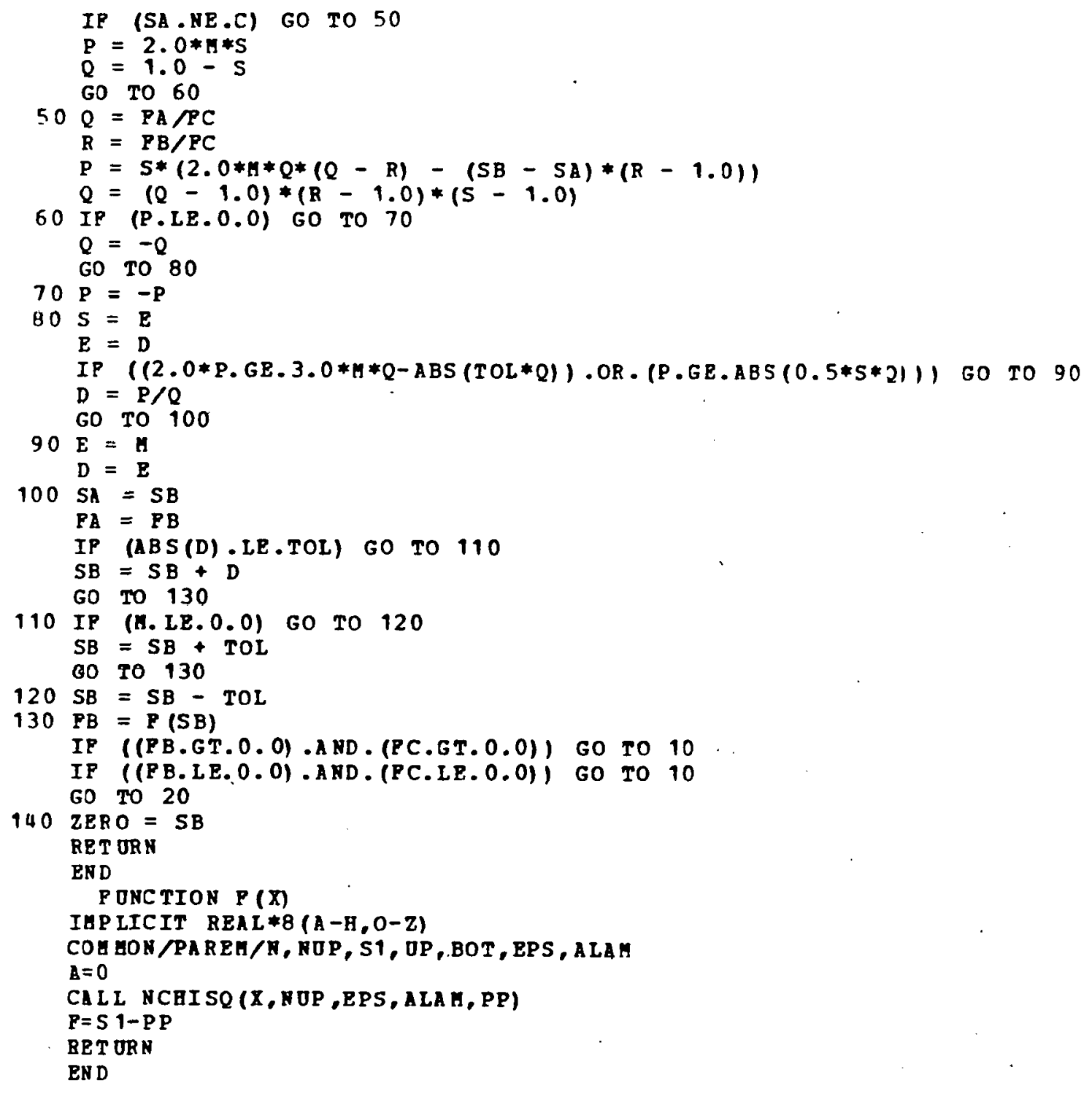


Table C-1

PERCENTAGE POINTS OF THE NONCENTRAL CHI-SQUARE DISTRIBUTION:

$P\left[X \geqslant X^{2}(0.99, f, \lambda)\right]=0.99$

\begin{tabular}{|c|c|c|c|c|c|c|c|c|}
\hline \multirow[b]{2}{*}{$f$} & \multicolumn{8}{|c|}{$\lambda$} \\
\hline & 0.0 & 0.5 & 0.25 & 0.50 & 1.0 & 5.0 & 10.0 & 25.0 \\
\hline 2 & 0.0201 & 0.0206 & 0.0228 & 0.0258 & 0.0331 & 0.2251 & 1.2268 & 7.8793 \\
\hline 3 & 0.1148 & 0.1168 & 0.1248 & 0.1356 & 0.1600 & 0.5574 & 1.7764 & 8.6143 \\
\hline 4 & 0.2971 & 0.3008 & 0.3162 & 0.3365 & 0.3808 & 0.9609 & 2.3467 & 9.3532 \\
\hline 5 & 0.5543 & 0.5599 & 0.5827 & 0.6123 & 0.6758 & 1.4120 & 2.9348 & 10.0959 \\
\hline 6 & 0.8721 & 0.8794 & 0.9091 & 0.9475 & 1.0286 & 1.8989 & 3.5383 & 10.8422 \\
\hline 7 & 1.2390 & 1.2479 & 1.2840 & 1.3303 & 1.4272 & 2.4141 & 4.1554 & 11.5919 \\
\hline 8 & 1.6465 & 1.6568 & 1.6986 & 1.7521 & 1.8632 & 2.9529 & 4.7845 & 12.3448 \\
\hline 9 & 2.0879 & 2.0995 & 2.1466 & 2.2065 & 2.3304 & 3.5115 & 5.4244 & 13.1009 \\
\hline 10 & 2.5582 & 2.5710 & 2.6228 & 2.6887 & 2.8241 & 4.0875 & 6.0740 & 13.8599 \\
\hline 11 & 3.0535 & 3.0674 & 3.1235 & 3.1947 & 3.3407 & 4.6785 & 6.7326 & 14.6219 \\
\hline 12 & 3.5706 & 3.5855 & 3.6455 & 3.7217 & 3.8773 & 5.2831 & 7.3994 & 15.3866 \\
\hline 13 & 4.1069 & 4.1227 & 4.1864 & 4.2671 & 4.4316 & 5.8998 & 8.0737 & 16.1539 \\
\hline 14 & 4.6604 & 4.6771 & 4.7442 & 4.8290 & 5.0017 & 6.5275 & 8.7550 & 16.9239 \\
\hline 15 & 5.2293 & 5.2468 & 5.3170 & 5.4057 & 5.5860 & 7.1651 & 9.4429 & 17.6963 \\
\hline 16 & 5.8122 & 5.8304 & 5.9035 & 5.9958 & 6.1831 & 7.8120 & 10.1368 & 18.4711 \\
\hline 17 & 6.4078 & 6.4267 & 6.5025 & 6.5981 & 6.7920 & 8.4673 & 10.8365 & 19.2482 \\
\hline 18 & 7.0149 & 7.0345 & 7.1128 & 7.2116 & 7.4116 & 9.1305 & 11.5416 & 20.0276 \\
\hline 19 & 7.6327 & 7.6529 & 7.7336 & 7.8353 & 8.0411 & 9.8010 & 12.2517 & 20.8091 \\
\hline 20 & 8.2604 & 8.2811 & 8.3641 & 8.4685 & 8.6798 & 10.4784 & 12.9666 & 21.5927 \\
\hline 21 & 8.8972 & 8.9185 & 9.0035 & 0.1106 & 9.3270 & 11.1621 & 13.6861 & 22.3784 \\
\hline 22 & 9.5425 & 9.5643 & 9.6513 & 9.7608 & 9.9822 & 11.8518 & 14.4100 & 23.1660 \\
\hline 23 & 10.1957 & 10.2180 & 10.3069 & 10.4188 & 10.6447 & 12.5472 & 15.1379 & 23.9555 \\
\hline 24 & 10.8564 & 10.8791 & 10.9698 & 11.0839 & 11.3142 & 13.2480 & 15.8698 & 24.7469 \\
\hline 25 & 11.5240 & 11.5471 & 11.6396 & 11.7558 & 11.9902 & 13.9538 & 16.6054 & 25.5401 \\
\hline 26 & 12.1981 & 12.2217 & 12.3158 & 12.4340 & 12.6724 & 14.6644 & 17.3446 & 26.3350 \\
\hline 27 & 12.8785 & 12.9025 & 12.9981 & 13.1182 & 13.3604 & 15.3796 & 18.0872 & 27.1317 \\
\hline 28 & 13.5647 & 13.5890 & 13.6862 & 13.8081 & 14.0540 & 16.0991 & 18.8332 & 27.9300 \\
\hline 29 & 14.2565 & 14.2811 & 14.3797 & 14.5034 & 14.7526 & 16.8228 & 19.5823 & 28.7299 \\
\hline 30 & 14.9535 & 14.9785 & 15.0784 & 15.2038 & 15.4563 & 17.5505 & 20.3344 & 29.5314 \\
\hline 35 & 18.5089 & 18.5355 & 18.6414 & 18.7743 & 19.0415 & 21.2426 & $24.1370^{\circ}$ & 33.5613 \\
\hline 40 & 22.1643 & 22.1921 & 22.3031 & 22.4421 & 22.7126 & 25.0125 & 28.0012 & 37.6255 \\
\hline 45 & 25.9013 & 25.9303 & 26.0454 & 26.1898 & 26.4797 & 28.8476 & 31.9181 & 41.7202 \\
\hline 50 & 29.7067 & 29.7366 & 29.8555 & 30.0044 & 30.3034 & 32.7382 & 35.8806 & 45.8426 \\
\hline 60 & 37.4849 & 37.5161 & 37.6413 & 37.7978 & 38.1117 & 40.6579 & 43.9218 & 54.1608 \\
\hline 70 & 45.4417 & 45.4742 & 45.6043 & 45.7668 & 46.0926 & 48.7287 & 52.0920 & 62.5640 \\
\hline 80 & 53.5401 & 53.5735 & 53.7077 & $53: 8751$ & 54.2108 & 56.9214 & 60.3680 & 71.0400 \\
\hline 90 & 61.7541 & 61.7884 & 61.9260 & 62.0976 & 62.4416 & 65.2152 & 68.7331 & 79.5795 \\
\hline 100 & 70.0649 & 70.0999 & 70.2405 & 70.4156 & 70.7667 & 73.5948 & 77.1747 & 88.1749 \\
\hline
\end{tabular}


Table C-2

PERCENTAGE POINTS OF THE NONCENTRAL CHI-SQUARE DISTRIBUTION:

$P\left[X \geqslant x^{2}(0.95, f, \lambda)=0.95\right.$

\begin{tabular}{|c|c|c|c|c|c|c|c|c|}
\hline \multirow[b]{2}{*}{$f$} & \multicolumn{8}{|c|}{$\lambda$} \\
\hline & 0.0 & 0.5 & 0.25 & 0.50 & 1.0 & 5.0 & 10.0 & 25.0 \\
\hline 2 & 0.1026 & 0.1052 & 0.1162 & 0.1316 & 0.1684 & 0.9262 & 3.0114 & 12.0802 \\
\hline 3 & 0.3518 & 0.3578 & 0.3823 & 0.4152 & 0.4887 & 1.5164 & 3.7290 & 12.9055 \\
\hline 4 & 0.7107 & 0.7197 & 0.7564 & 0.8046 & 0.9087 & 2.1352 & 4.4551 & 13.7329 \\
\hline 5 & 1.1455 & 1.1570 & 1.2040 & 1.2649 & 1.3941 & 2.7766 & 5.1891 & 14.5623 \\
\hline 6 & 1.6354 & 1.6491 & 1.7047 & 1.7762 & 1.9261 & 3.4365 & 5.9305 & 15.3936 \\
\hline 7 & 2.1673 & 2.1829 & 2.2158 & 2.3264 & 2.4937 & 4.1119 & 6.6786 & 16.2268 \\
\hline 8 & 2.7326 & 2.7498 & 2.8190 & 2.9073 & 3.0896 & 4.8008 & 7.4330 & 17.0617 \\
\hline 9 & 3.3251 & 3.3436 & 3.4184 & 3.5134 & 3.7087 & 5.5013 & 8.1931 & 17.8984 \\
\hline 10 & 3.9403 & 3.9600 & 4.0396 & 4.1406 & 4.3474 & 6.2123 & 8.9587 & 18.7368 \\
\hline 11 & 4.5748 & 4.5956 & 4.6796 & 4.7858 & 5.0028 & 6.9325 & 9.7292 & 19.5768 \\
\hline 12 & 5.2260 & 5.2478 & 5.3356 & 5.4466 & 5.6727 & 7.6612 & 10.5044 & 20.4183 \\
\hline 13 & 5.8919 & 5.9146 & 6.0058 & 6.1211 & 6.3555 & 8.3974 & 11.2841 & 21.2615 \\
\hline 14 & 6.5706 & 6.5941 & 6.6886 & 6.8077 & 7.0497 & 9.1406 & 12.0678 & 22.1061 \\
\hline 15 & 7.2609 & 7.2852 & 7.3826 & 7.5053 & 7.7541 & 9.8903 & 12.8554 & 22.9521 \\
\hline 16 & 7.9616 & 7.9865 & 8.0866 & 8.2126 & 8.4678 & 10.6458 & 13.6468 & 23.7996 \\
\hline 17 & 8.6718 & 8.6973 & 8.7998 & 8.9288 & 9.1899 & 11.4069 & 14.4416 & 24.6484 \\
\hline 18 & 9.3905 & 9.4166 & 9.5214 & 9.6532 & 9.9197 & 12.1731 & 15.2397 & 25.4985 \\
\hline 19 & 10.1170 & 10.1437 & 10.2506 & 10.3851 & 10.6566 & 12.9442 & 16.0410 & 26.3500 \\
\hline 20 & 10.8508 & 10.8780 & 10.9869 & 11.1238 & 11.4001 & 13.7197 & 16.8453 & 27.2027 \\
\hline 21 & 11.5913 & 11.6189 & 11.7297 & 11.8689 & 12.1497 & 14.4995 & 17.6524 & 28.0566 \\
\hline 22 & 12.3380 & 12.3661 & 12.4786 & 12.6200 & 12.9049 & 15.2832 & 18.4622 & 28.9117 \\
\hline 23 & 13.0905 & 13.1190 & 13.2332 & 13.3766 & 13.6655 & 16.0708 & 19.2747 & 29.7680 \\
\hline 24 & 13.8484 & 13.8773 & 13.9930 & 14.1383 & 14.4310 & 16.8619 & 20.0897 & 30.6254 \\
\hline 25 & 14.6114 & 14.6406 & 14.7570 & 14.9050 & 15.2011 & 17.6564 & 20.9071 & 31.4839 \\
\hline 26 & 15.3792 & 15.4087 & 15.5274 & 15.6762 & 15.9757 & 18.4542 & 21.7267 & 32.3435 \\
\hline 27 & 16.1514 & 16.1813 & 16.3013 & 16.4517 & 16.7544 & 19.2550 & 22.5486 & 33.2042 \\
\hline 28 & 16.9279 & 16.9581 & 17.0793 & 17.2313 & 17.5371 & 20.0588 & 23.3727 & 34.0659 \\
\hline 29 & 17.7084 & 17.7389 & 17.8613 & 18.0148 & 18.3235 & 20.8654 & 24.1988 & 34.9286 \\
\hline 30 & 18.4927 & 18.5235 & 18.6470 & 18.8020 & 13.1134 & 21.6747 & 25.0269 & 35.7923 \\
\hline 35 & 22.4650 & 22.4971 & 22.6257 & 22.7869 & 23.1104 & 25.7578 & 29.1948 & 40.1248 \\
\hline 40 & 26.5093 & 26.5424 & 26.6752 & 26.8415 & 27.1751 & 29.8942 & 33.4034 & 44.4791 \\
\hline 45 & 30.6123 & 30.6463 & 30.7825 & 30.9531 & 31.2951 & 34.0754 & 37.6473 & 48.8531 \\
\hline 50 & 34.7643 & 34.7990 & 34.9382 & 35.1125 & 35.4618 & 38.2949 & 41.9219 & 53.2449 \\
\hline 60 & 43.1880 & 43.2240 & 43.3680 & 43.5483 & 43.9096 & 46.8301 & 50.5499 & 62.0767 \\
\hline 70 & 51.7393 & 51.7762 & 51.9242 & 52.1092 & 52.4799 & 55.4703 & 59.2659 & 70.9646 \\
\hline 80 & 60.3915 & 60.4292 & 60.5803 & 60.7692 & 61.1476 & 64.1957 & 68.0546 & 79.9012 \\
\hline 90 & 69.1260 & 69.1644 & 69.3181 & 69.5103 & 69.8952 & 72.9919 & 76.9049 & 88.8804 \\
\hline 100 & 77.9295 & 77.9684 & 78.1244 & 78.3193 & 78.7097 & 81.8481 & 85.8080 & 97.8974 \\
\hline
\end{tabular}


Table C-3

PERCENTAGE POINTS OF THE NONCENTRAL CHI-SQUARE DISTRIBUTION:

$P\left[X \geqslant X^{.2}(0.90, f, \lambda]=0.90\right.$

\begin{tabular}{|c|c|c|c|c|c|c|c|c|}
\hline \multirow[b]{2}{*}{$\mathbf{f}$} & \multicolumn{8}{|c|}{$\lambda$} \\
\hline & 0.0 & 0.5 & 0.25 & 0.50 & 1.0 & 5.0 & 10.0 & 25.0 \\
\hline 2 & 0.2107 & 0.2161 & 0.2387 & 0.2701 & 0.3443 & 1.6160 & 4.3260 & 14.6947 \\
\hline 3 & 0.5844 & 0.5942 & 0.6349 & 0.6891 & 0.8093 & 2.3252 & 5.1199 & 15.5640 \\
\hline 4 & 1.0636 & 1.0770 & 1.1318 & 1.2035 & 1.3573 & 3.0484 & 5.9187 & 16.4346 \\
\hline 5 & 1.6103 & 1.6265 & 1.6924 & 1.7775 & 1.9571 & 3.7844 & 6.7222 & 17.3065 \\
\hline 6 & 2.2041 & 2.2226 & 2.2974 & 2.3933 & 2.5934 & 4.5316 & 7.5302 & 18.1797 \\
\hline 7 & 2.8331 & 2.8534 & 2.9355 & 3.0404 & 3.2573 & 5.2888 & 8.3425 & 19.0542 \\
\hline 8 & 3.4895 & 3.5114 & 3.5997 & 3.7120 & 3.9431 & 6.0548 & 9.1587 & 19.9298 \\
\hline 9 & 4.1682 & 4.1914 & 4.2849 & 4.4037 & 4.6469 & 6.8287 & 9.9788 & 20.8066 \\
\hline 10 & 4.8652 & 4.8895 & 4.9877 & 5.1120 & 5.3658 & 7.6097 & 10.8024 & 21.6846 \\
\hline 11 & 5.5778 & 5.6032 & 5.7054 & 5.8346 & 6.0977 & 8.3972 & 11.6294 & 22.5637 \\
\hline 12 & 6.3038 & 6.3301 & 6.4359 & 6.5694 & 6.8408 & 9.1905 & 12.4595 & 23.4438 \\
\hline 13 & 7.0415 & 7.0686 & 7.1776 & 7.3151 & 7.5939 & 9.9893 & 13.2927 & 24.3250 \\
\hline 14 & 7.7895 & 7.8174 & 7.9293 & 8.0703 & 8.3559 & 10.7931 & 14.1287 & 25.2073 \\
\hline 15 & 8.5468 & 8.5753 & 8.6898 & 8.8340 & 9.1257 & 11.6014 & 14.9674 & 26.0905 \\
\hline 16 & 9.3122 & 9.3414 & 9.4583 & 9.6054 & 9.9028 & 12.4141 & 15.8087 & 26.9747 \\
\hline 17 & 10.0852 & 10.1149 & 10.2340 & 10.3838 & 10.6864 & 13.2309 & 16.6525 & 27.8599 \\
\hline 18 & 10.8649 & 10.8951 & 11.0163 & 11.1686 & 11.4760 & 14.0513 & 17.4986 & 28.7460 \\
\hline 19 & 11.6509 & 11.6816 & 11.8047 & 11.9593 & 12.2711 & 14.8753 & 18.3469 & 29.6330 \\
\hline 20 & 12.4426 & 12.4737 & 12.5986 & 12.7554 & 13.0713 & 15.7027 & 19.1974 & 30.5209 \\
\hline 21 & 13.2396 & 13.2711 & 13.3976 & 13.5564 & 13.8763 & 16.5331 & 20.0500 & 31.4096 \\
\hline 22 & 11.0416 & 11.0734 & 14.2014 & 14.3621 & 14.6856 & 17.3666 & 20.9045 & 32.2992 \\
\hline 23 & 14.8480 & 14.8802 & 15.0097 & 15.1721 & 15.4991 & 18.2028 & 21.7609 & 33.1897 \\
\hline 24 & 15.6587 & 15.6913 & 15.8221 & 15.9862 & 16.3164 & 19.0417 & 22.6191 & 34.0809 \\
\hline 25 & 16.4734 & 16.5064 & 16.6385 & 16.8041 & 17.1374 & 19.8832 & 23.4791 & 34.9729 \\
\hline 26 & 17.2919 & 17.3252 & 17.4585 & 17.6256 & 17.9617 & 20.7271 & 24.3107 & 35.8657 \\
\hline 27 & 18.1139 & 18.1475 & 18.2819 & 18.4505 & 18.7893 & 21.5733 & 25.2040 & 36.7593 \\
\hline 28 & 18.9392 & 18.9731 & 19.1086 & 19.2785 & 19.6200 & 22.4217 & 26.0688 & 37.6536 \\
\hline 29 & 19.7677 & 19.8018 & 19.9384 & 20.1096 & 20.4536 & 23.2722 & 26.0352 & 38.5486 \\
\hline 30 & 20.5992 & 20.6336 & 20.7712 & 20.9436 & 21.2899 & 24.1248 & 27.8030 & 39.4443 \\
\hline 35 & 24.7967 & 24.8321 & 24.9740 & 25.1517 & 25.5084 & 28.4153 & 32.1624 & 43.9332 \\
\hline 40 & 29.0505 & 29.0868 & 29.2323 & 29.4143 & 29.7795 & 32.7463 & 36.5522 & 48.4379 \\
\hline 45 & 33.3504 & 33.3874 & 33.5358 & 33.7215 & 34.0939 & 37.1114 & 40.9683 & 52.9570 \\
\hline 50 & 37.6886 & 37.7263 & 37.8772 & 38.0661 & 38.4445 & 41.5059 & 45.4076 & 57.4893 \\
\hline 60 & 46.4589 & 46.4976 & 46.6526 & 46.8465 & 47.2348 & 50.3685 & 54.3458 & 66.5894 \\
\hline 70 & 55.3289 & 55.3685 & 55.5266 & 55.7245 & 56.1207 & 59.3120 & 63.3508 & 75.7315 \\
\hline 80 & 64.2778 & 64.3180 & 64.4788 & 64.6799 & 65.0824 & 68.3211 & 72.4113 & 84.9100 \\
\hline 90 & 73.2911 & 73.3318 & 73.4948 & 73.6985 & 74.1064 & 77.3848 & 81.5190 & 94.1207 \\
\hline 100 & 82.3581 & 82.3993 & 82.5641 & 82.7701 & 83.1825 & 86.4951 & 90.6672 & 103.3600 \\
\hline
\end{tabular}


Table C-4

PERCENTAGE POINTS OF THE NONCENTRAL CHI-SOUARE DISTRIBUTION:

$P\left[X \geqslant x^{.2}(0.10, f, \lambda)\right]=0.10$

\begin{tabular}{|c|c|c|c|c|c|c|c|c|}
\hline \multirow[b]{2}{*}{$f$} & \multicolumn{8}{|c|}{$\lambda$} \\
\hline & 0.0 & 0.5 & 0.25 & 0.50 & 1.0 & 5.0 & 10.0 & 25.0 \\
\hline 2 & 4.6052 & 4.7201 & 5.1739 & 5.7251 & 6.7701 & 13.6402 & 20.9399 & 40.5818 \\
\hline 3 & 6.2514 & 6.3554 & 6.7665 & 7.2692 & 8.2371 & 14.8964 & 22.1281 & 41.7046 \\
\hline 4 & 7.7794 & 7.8765 & 8.2610 & 8.7333 & 9.6504 & 16.1433 & 23.3126 & 42.8263 \\
\hline 5 & 9.2364 & 9.3286 & 9.6945 & 10.1452 & 11.0254 & 17.3817 & 24.4935 & 43.9470 \\
\hline 6 & 10.6446 & 10.7332 & 11.0851 & 11.5196 & 12.3714 & 18.6125 & 25.6710 & 45.0666 \\
\hline 7 & 12.0170 & 12.1028 & 12.4437 & 12.8653 & 13.6943 & 19.8362 & 26.8453 & 46.1853 \\
\hline 8 & 13.3616 & 13.4450 & 13.7769 & 14.1881 & 14.9982 & 21.0536 & 28.0165 & 47.3030 \\
\hline 9 & 14.6837 & 14.7652 & 15.0897 & 15.4920 & 16.2862 & 22.2650 & 29.1848 & 48.4197 \\
\hline 10 & 15.9872 & 16.0670 & 16.3852 & 16.7801 & 17.5606 & 23.4709 & 30.3504 & 49.5355 \\
\hline 11 & 17.2750 & 17.3535 & 17.6662 & 18.0545 & 18.8231 & 24.6718 & 31.5133 & 50.6503 \\
\hline 12 & 18.5493 & 18.6266 & 18.9345 & 19.3171 & 20.0752 & 25.8680 & 32.6737 & 51.7643 \\
\hline 13 & 19.8119 & 19.8881 & 20.1918 & 20.5693 & 21.3180 & 27.0597 & 33.8317 & 52.8774 \\
\hline 14 & 21.0641 & 21.1393 & 21.4392 & 21.8123 & 22.5525 & 28.2474 & 34.9874 & 53.9897 \\
\hline 15 & 22.3071 & 22.3814 & 22.6780 & 23.0469 & 23.7795 & 29.4311 & 36.1409 & 55.1011 \\
\hline 16 & 23.5418 & 23.6154 & 23.9088 & 24.2740 & $24.9996^{\circ}$ & 30.6112 & 37.2922 & 56.2117 \\
\hline 17 & 24.7690 & 24.8419 & 25.1325 & 25.4944 & 26.2136 & 31.7879 & 38.4415 & 57.3215 \\
\hline 18 & 25.9894 & 26.0616 & 26.3496 & 26.7084 & 27.4218 & 32.9613 & 39.5889 & 58.4306 \\
\hline 19 & 27.2036 & 27.2751 & 27.5608 & 27.9167 & 28.6246 & 34.1316 & 40.7343 & 59.5388 \\
\hline 20 & 28.4120 & 28.4830 & 28.7665 & 29.1197 & 29.8226 & 35.2990 & 41.8780 & 60.6464 \\
\hline 21 & 29.6151 & 29.6856 & 29.9671 & 30.3178 & 31.0160 & 36.4636 & 43.0199 & 61.7531 \\
\hline 22 & 30.8133 & 30.8833 & 31.1629 & 31.5114 & 32.2052 & 37.6256 & 44.1601 & 62.8592 \\
\hline 23 & 32.0069 & 32.0765 & 32.3543 & 32.7006 & 33.3903 & 38.7851 & 45.2986 & 63.9645 \\
\hline 24 & 33.1962 & 33.2654 & 33.5415 & 33.8859 & 34.5717 & 39.9422 & 46.4356 & 65.0692 \\
\hline 25 & 34.3816 & 34.4503 & 34.7249 & 35.0674 & 35.7496 & 41.0969 & 47.5711 & 66.1732 \\
\hline 26 & 35.5632 & 35.6315 & 35.9047 & 36.2453 & 36.9241 & 42.2495 & 48.7051 & 67.2765 \\
\hline 27 & 36.7412 & 36.8092 & 37.0810 & 37.4200 & 38.0955 & 43.3999 & 49.8376 & 68.3791 \\
\hline 28 & 37.9159 & 37.9836 & 38.2541 & 38.5914 & 39.2639 & 44.5483 & 50.9688 & 69.4811 \\
\hline 29 & 39.0875 & 39.1548 & 39.4241 & 39.7599 & 40.4294 & 45.6948 & 52.0986 & 70.5825 \\
\hline 30 & 40.2560 & 40.3231 & 40.5911 & 40.9255 & 41.5923 & 46.8394 & 53.2271 & 71.6833 \\
\hline 35 & 46.0588 & 46.1246 & 46.3875 & 46.7156 & 47.3703 & 52.5366 & 58.8515 & 77.1782 \\
\hline 40 & 51.8051 & 51.8698 & 52.1286 & 52.4517 & 53.0965 & 58.1959 & 64.4482 & 82.6591 \\
\hline 45 & 57.5053 & 57.5692 & 57.8246 & 58.1435 & 58.7801 & 63.8229 & 70.0208 & 88.1271 \\
\hline 50 & 63.1671 & 63.2303 & 63.4828 & 63.7981 & 64.4278 & 69.4218 & 75.5719 & 93.5832 \\
\hline 60 & 74.3970 & 74.4590 & 74.7069 & 75.0165 & 75.6350 & 80.5489 & 86.6181 & 104.4631 \\
\hline 70 & 85.5270 & 85.5881 & 85.8324 & 86.1376 & 86.7473 & 91.5978 & 97.6010 & 115.3045 \\
\hline 80 & 96.5782 & 96.6386 & 96.8799 & 97.1815 & 97.7842 & 102.5827 & 108.5309 & 126.1120 \\
\hline 90 & 107.5650 & 107.6248 & 107.8637 & 108.1623 & 108.7591 & 113.5142 & 119.4154 & 136.8894 \\
\hline 100 & 118.4980 & 118.5572 & 118.7942 & 119.0903 & 119.6820 & 124.4001 & 130.2606 & 147.6398 \\
\hline
\end{tabular}


Table C-5

PERCENTAGE POINTS OF THE NONCENTRAL CHI-SQUARE DISTRIBUTION:

$P\left[X \geqslant X^{\prime 2}(0.05, f, \lambda)\right]=0.05$

\begin{tabular}{|c|c|c|c|c|c|c|c|c|}
\hline \multirow[b]{2}{*}{$f$} & \multicolumn{8}{|c|}{$\lambda$} \\
\hline & 0.0 & 0.5 & 0.25 & 0.50 & 1.0 & 5.0 & 10.0 & 25.0 \\
\hline 2 & 5.9915 & 6.1404 & 6.7167 & 7.3962 & 8.6422 & 16.3835 & 24.3441 & 45.3082 \\
\hline 3 & 7.8147 & 7.9444 & 8.4509 & 9.0588 & 10.2025 & 17.6946 & 25.5754 & 46.4611 \\
\hline 4 & 9.4877 & 9.6059 & 10.0702 & 10.6329 & 11.7072 & 18.9959 & 26.8026 & 47.6128 \\
\hline 5 & 11.0705 & 11.1809 & 11.6162 & 12.1471 & 13.1702 & 20.2882 & 28.0258 & 48.7632 \\
\hline 6 & 12.5916 & 12.6963 & 13.1101 & 13.6171 & 14.6004 & 21.5722 & 29.2452 & 49.9125 \\
\hline 7 & 14.0671 & 14.1674 & 14.5646 & 15.0527 & 16.0039 & 22.8484 & 30.4611 & 51.0606 \\
\hline 8 & 15.5073 & 15.6041 & 15.9879 & 16.4606 & 17.3852 & 24.1175 & 31.6735 & 52.2076 \\
\hline 9 & 16.9190 & 17.0128 & 17.3855 & 17.8455 & 18.7476 & 25.3799 & 32.8826 & 53.3535 \\
\hline 10 & 18.3070 & 18.3985 & 18.7618 & 19.2109 & 20.0936 & 26.6362 & 34.0896 & 51.1982 \\
\hline 11 & 19.6751 & 19.7645 & 20.1197 & 20.5594 & 21.4253 & 27.8866 & 35.2916 & 55.6420 \\
\hline 12 & 21.0261 & 21.1136 & 21.4619 & 21.8933 & 22.7443 & 29.1316 & 36.4917 & 56.7847 \\
\hline 13 & 22.3620 & 22.4480 & 22.7901 & 23.2143 & 24.0520 & 30.3714 & 37.6890 & $5 \% .9264$ \\
\hline 14 & 23.6848 & 23.7693 & 24.1060 & 24.5237 & 25.3495 & 31.6065 & 38.8836 & 59.0670 \\
\hline 15 & 24.9958 & 25.0790 & 25.4108 & 25.8227 & 26.6377 & 32.8370 & 40.0756 & 60.2068 \\
\hline 16 & 26.2962 & 26.3783 & 26.7057 & $2,7.112 .3$ & 27.9175 & 34.0632 & 41.2652 & 61.3455 \\
\hline 17 & 27.5871 & 27.6682 & 27.9915 & $28: 3933$ & 29.1896 & 35.2854 & 42.4524 & 62.4833 \\
\hline 18 & 28.8693 & 28.9494 & 29.2691 & 29.6664 & 30.4545 & 36.5036 & 43.6373 & 63.6202 \\
\hline 19 & 30.1435 & 30.2228 & 30.5390 & 30.9324 & 31.7128 & 37.7183 & 44.8199 & 64.7562 \\
\hline 20 & 31.4104 & 31.4889 & 31.8020 & 32.1916 & 32.9650 & 38.9294 & 46.0004 & 65.8913 \\
\hline 21 & 32.6706 & 32.7483 & 33.0586 & 33.4447 & 34.2115 & 40.1371 & 47.1788 & 67.0255 \\
\hline 22 & 33.9244 & 34.0015 & 34.3091 & 34.6919 & 35.4527 & 41.3417 & 48.3553 & 68.1589 \\
\hline 23 & 35.1725 & 35.2489 & 35.5539 & 35.9338 & 36.6888 & 42.5433 & 49.5297 & 69.2914 \\
\hline 24 & 36.4150 & 36.4909 & 36.7936 & 37.1706 & 37.9202 & 43.7419 & 50.7023 & 70.4231 \\
\hline 25 & 37.6525 & 37.7278 & 38.0283 & 38.4026 & 39.1472 & 44.9377 & 51.8731 & 71.5540 \\
\hline 26 & 38.8851 & 38.9599 & 39.2584 & 39.6302 & 40.3700 & 46.1309 & 53.0421 & 72.6841 \\
\hline 27 & 40.1133 & 40.1875 & 40.4841 & 40.8535 & 41.5889 & 47.3215 & 54.2094 & 73.8134 \\
\hline 28 & 41.3371 & 41.4109 & 41.7056 & 42.0729 & 42.8039 & 48.5096 & 55.3750 & 74.9420 \\
\hline 29 & 42.5570 & 42.6303 & 42.9233 & 43.2884 & 44.0154 & 49.6953 & 56.5390 & 76.0698 \\
\hline 30 & 43.7730 & 43.8459 & 44.1372 & 44.5003 & 45.2235 & 50.8787 & 57.7014 & 77.1968 \\
\hline 35 & 49.8018 & 49.8730 & 50.1572 & 50.5116 & 51.2180 & 56.7641 & 63.4914 & 82.8214 \\
\hline 40 & 55.7585 & 55.8282 & 56.1066 & 56.4541 & 57.1470 & 62.6027 & 69.2478 & 88.4291 \\
\hline 45 & 61.6562 & 61.7247 & 61.9985 & 62.3402 & 63.0217 & 68.4011 & 74.9745 & 94.0212 \\
\hline 50 & 67.5048 & 67.5723 & 67.8421 & 68.1789 & 68.8510 & 74.1646 & 80.6747 & 99.5989 \\
\hline 60 & 79.0819 & 79.1478 & 79.4113 & 79.7402 & 80.3970 & 85.6028 & 92.0060 & 110.7147 \\
\hline 70 & 90.5312 & 90.5959 & 90.8544 & 91.1773 & 91.8222 & 96.9427 & 103.2585 & 121.7832 \\
\hline 80 & 101.8795 & 101.9431 & 102.1978 & 102.5158 & 103.1511 & 108.2018 & 114.4446 & 132.8099 \\
\hline 90 & 113.1453 & 113.2081 & 113.4595 & 113.7735 & 114.4009 & 119.3933 & 125.5738 & 143.7992 \\
\hline 100 & 124.3421 & 124.4043 & 124.6529 & $124.963 ़ 5$ & 125.5842 & 130.5270 & 136.6536 & 154.7550 \\
\hline
\end{tabular}


Table C-6

PERCENTAGE POINTS OF THE NONCENTRAL CHI-SQUARE DISTRIBUTION:

$P\left[X \geqslant X^{2}(0.01, f, \lambda)\right]=0.01$

\begin{tabular}{|c|c|c|c|c|c|c|c|c|}
\hline \multirow[b]{2}{*}{$f$} & \multicolumn{8}{|c|}{$\lambda$} \\
\hline & 0.0 & 0.5 & 0.25 & 0.50 & 1.0 & 5.0 & 10.0 & 25.0 \\
\hline 2 & 9.2103 & 9.4369 & 10.2784 & 11.2165 & 12.8487 & 22.2324 & 31.4363 & 54.8833 \\
\hline 3 & 11.3449 & 11.5320 & 12.2448 & 13.0694 & 14.5609 & 23.6380 & 32.7427 & 56.0897 \\
\hline 4 & 13.2767 & 13.4414 & 14.0774 & 14.8282 & 16.2179 & 25.0333 & 34.0446 & 57.2347 \\
\hline 5 & 15.0863 & 15.2363 & 15.8202 & 16.5183 & 17.8303 & 26.4188 & 35.3420 & 58.4982 \\
\hline 6 & 16.8119 & 16.9513 & 17.4972 & 18.1554 & 19.4058 & 27.7952 & 36.6351 & 59.7004 \\
\hline 7 & 18.4753 & 18.6068 & 19.1234 & 19.7500 & 20.9501 & 29.1629 & 37.9241 & 60.9011 \\
\hline 8 & 20.0902 & 20.2154 & 20.7086 & 21.3096 & 22.4676 & 30.5226 & 39.2092 & 62.1005 \\
\hline 9 & 21.6660 & 21.7860 & 22.2601 & 22.8397 & 23.9619 & 31.8746 & 40.4904 & 63.2985 \\
\hline 10 & 23.2092 & 23.3250 & 23.7830 & 24.3445 & 25.4359 & 33.2194 & 41.7680 & 64.4952 \\
\hline 11 & 24.7250 & 24.8371 & 25.2814 & 25.8273 & 26.8916 & 34.5574 & 43.0420 & 65.6907 \\
\hline 12 & 26.2170 & 26.3260 & 26.7584 & 27.2907 & 28.3310 & 35.8889 & 44.3125 & 66.8849 \\
\hline 13 & 27.6882 & 27.7946 & 28.2165 & 28.7368 & $29.7559^{\circ}$ & 37.2143 & 45.5798 & 68.0778 \\
\hline 14 & 29.1412 & 29.2452 & 29.6579 & 30.1676 & 31.1675 & 38.5339 & 46.8438 & 69.2695 \\
\hline 15 & 30.5779 & 30.6797 & 31.0843 & 31.5843 & 32.5670 & 39.8479 & 48.1047 & 70.4600 \\
\hline 16 & 31.9999 & 32.0998 & 32.4970 & 32.9884 & 33.9554 & 41.1567 & 49.3626 & 71.6494 \\
\hline 17 & 33.4086 & 33.5068 & 33.8973 & 34.3808 & 35.3335 & 42.4604 & 50.6176 & 72.8375 \\
\hline 18 & 34.8053 & 34.9019 & 35.2863 & 35.7626 & 36.7022 & 43.7593 & 51.8697 & 74.0246 \\
\hline 19 & 36.1909 & 36.2860 & 36.6649 & 37.1346 & 38.0620 & 45.0536 & 53.1192 & 75.2105 \\
\hline 20 & 37.5662 & 37.6601 & 38.0338 & 38.4974 & 39.4136 & 46.3434 & 54.3659 & 76.3953 \\
\hline 21 & 38.9322 & 39.0248 & 39.3938 & 39.8518 & 40.7575 & 47.6291 & 55.6101 & 77.5790 \\
\hline 22 & 40.2093 & 40.3808 & 40.7455 & 41.1083 & 42.0042 & 48.9107 & 56.8518 & 78.7617 \\
\hline 23 & 41.6384 & 41.7288 & 42.0894 & 42.5373 & 43.4241 & 50.1885 & 58.0910 & 79.9433 \\
\hline 24 & 42.9798 & 43.0693 & 43.4261 & 43.8694 & 44.7477 & 51.4625 & 59.3279 & 81.1239 \\
\hline 25 & 44.3141 & 44.4027 & 44.7559 & 45.1949 & 46.0652 & 52.7329 & 60.5625 & 82.3035 \\
\hline 26 & 45.6417 & 45.7294 & 46.0793 & 46.5143 & 47.3770 & 53.9998 & 61.7948 & 83.4820 \\
\hline 27 & 46.9629 & 47.0498 & 47.3966 & 47.8278 & 48.6834 & 55.2634 & 63.0250 & 84.6596 \\
\hline 28 & 48.2782 & 48.3644 & 48.7082 & 49.1358 & 49.9846 & 56.5238 & 64.2530 & 85.8362 \\
\hline 29 & 49.5879 & 43.6733 & 50.0143 & 50.4386 & 51.2810 & 67.7811 & 65.4790 & 87.0119 \\
\hline 30 & 50.8922 & $50.9 \% 69$ & 51.3153 & 51.7364 & 52.5727 & 59.0354 & 66.7029 & 88.1866 \\
\hline 35 & 57.3421 & 57.4239 & 57.7509 & 58.1582 & 58.9681 & 65.2651 & 72.7942 & 94.0465 \\
\hline 40 & 63.6907 & 63.7703 & 64.0882 & 64.4844 & 65.2731 & 71.4327 & 78.8419 & 99.8849 \\
\hline 45 & 69.9568 & 70.0345 & 70.3450 & 70.7321 & 71.5032 & 77.5466 & 84.8507 & 105.7032 \\
\hline 50 & 76.1539 & 76.2300 & 76.5343 & 76.9138 & 77.6701 & 83.6134 & 90.8246 & 111.5028 \\
\hline 60 & 88.3794 & 88.4530 & 88.7474 & 89.1147 & 89.8473 & 95.6269 & 102.6803 & 123.0503 \\
\hline 70 & 100.4252 & 100.4969 & 100.7837 & 101.1416 & 101.8559 & 107.5060 & 114.4301 & 134.5356 \\
\hline 80 & 112.3288 & 112.3990 & 112.6797 & 113.0302 & 113.7297 & 119.2743 & 126.0901 & 145.9654 \\
\hline 90 & 124.1163 & 124.1852 & 124.4610 & 124.8053 & 125.4928 & 130.9493 & 137.6727 & 157.3454 \\
\hline 100 & 135.8067 & 135.8746 & 136.1462 & 136.4853 & 137.1626 & 142.5442 & 149.1876 & 168.6802 \\
\hline
\end{tabular}




\section{APPENDIX D}

H VALUES

IUPLICIT REAL $* 8(A-H, O-Z)$

RBA L*8 HACHBP

DATA HACREP/3.55E-15/

COH BOR/PAREY/R, ROP, S1, OP, BOT, EPS, ALAE

DIGENSIOR GAH (3), B (9)

EITBRNAL $P$

EPS $=1 . D-6$

102 PORHAT (1月1,T20, GAM $=.90$. T61, GAH $=.95$, T91, GAH $=.991 /$

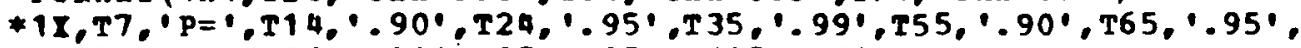

× T75, $\left..99 \cdot .785, \cdot .901, T 95, \cdot .951, T 105, \cdot 99{ }^{\prime}\right)$

GAE (1) $=0.90$

$\operatorname{GAB}(2)=0.95$

GAB $(3)=0.99$

DO $120 \mathrm{JJ}=2,30$

MRITE $(6,125) \mathrm{JJ}$

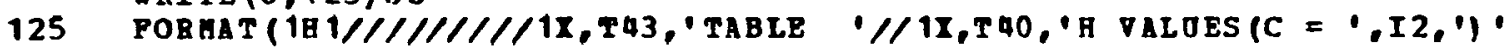

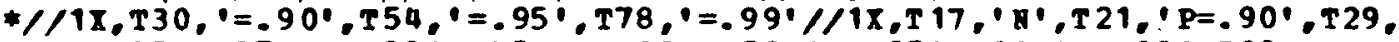

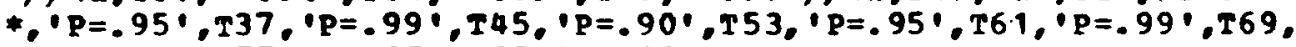

$* \cdot P=.900^{\prime}, \mathrm{T77}, \cdot \mathrm{P}=.95^{\circ}, \mathrm{T85}, \cdot \mathrm{P}=.990^{\circ} \mathrm{N}$

$\mathrm{n}=1$

IDEL $=1$

$1 \quad M=B+R D E L$

$\mathbb{R O P}=\mathbf{J} \mathrm{J}$

ALAA=DFLOAT (NOP) /DPLOAT (N)

$\triangle L A B=\triangle L \triangle A / 2.0 D O$

$I=0$

DO $110 \quad I=1,3$

DO $100 \mathrm{~J}=1,3$

P1 = GA I ( J)

$\mathrm{L}=\mathrm{L}+\mathrm{I}$

$S 1=P 1$

$\mathrm{NO}=\mathrm{N}-1$

c

GBT CBRTRAL CHISQ

$D P=D P L O A T(N O) * D P L O A T$ (ROP)

P2 $=G A B(I)$

$P 2=1.0 D 0-P 2$

CALI, IDCGI (P2,DF, $X, I E R)$

$c$

$D E R O H=X / D P$

C GET HOA-CERYA CHISO

C

$\mathrm{ILO}=.01$

$\mathrm{XBI}=75.0$

$T=.5 D-7$

$\triangle N S=2$ ERO $(X L O, X R I$, AACHEP $, T, P)$

IP (N. GT . 500) D ENOH $=1.0$

100

$\mathrm{H}(\mathrm{L})=\mathrm{ANS} / \mathrm{DEROH}$

110

CONTINOE

CONTINOE

IP(R.GT.90) GO TO 129

$\operatorname{RBITE}(6,103) \times,(\mathrm{H}(L), L=1,9)$

103 PORMAT (15X,I2,1X,9P8.2)

GO TO 131

129 IP(N.GT.500)GO TO 137

RRITE $(6,104)$ ) ( (H (L) , L =1,9)

GO TO 131

DRITE $(6,107)$ (R (L) , L=1,9)

107

PORAAT (18X, 9P 8.2)

139 CORTIHOE 


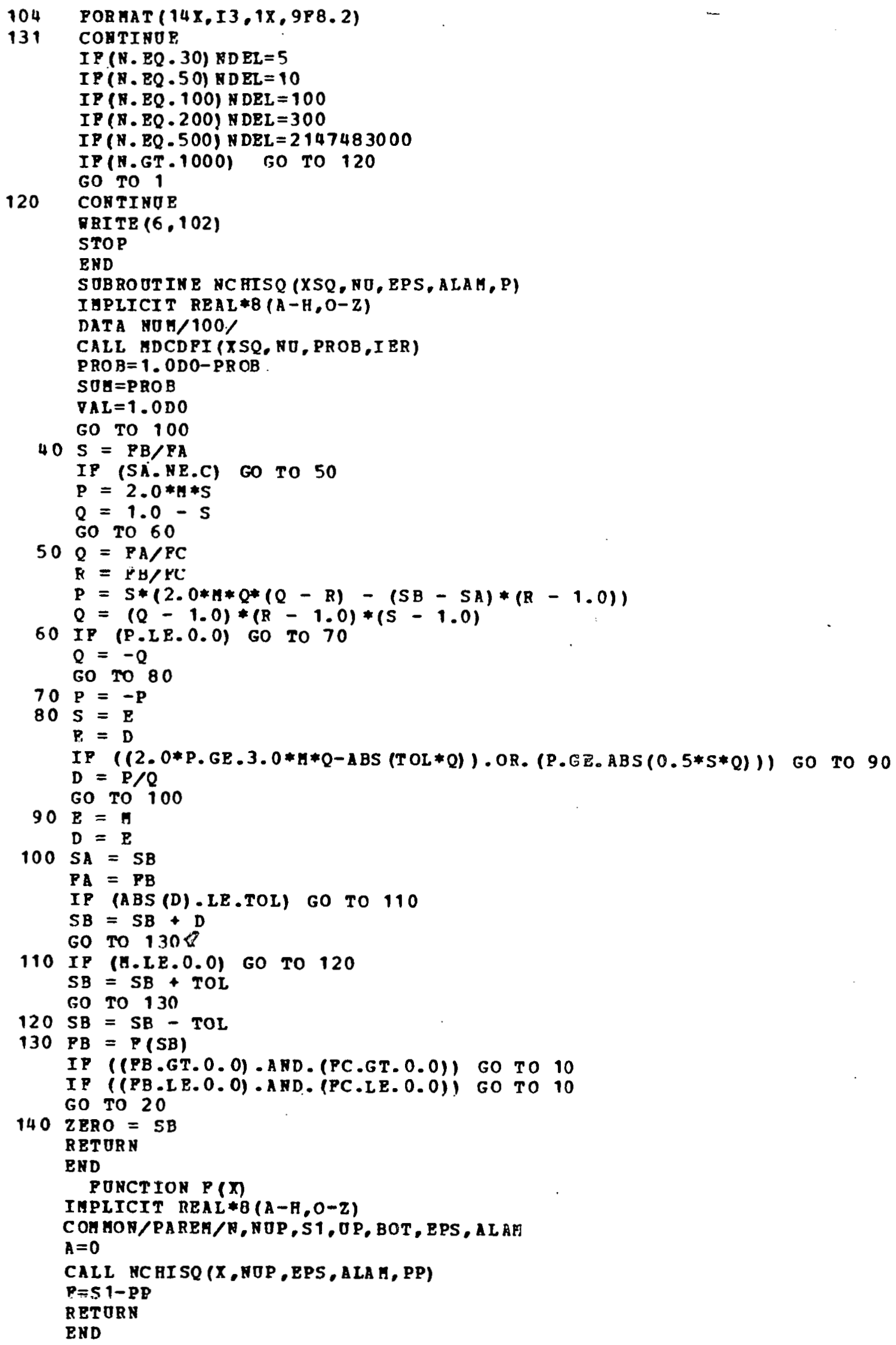


Table D-1

HVALUES $(C=2)$

\begin{tabular}{|c|c|c|c|c|c|c|c|c|c|}
\hline \multirow[b]{2}{*}{$N$} & \multicolumn{3}{|c|}{$\gamma=0.90$} & \multicolumn{3}{|c|}{$\gamma=0.95$} & \multicolumn{3}{|c|}{$\gamma=0.99$} \\
\hline & $P=0.90$ & $P=0.95$ & $P=0.99$ & $P=0.90$ & $P=0.95$ & $P=0.99$ & $P=0.90$ & $P=0.95$ & $P=0.99$ \\
\hline 2 & 64.27 & 82.04 & 121.97 & 132.11 & 168.65 & 250.73 & 674.56 & 861.08 & 1280.20 \\
\hline 3 & 22.87 & 29.43 & 44.34 & 34.23 & 44.05 & 66.36 & 81.89 & 105.39 & 158.76 \\
\hline 4 & 15.59 & 20.14 & 30.54 & 21.02 & 27.15 & 41.17 & 39.42 & 50.92 & 77.22 \\
\hline 5 & 12.63 & 16.35 & 24.89 & 16.13 & 20.88 & 31.78 & 26.83 & 34.73 & 52.87 \\
\hline 6 & 11.02 & 14.28 & 21.80 & 13.61 & 17.64 & 26.92 & 20.98 & 27.20 & 41.51 \\
\hline 7 & 10.00 & 12.98 & 19.84 & 12.07 & 15.66 & 23.93 & 17.67 & 22.93 & 35.05 \\
\hline 8 & 9.30 & 12.07 & 18.48 & 11.03 & 14.32 & 21.91 & 15.57 & 20.21 & 30.92 \\
\hline 9 & 8.78 & 11.41 & 17.47 & 10.27 & 13.34 & 20.44 & 14.08 & 18.29 & 28.01 \\
\hline 10 & 8.39 & 10.89 & 16.70 & 9.70 & 12.61 & 19.32 & 13.01 & 16.90 & 25.90 \\
\hline 11 & 8.07 & 10.49 & 16.08 & 9.25 & 12.03 & 18.44 & 12.17 & 15.81 & 24.24 \\
\hline 12 & 7.81 & 10.15 & 15.57 & 8.89 & 11.56 & 17.73 & 11.51 & 14.96 & 22.95 \\
\hline 13 & 7.60 & 9.88 & 15.15 & 8.59 & 11.17 & 17.14 & 10.97 & 14.26 & 21.88 \\
\hline 14 & 7.42 & 9.64 & 14.80 & 8.34 & 10.84 & 16.64 & 10.52 & 13.68 & 20.99 \\
\hline 15 & 7.26 & 9.44 & 14.49 & 8.12 & 10.56 & 16.21 & 10.15 & 13.19 & 20.25 \\
\hline 16 & 7.12 & 9.26 & 14.22 & 7.94 & 10.32 & 15.84 & 9.82 & 12.77 & 19.60 \\
\hline 17 & 7.01 & 9.11 & 13.99 & 7.77 & 10.11 & 15.52 & 9.54 & 12.41 & 19.05 \\
\hline 18 & 6.90 & 8.97 & 13.78 , & 7.63 & 9.92 & 15.23 & 9.30 & 12.09 & 18.56 \\
\hline 19 & 6.80 & 8.85 & 13.59 & 7.50 & 9.75 & 14.98 & 9.08 & 11.81 & 18.14 \\
\hline 20 & 6.72 & 8.74 & 13.42 & 7.38 & 9.60 & 14.75 & 8.88 & 11.55 & 17.75 \\
\hline 21 & 6.64 & 8.64 & 13.27 & 7.28 & 9.47 & 14.54 & 8.71 & 11.33 & 17.41 \\
\hline 22 & 6.57 & 8.55 & 13.13 & 7.18 & 9.34 & 11.35 & 8.56 & 11.13 & 17.10 \\
\hline 23 & 6.51 & 8.46 & 13.00 & 7.10 & 9.23 & 14.18 & 8.41 & 10.94 & 16.81 \\
\hline 24 & 6.45 & 8.39 & 12.88 & 7.02 & 9.13 & 14.02 & 8.28 & 10.77 & 16.55 \\
\hline 25 & 6.39 & 8.32 & 12.78 & 6.95 & 9.03 & 13.88 & 8.16 & 10.62 & 16.31 \\
\hline 26 & 6.34 & 8.25 & 12.68 & 6.88 & 8.95 & 13.74 & 8.05 & 10.48 & 16.10 \\
\hline 27 & 6.30 & 8.19 & 12.58 & 6.81 & 8.86 & 13.62 & 7.95 & 10.34 & 15.89 \\
\hline 28 & 6.25 & 8.13 & 12.50 & 6.76 & 8.79 & 13.50 & 7.86 & 10.22 & 15.71 \\
\hline 29 & 6.21 & 8.08 & 12.42 & 6.70 & 8.72 & 13.40 & 7.77 & 10.11 & 15.53 \\
\hline 30 & 6.17 & 8.03 & 12.34 & 6.65 & 8.65 & 13.30 & 7.69 & $\$ 10.00$ & 15.37 \\
\hline 35 & 6.01 & 7.82 & 12.02 & 6.44 & 8.38 & 12.87 & 7.35 & 9.56 & 14.69 \\
\hline 40 & 5.89 & 7.66 & 11.78 & 6.28 & 8.17 & 12.55 & 7.09 & 9.23 & 14.18 \\
\hline 45 & 5.79 & 7.54 & 11.59 & 6.15 & 8.00 & 12.29 & 6.89 & 8.97 & 33.78 \\
\hline 50 & 5.72 & 7.44 & 11.43 & 6.04 & 7.86 & 12.09 & 6.73 & 8.76 & 13.46 \\
\hline 60 & 5.59 & 7.28 & 11.18 & 5.88 & 7.65 & 11.76 & 6.48 & 8.43 & 12.96 \\
\hline 70 & 5.50 & 7.16 & 11.00 & 5.76 & 7.50 & 11.52 & 6.30 & 8.20 & 12.60 \\
\hline 80 & 5.43 & 7.06 & 10.86 & 5.67 & 7.38 & 11.34 & 6.16 & 8.01 & 12.32 \\
\hline 90 & 5.37 & 6.99 & 10.74 & 5.59 & 7.28 & 11.19 & 6.05 & 7.87 & 12.09 \\
\hline 100 & 5.32 & 6.93 & 10.65 & 5.53 & 7.20 & 11.07 & 5.95 & 7.75 & 11.91 \\
\hline 200 & 5.08 & 6.61 & 10.17 & 5.22 & 6.79 & 10.44 & 5.49 & 7.15 & 10.99 \\
\hline 500 & 4.89 & 6.37 & 9.79 & 4.97 & 6.47 & 9.95 & 5.13 & 6.68 & 10.27 \\
\hline$\infty$ & 4.61 & 5.99 & 9.21 & 4.61 & 5.99 & 9.21 & 4.61 & 5.99 & 9.21 \\
\hline
\end{tabular}


Table D-2

H VALUES $(C=3)$

\begin{tabular}{|c|c|c|c|c|c|c|c|c|c|}
\hline \multirow[b]{2}{*}{$\mathrm{N}$} & \multicolumn{3}{|c|}{$\gamma=0.90$} & \multicolumn{3}{|c|}{$\gamma=0.95$} & \multicolumn{3}{|c|}{$\gamma=0.99$} \\
\hline & $P=0.90$ & $P=0.95$ & $P=0.99$ & $P=0.90$ & $P=0.95$ & $P=0.99$ & $P=0.90$ & $P=0.95$ & $P=0.99$ \\
\hline 2 & 47.03 & 57.87 & 81.69 & 78.12 & 96.12 & 135.68 & 239.47 & 294.64 & 415.90 \\
\hline 3 & 22.43 & 27.78 & 39.65 & 30.24 & 37.45 & 53.45 & 56.71 & 70.24 & 100.25 \\
\hline 4 & 16.76 & 20.82 & 29.88 & 21.01 & 26.11 & 37.47 & 33.48 & 41.60 & 59.70 \\
\hline 5 & 14.21 & 17.69 & 25.48 & 17.15 & 21.35 & 30.74 & 25.11 & 31.26 & 45.01 \\
\hline 6 & 12.76 & 15.90 & 22.94 & 15.02 & 18.72 & 27.00 & 20.87 & 26.00 & 37.52 \\
\hline 7 & 11.81 & 14.73 & 21.27 & 13.66 & 17.04 & 24.62 & 18.21 & 22.84 & 33.00 \\
\hline 8 & 11.13 & 13.89 & 20.09 & 12.72 & 15.87 & 22.95 & 16.59 & 20.70 & 29.93 \\
\hline 9 & 10.63 & 13.27 & 19.20 & 12.02 & 15.01 & 21.72 & 15.35 & 19.16 & 27.72 \\
\hline 10 & 10.24 & 12.78 & 18.51 & 11.48 & 14.34 & 20.76 & 14.41 & 17.99 & 26.05 \\
\hline 11 & 9.92 & 12.39 & 17.95 & 11.05 & 13.80 & 20.00 & 13.68 & 17.08 & 24.74 \\
\hline 12 & 9.66 & 12.07 & 17.49 & 10.70 & 13.37 & 19.37 & 13.09 & 16.35 & 23.69 \\
\hline 13 & 9.44 & 11.80 & 17.10 & 10.41 & 13.00 & 18.85 & 12.60 & 15.74 & 22.82 \\
\hline 14 & 9.26 & 11.57 & 16.77 & 10.16 & 12.69 & 18.40 & 12.19 & 15.23 & 22.08 \\
\hline 15 & 9.10 & 11.36 & 16.48 & 9.95 & 12.43 & 18.02 & 11.85 & 14.80 & 21.46 \\
\hline 16 & 896 & 111.9 & 16.23 & 9.76 & 12.19 & 17.68 & 11.54 & 14.42 & 20.92 \\
\hline 17 & 8.83 & 11.04 & 16.01 & 9.60 & 11.99 & 17.39 & 11.28 & 14.09 & 20.44 \\
\hline 18 & 8.72 & 10.90 & 15.81 & 9.45 & 11.81 & 17.13 & 11.05 & 13.80 & 20.02 \\
\hline 19 & 8.62 & 10.78 & 15.63 & 9.32 & 11.65 & 16.89 & 10.84 & 13.54 & 19.65 \\
\hline 20 & 8.54 & 10.67 & 15.47 & 9.20 & 11.50 & 16.68 & 10.65 & 13.31 & 19.31 \\
\hline 21 & .8 .45 & 10.57 & 15.33 & 9.10 & 11.37 & 16.49 & 10.49 & 13.10 & 19.01 \\
\hline 22 & 8.38 & 10.47 & 15.20 & 9.00 & 11.25 & 16.32 & 10.33 & 12.91 & 18.74 \\
\hline 23 & 8.31 & 10.39 & 15.07 & 8.91 & 11.14 & 16.16 & 10.19 & 12.74 & 18.49 \\
\hline 24 & 8.25 & 10.31 & 14.96 & 8.83 & 11.03 & 16.01 & 10.07 & 12.58 & 18.26 \\
\hline 25 & 8.19 & 10.24 & 14.86 & 8.75 & 10.94 & 15.88 & 9.95 & 12.44 & 18.05 \\
\hline 26 & 8.14 & 10.17 & 14.76 & 8.68 & 10.85 & 15.75 & 9.84 & 12.30 & 17.85 \\
\hline 27 & 8.09 & 10.11 & $14.67^{\circ}$ & 8.62 & 10.77 & 15.63 & 9.74 & 12.18 & 17.67 \\
\hline 28 & 8.04 & 10.05 & 14.59 & 8.56 & 10.70 & 15.52 & 9.65 & 12.06 & 17.50 \\
\hline 29 & 8.00 & 10.00 & 14.51 & 8.50 & 10.63 & 15.42 & 9.56 & 11.95 & 17.35 \\
\hline 30 & 7.96 & 9.95 & 14,44 & 8.45 & 10.56 & 15.33 & 9.48 & 11.85 & 17.20 \\
\hline 35 & 7.79 & 9.74 & 14.13 & 8.23 & 10.29 & 14.93 & 9.14 & 11.43 & 16.59 \\
\hline 40 & 7.66 & 9.57 & 13.90 & 8.06 & 10.07 & 14.62 & 8.89 & 11.11 & 16.12 \\
\hline 45 & 7.55 & 9.44 & 13.71 & 7.92 & 9.90 & 14.37 & 8.68 & 10.85 & 15.75 \\
\hline 50 & 7.47 & 9.34 & 13.55 & 7.81 & 9.77 & 14.17 & 8.52 & 10.65 & 15.45 \\
\hline 60 & 7.34 & 9.17 & 13.31 & 7.64 & 9.55 & 13.86 & 8.26 & 10.33 & 14.99 \\
\hline 70 & 7.24 & 9.04 & 13.13 & 7.51 & 9.39 & 13.63 & 8.07 & 10.09 & 14.65 \\
\hline 80 & 7.16 & 8.95 & 12.99 & 7.41 & 9.27 & 13.45 & 7.92 & 9.91 & 14.38 \\
\hline 90 & 7.10 & 8.87 & 12.88 & 7.33 & 9.17 & 13.31 & 7.81 & 9.76 & 14.17 \\
\hline 100 & 7.04 & 8.80 & 12.78 & 7.27 & 0.08 & 13.19 & 7.71 & 9.64 & 13.99 \\
\hline 200 & 6.78 & 8.48 & 12.30 & 6.93 & 8.66 & 12.57 & 7.22 & 9.02 & 13.10 \\
\hline 500 & 6.57 & 8.21 & 11.92 & 6.66 & 8.32 & 12.08 & 6.83 & 8.54 & 12.40 \\
\hline$\infty$ & 6.25 & 7.81 & 11.34 & 6.25 & 7.81 & 11.34 & 6.25 & 7.81 & 11.34 \\
\hline
\end{tabular}


Table D-3

H VALUES $(C=4)$

\begin{tabular}{|c|c|c|c|c|c|c|c|c|c|}
\hline \multirow[b]{2}{*}{$\mathbf{N}$} & \multicolumn{3}{|c|}{$\gamma=0.90$} & \multicolumn{3}{|c|}{$\gamma=0.95$} & \multicolumn{3}{|c|}{$\lambda=0.99$} \\
\hline & $P=0.90$ & $P=0.95$ & $P=0.99$ & $P=0.90$ & $P=0.95$ & $P=0.99$ & $P=0.90$ & $P=0.95$ & $P=0.99$ \\
\hline 2 & 42.84 & 51.53 & 70.34 & 64.11 & 77.12 & 105.27 & 153.38 & 184.49 & 251.85 \\
\hline 3 & 23.49 & 28.41 & 39.16 & 29.99 & 36.29 & 50.02 & 49.90 & 60.37 & 83.22 \\
\hline 4 & 18.37 & 22.29 & 30.87 & 22.16 & 26.89 & 37.25 & 32.46 & 39.38 & 54.55 \\
\hline 5 & 15.96 & 19.39 & 26.94 & 18.67 & 22.68 & 31.51 & 25.59 & 31.09 & 43.20 \\
\hline 6 & 14.54 & 17.68 & 24.60 & 16.67 & 20.27 & 28.22 & 21.92 & 26.65 & 37.10 \\
\hline 7 & 13.59 & 16.54 & 23.05 & 15.37 & 18.70 & 26.06 & 19.62 & 23.88 & 33.27 \\
\hline 8 & 12.91 & 15.72 & 21.92 & 14.45 & 17.59 & 24.53 & 18.04 & 21.97 & 30.64 \\
\hline 9 & 12.40 & 15.10 & 21.07 & 13.76 & 16.76 & 23.38 & 16.89 & 20.57 & 28.71 \\
\hline 10 & 12.00 & 14.62 & 20.40 & 13.22 & 16.11 & 22.49 & 16.01 & 19.50 & 27.23 \\
\hline 11 & 11.67 & 14.22 & 19.86 & 12.79 & 15.59 & 21.77 & 15.32 & 18.66 & 26.06 \\
\hline 12 & 11.40 & 13.89 & 19.41 & 12.44 & 15.16 & 21.17 & 14.74 & 17.97 & 25.10 \\
\hline 13 & 11.18 & 13.62 & 19.03 & 12.14 & 14.80 & 20.67 & 14.27 & 17.39 & 24.30 \\
\hline 14 & 10.98 & 13.39 & 18.71 & 11.89 & 1449 & 20.25 & 13.87 & 16.91 & 23.63 \\
\hline 15 & 10.81 & 13.18 & 18.43 & 11.67 & 14.22 & 19.88 & 13.53 & 16.19 & 23.05 \\
\hline 16 & 10.67 & 13.00 & 18.18 & 11.48 & 13.99 & 19.56 & 13.23 & 16.13 & 22.55 \\
\hline 17 & 10.54 & 12.85 & 17.96 & 11.31 & 13.79 & 19.27 & 12.97 & 15.81 & 22.10 \\
\hline 18 & 10.42 & 12.71 & 17.77 & 11.16 & 13.60 & 19.02 & 12.74 & 15.53 & 21.71 \\
\hline 19 & 10.32 & 12.58 & 17.59 & 11.02 & 13.44 & 18.79 & 12.53 & 15.28 & 21.36 \\
\hline 20 & 10.22 & 12.47 & 17.43 & 10.90 & 13.29 & 18.59 & 12.35 & 15.05 & 21.05 \\
\hline 21 & 10.14 & 12.36 & 17.29 & 10.79 & 13.16 & 18.40 & 12.18 & 14.85 & 20.76 \\
\hline 22 & 10.06 & 12.27 & 17.16 & 10.69 & 13.04 & 18.23 & 12.03 & 14.66 & 20.51 \\
\hline 23 & 9.99 & 12.18 & 17.04 & 10.60 & 12.92 & 18.08 & 11.89 & 14.49 & 20.27 \\
\hline 24 & 9.92 & 12.10 & 16.92 & 10.52 & 12.82 & 17.93 & 1176 & 14.34 & 20.05 \\
\hline 25 & 9.86 & 12.03 & 16.82 & 10.44 & 12.73 & 17.80 & 11.64 & 14.19 & 19.85 \\
\hline 26 & 9.81 & 11.96 & 16.73 & 10.36 & 12.64 & 17.68 & 11.53 & 14.06 & 19.67 \\
\hline 27 & 9.75 & 11.89 & 16.64 & 10.30 & 12.56 & 17.56 & 11.43 & 13.94 & 19.49 \\
\hline 28 & 9.70 & 11.83 & 16.55 & 10.23 & 12.48 & 17.46 & 11.33 & 13.82 & 19.33 \\
\hline 20 & 9.66 & 11.78 & 16.48 & 10.17 & 12.41 & 17.36 & 11.25 & 13.71 & 19.18 \\
\hline 30 & 9.62 & 11.73 & 16.40 & 10.12 & 12.34 & 17.26 & 11.16 & 13.61 & 19.04 \\
\hline 35 & 9.43 & 11.50 & 16.09 & 9.89 & 12.06 & 16.87 & 10.82 & 13.19 & 18.16 \\
\hline 40 & 9.29 & 11.33 & 15.86 & 9.71 & 11.84 & 16.56 & 10.55 & 12.87 & 18.01 \\
\hline 45 & 9.18 & 11.20 & 15.67 & 9.56 & 11.66 & 16.32 & 10.34 & 12.61 & 17.65 \\
\hline 50 & 9.09 & 11.08 & 15.51 & 9.45 & 11.52 & 16.12 & 10.17 & 12.40 & 17.36 \\
\hline 60 & 8.95 & 10.91 & 15.27 & 9.27 & 11.30 & 15.81 & 9.91 & 12.08 & 16.90 \\
\hline 70 & 8.84 & 10.78 & 15.09 & 9.13 & 11.13 & 15.58 & 9.71 & 11.84 & 16.57 \\
\hline 80 & 8.76 & 10.68 & 14.94 & 9.02 & 11.01 & 15.40 & 9.56 & 11.65 & 16.31 \\
\hline 90 & 8.69 & 10.60 & 14.83 & 8.94 & 10.90 & 15.25 & 9.43 & 11.50 & 16.10 \\
\hline 100 & 8.63 & 10.53 & 14.73 & 8.87 & 10.81 & 15.13 & 9.33 & 11.38 & 15.92 \\
\hline 200 & 8.35 & 10.18 & 14.25 & 8.51 & 10.38 & 14.52 & 8.81 & 10.75 & 15.04 \\
\hline 500 & 8.12 & 9.91 & 13.86 & 8.22 & 10.02 & 14.03 & 8.40 & 10.25 & 14.34 \\
\hline$\infty$ & 7.78 & 9.49 & 13.28 & 7.78 & 9.49 & 13.28 & 7.78 & 9.49 & 13.28 \\
\hline
\end{tabular}


Table D-4

$H$ VALUES $(C=5)$

\begin{tabular}{|c|c|c|c|c|c|c|c|c|c|}
\hline \multirow[b]{2}{*}{$\mathrm{N}$} & \multicolumn{3}{|c|}{$\gamma=0.90$} & \multicolumn{3}{|c|}{$\gamma=0.95$} & \multicolumn{3}{|c|}{$\gamma=0.99$} \\
\hline & $P=0.90$ & $P=0.95$ & $P=0.99$ & $P=0.90$ & $P=0.95$ & $P=0.99$ & $P=0.90$ & $P=0.95$ & $P=0.99$ \\
\hline 2 & 42.00 & 49.72 & 66.25 & 59.05 & 69.90 & 93.14 & 122.28 & 144.75 & 192.88 \\
\hline 3 & 25.00 & 29.74 & 39.99 & 30.88 & 36.74 & 49.39 & 47.60 & 56.64 & 76.14 \\
\hline 4 & 20.11 & 23.99 & 32.39 & 23.67 & 28.23 & 38.13 & 32.88 & 39.22 & 52.97 \\
\hline 5 & 17.72 & 21.17 & 28.66 & 20.32 & 24.28 & 32.87 & 26.72 & 31.92 & 43.21 \\
\hline 6 & 16.29 & 19.48 & 26.42 & 18.37 & 21.97 & 29.79 & 23.32 & 27.88 & 37.80 \\
\hline 7 & 15.33 & 18.34 & 24.90 & 17.08 & 20.43 & 27.74 & 21.13 & 25.28 & 34.32 \\
\hline 8 & 14.64 & 17.52 & 23.80 & 16.16 & 19.33 & 26.27 & 19.62 & 23.48 & 31.90 \\
\hline 9 & 14.10 & 16.88 & 22.95 & 15.46 & 18.50 & 25.15 & 18.51 & 22.16 & 30.12 \\
\hline 10 & 13.69 & 16.39 & 22.29 & 14.91 & 17.86 & 24.28 & 17.64 & 21.12 & 28.72 \\
\hline 11 & 13.35 & 15.99 & 21.75 & 14.47 & 17.33 & 23.58 & 16.95 & 20.30 & 27.61 \\
\hline 12 & 13.07 & 15.65 & 21.30 & 14.11 & 16.90 & 23.00 & 16.39 & 19.63 & 26.70 \\
\hline 13 & 12.83 & 15.37 & 20.92 & 13.81 & 16.54 & 22.51 & 15.92 & 19.06 & 25.94 \\
\hline 14 & 12.63 & 15.13 & 20.60 & 13.55 & 16.23 & 22.09 & 15.52 & 18.59 & 25.30 \\
\hline 15 & 12.46 & 14.92 & 20.31 & 13.32 & 15.96 & 21.72 & 15.17 & 18.18 & 24.74 \\
\hline 16 & 12.30 & 14.74 & 20.06 & 13.12 & 15.72 & 21.41 & 14.87 & 17.82 & 24.26 \\
\hline 17 & 12.16 & 14.57 & 19.84 & 12.95 & 15.51 & 21.12 & 14.61 & 17.50 & 23.83 \\
\hline 18 & 12.04 & 14.43 & 19.65 & 12.79 & 15.33 & 20.87 & 14.38 & 17.22 & 23.46 \\
\hline 19 & 11.93 & 14.30 & 19.47 & 12.65 & 15.16 & 20.65 & 14.17 & 16.98 & 23.12 \\
\hline 20 & 11.83 & 14.18 & 19.31 & 12.53 & 15.01 & 20.44 & 13.98 & 16.75 & 22.81 \\
\hline 21 & 11.74 & 14.07 & 19.17 & 12.41 & 14.87 & 20.26 & 13.81 & 16.55 & 22.54 \\
\hline 22 & 11.66 & 13.97 & 19.03 & 12.31 & 14.75 & 20.09 & 13.65 & 16.36 & 22.28 \\
\hline 23 & 11.59 & 13.88 & 18.91 & 12.21 & 14.63 & 19.93 & 13.51 & 16.19 & 22.05 \\
\hline 24 & 11.52 & 13.80 & 18.80 & 12.12 & 14.53 & 19.79 & 13.38 & 16.03 & 21.84 \\
\hline 25 & 11.45 & 13.72 & 18.69 & 12.04 & 14.43 & 19.66 & 13.26 & 15.89 & 21.65 \\
\hline 26 & 11.39 & 13.65 & 18.60 & 11.97 & 14.34 & 19.53 & 13.15 & 15.76 & 21.46 \\
\hline 27 & 11.34 & 13.59 & 18.51 & 11.89 & 14.25 & 19.42 & 13.04 & 15.63 & 21.30 \\
\hline 28 & 11.28 & 13.52 & 18.42 & 11.83 & 14.18 & 19.31 & 12.95 & 15.52 & 21.14 \\
\hline 29 & 11.24 & 13.47 & 18.34 & 11.77 & 14.10 & 19.21 & 12.86 & 15.41 & 20.99 \\
\hline 30 & 11.19 & 13.41 & 18.27 & 11.71 & 14.03 & 19.12 & 12.77 & 15.31 & 20.85 \\
\hline 35 & 11.00 & . $\quad 13.18$ & 17.96 & 11.46 & 13.74 & 18.72 & 12.42 & 14.88 & 20.27 \\
\hline 40 & 10.86 & 13.00 & 17.71 & 11.28 & 13.52 & 18.41 & 12.14 & 14.55 & 19.83 \\
\hline 45 & 10.73 & 12.86 & 17.52 & 11.13 & 13.34 & 18.17 & 11.93 & 14.29 & 19.48 \\
\hline 50 & 10.63 & 12.74 & 17.36 & 11.00 & 13.19 & 17.97 & 11.75 & 14.08 & 19.19 \\
\hline 60 & 10.48 & 12.56 & 17.11 & 1081 & 12.96 & 17.66 & 11.47 & 13.75 & 18.74 \\
\hline 70 & 10.37 & 12.42 & 16.93 & 10.67 & 12.79 & 17.42 & 11.27 & 13.50 & 18.40 \\
\hline 80 & 10.28 & 12.32 & 16.78 & 10.66 & 12.65 & 17.24 & 11.11 & 13.31 & 18.14 \\
\hline 90 & 10.21 & 12.23 & 16.67 & 10.47 & 12.54 & 17.09 & 10.98 & 13.16 & 17.93 \\
\hline 100 & 10.15 & 12.16 & 16.57 & 10.39 & 12.45 & 16.97 & 10.87 & 13.03 & 17.76 \\
\hline 200 & 9.84 & 11.80 & 16.08 & 10.01 & 12.00 & 16.35 & 10.33 & 12.38 & 16.87 \\
\hline 500 & 9.60 & 11.51 & 15.68 & 9.70 & 11.63 & 15.85 & 9.89 & 11.86 & 16.16 \\
\hline$\infty$ & 9.24 & 11.07 & 15.09 & 9.24 & 11.07 & 15.09 & 9.24 & 11.07 & 15.09 \\
\hline
\end{tabular}


Table D-5

H VALUES $(C=6)$

\begin{tabular}{|c|c|c|c|c|c|c|c|c|c|}
\hline \multirow{2}{*}{$N$} & \multicolumn{3}{|c|}{$\gamma=0.90$} & \multicolumn{3}{|c|}{$\gamma=0.95$} & \multicolumn{3}{|c|}{$\gamma=0.99$} \\
\hline & $P=0.90$ & $P=0.95$ & $P=0.99$ & $P=0.90$ & $P=0.95$ & $P=0.99$ & $P=0.90$ & $P=0.95$ & $P=0.99$ \\
\hline 2 & 42.46 & 49.65 & 64.94 & 57.24 & 66.94 & 87.55 & 107.36 & 125.55 & 164.20 \\
\hline 3 & 26.68 & 31.35 & 41.34 & 32.19 & 37.82 & 49.87 & 47.14 & 55.39 & 73.04 \\
\hline 4 & 21.87 & 25.76 & 34.11 & 25.31 & 29.81 & 39.47 & 33.93 & 39.96 & 52.91 \\
\hline 5 & 19.48 & 22.97 & 30.48 & 22.03 & 25.97 & 34.47 & 28.12 & 33.16 & 44.00 \\
\hline 6 & 18.02 & 21.27 & 28.26 & 20.07 & 23.69 & 31.49 & 24.84 & 29.31 & 38.96 \\
\hline 7 & 17.03 & 20.11 & 26.75 & 18.77 & 22.16 & 29.49 & 22.73 & 26.84 & 35.70 \\
\hline 8 & 16.31 & 19.26 & 25.65 & 17.83 & 21.06 & 28.04 & 21.24 & 25.09 & 33.40 \\
\hline 9 & 15.76 & 18.62 & 24.81 & 17.12 & 20.23 & 26.95 & 20.13 & 23.78 & 31.68 \\
\hline 10 & 15.33 & 18.12 & 24.14 & 16.56 & 19.58 & 26.09 & 19.26 & 22.77 & 30.34 \\
\hline 11 & 14.98 & 17.70 & 23.60 & 16.11 & 19.04 & 25.39 & 18.57 & 21.95 & 29.26 \\
\hline 12 & 14.68 & 17.36 & 23.14 & 15.74 & 18.61 & 24.81 & 18.01 & 21.29 & 28.38 \\
\hline 13 & 14.44 & 17.07 & 22.76 & 15.42 & 18.23 & 24.32 & 17.53 & 20.73 & 27.64 \\
\hline 14 & 14.23 & 16.82 & 22.43 & 15.15 & 17.92 & 23.90 & 17.13 & 20.25 & 27.01 \\
\hline 15 & 14.04 & 16.60 & 22.14 & 14.92 & 17.64 & 23.53 & 16.78 & 19.84 & 26.47 \\
\hline 16 & 13.88 & 16.41 & 21.89 & 14.72 & 17.40 & 23.21 & 16.48 & 19.48 & 25.99 \\
\hline 17 & 13.74 & 16.24 & 21.67 & 14.54 & 17.19 & 22.93 & 16.21 & 19.17 & 25.57 \\
\hline 18 & 13.61 & 16.09 & 21.47 & 14.37 & 17.00 & 22.68 & 15.97 & 18.89. & 25.20 \\
\hline 19 & 13.49 & 15.96 & 21.29 & 14.23 & 16.83 & 22.45 & 15.76 & 18.64 & 24.87 \\
\hline 20 & 13.39 & 15.83 & 21.13 & 14.10 & 16.67 & 22.25 & 15.57 & 18.41 & 24.56 \\
\hline 21 & 13.29 & 15.72 & 20.98 & 13.98 & 16.53 & 22.06 & 15.39 & 18.20 & 24.29 \\
\hline 22 & 13.21 & 15.62 & 20.84 & 13.87 & 16.40 & 21.89 & 15.23 & 18.02 & 24.04 \\
\hline 23 & 13.13 & 15.53 & 20.72 & 13.77 & 16.28 & 21.73 & 15.09 & 17.84 & 23.81 \\
\hline 24 & 13.05 & 15.44 & 20.60 & 13.68 & 16.17 & 21.59 & 14.95 & 17.69 & 23.60 \\
\hline 25 & 12.99 & 15.36 & 20.50 & 13.59 & 16.07 & 21.45 & 14.83 & 17.54 & 23.41 \\
\hline 26 & 12.92 & 15.28 & 20.40 & 13.51 & 15.98 & 21.33 & 14.71 & 17.40 & 23.23 \\
\hline 27 & 12.86 & 15.21 & 20.31 & 13.44 & 15.89 & 21.21 & 14.61 & 17.28 & 23.06 \\
\hline 28 & 12.81 & 15.15 & 20.22 & 13.37 & 15.81 & 21.10 & 14.51 & 17.16 & 22.90 \\
\hline 29 & 12.76 & 15.09 & 20.14 & 13.30 & 15.74 & 21.00 & 14.42 & 17.05 & 22.76 \\
\hline 30 & 12.71 & 15.03 & 20.06 & 13.24 & 15.66 & 20.91 & 14.33 & 16.95 & 22.62 \\
\hline 35 & 12.51 & 14.79 & 19.75 & 12.99 & 15.36 & 20.51 & 13.96 &, 16.51 & 22.04 \\
\hline 40 & 12.35 & 14.61 & 19.50 & 12.79 & 15.13 & 20.20 & 13.68 & 16.18 & 21.60 \\
\hline 45 & 12.22 & 14.46 & 19.30 & 12.63 & 14.94 & 19.95 & 13.45 & 15.91 & 21.25 \\
\hline 50 & 12.12 & 14.33 & 19.14 & 12.50 & 14.79 & 19.74 & 13.27 & 15.70 & 20.96 \\
\hline 60 & 11.96 & 14.14 & 18.88 & 12.30 & 14.55 & 19.43 & 12.98 & 15.36 & 20.50 \\
\hline 70 & 11.84 & 14.00 & 18.69 & 12.15 & 14.37 & 19.19 & 12.77 & 15.11 & 20.17 \\
\hline 80 & 11.74 & 13.89 & 18.55 & 12.03 & 14.23 & 19.00 & 12.60 & 14.91 & 19.90 \\
\hline 90 & 11.67 & 13.80 & 18.43 & 11.94 & 14.12 & 18.85 & 12.47 & 14.75 & 19.69 \\
\hline 100 & 11.61 & 13.73 & 18.33 & 11.86 & 14.03 & 18.73 & 12.36 & 14.62 & 19.52 \\
\hline 200 & 11.29 & 13.35 & 17.82 & 11.46 & 13.55 & 18.10 & 11.79 & 13.95 & 18.62 \\
\hline 500 & 11.03 & 13.05 & 17.42 & 11.14 & 13.17 & 17.59 & 11.34 & 13.41 & 17.90 \\
\hline$\infty$ & 10.64 & 12.59 & 16.81 & 10.64 & 12.59 & 16.81 & 10.64 & 12.59 & 16.81 \\
\hline
\end{tabular}


Table D-6

H VALUES $(C=7)$

\begin{tabular}{|c|c|c|c|c|c|c|c|c|c|}
\hline \multirow[b]{2}{*}{$\mathrm{N}$} & \multicolumn{3}{|c|}{$\gamma=0.90$} & \multicolumn{3}{|c|}{$\gamma=0.95$} & \multicolumn{3}{|c|}{$\gamma=0.99^{\circ}$} \\
\hline & $P=0.90$ & $P=0.95$ & $P=0.99$ & $P=0.90$ & $P=0.95$ & $P=0.99$ & $P=0.90$ & $P=0.95$ & $P=0.99$ \\
\hline 2 & 43.52 & 50.41 & 64.94 & 56.89 & 65.90 & 84.89 & 99.66 & 115.42 & 148.70 \\
\hline 3 & 28.44 & 33.09 & 42.96 & 33.73 & 39.24 & 50.94 & 47.61 & 55.39 & 71.91 \\
\hline 4 & 23.64 & 27.57 & 35.92 & 27.01 & 31.49 & 41.03 & 35.22 & 41.07 & 53.52 \\
\hline 5 & 21.21 & 24.76 & 32.33 & 23.73 & 27.70 & 36.18 & 29.64 & 34.60 & 45.18 \\
\hline 6 & 19.72 & 23.03 & 30.12 & 21.76 & 25.42 & 33.25 & 26.43 & 30.88 & 40.38 \\
\hline 7 & 18.69 & 21.84 & 28.60 & 20.44 & 23.88 & 31.27 & 24.34 & 28.45 & 37.24 \\
\hline 8 & 17.95 & 20.98 & 27.49 & 19.48 & 22.77 & 29.83 & 22.86 & 26.72 & 35.00 \\
\hline 9 & 17.38 & 20.32 & 26.64 & 18.75 & 21.93 & 28.74 & 21.74 & 25.42 & 33.32 \\
\hline 10 & 16.93 & 19.80 & 25.96 & 18.18 & 21.26 & 27.87 & 20.87 & 24.41 & 32.01 \\
\hline 11 & 16.56 & 19.37 & 25.41 & 17.71 & 20.72 & 27.17 & 20.18 & 23.60 & 30.95 \\
\hline 12 & 16.26 & 19.02 & 24.95 & 17.33 & 20.27 & 26.59 & 19.60 & 22.93 & 30.08 \\
\hline 13 & 16.00 & 18.72 & 24.56 & 17.00 & 19.89 & 26.10 & 19.12 & 22.37 & 29.35 \\
\hline 14 & 15.78 & 18.46 & 24.22 & 16.72 & 19.57 & 25.67 & 18.71 & 21.89 & 28.73 \\
\hline 15 & 15.59 & 18.24 & 23.93 & 16.48 & 19.29 & 25.31 & 18.36 & 21.48 & 28.19 \\
\hline 16 & 15.42 & 18.04 & 23.67 & 16.27 & 19.04 & 24.98 & 18.05 & 21.12 & 27.72 \\
\hline 17 & 15.27 & 17.86 & 23.45 & 16.08 & 18.82 & 24.70 & 17.77 & 20.80 & 27.30 \\
\hline 18 & 15.13 & 17.71 & 23.24 & 15.91 & 18.62 & 24.44 & 17.53 & 20.52 & 26.93 \\
\hline 19 & 15.01 & 17.57 & 23.06 & 15.76 & 18.45 & 24.21 & 17.31 & 20.26 & 26.60 \\
\hline 20 & 14.90 & 17.44 & 22.89 & 15.63 & 18.29 & 24.00 & 17.12 & 20.03 & 26.29 \\
\hline 21 & 14.80 & 17.32 & 22.74 & 15.50 & 18.14 & 23.82 & 16.94 & 19.82 & 26.02 \\
\hline 22 & 14.71 & 17.22 & 22.60 & 15.39 & 18.01 & 23.64 & 16.77 & 19.63 & 25.77 \\
\hline 23 & 14.63 & 17.12 & 22.47 & 15.28 & 17.89 & 23.48 & 16.62 & 19.46 & 25.54 \\
\hline 24 & 14.55 & 17.03 & 22.36 & 15.19 & 17.77 & 23.34 & 16.49 & 19.30 & 25.33 \\
\hline 25 & 14.48 & 16.95 & 22.25 & 15.10 & 17.67 & 23.20 & 16.36 & 19.15 & 25.14 \\
\hline 26 & 14.41 & 16.87 & 22.15 & 15.02 & 17.57 & 23.07 & 16.24 & 19.01 & 24.96 \\
\hline 27 & 14.35 & 16.80 & 22.05 & 14.94 & 17.48 & 22.96 & 16.13 & 18.88 & 24.79 \\
\hline 28 & 14.29 & 16.73 & 21.96 & 14.87 & 17.40 & 22.85 & 16.03 & 18.76 & 24.63 \\
\hline 29 & 14.24 & 16.67 & 21.88 & 14.80 & 17.32 & 22.74 & 15.93 & 18.65 & 24.49 \\
\hline 30 & 14.19 & 16.61 & 21.80 & 14.74 & 17.25 & 22.65 & 15.84 & 18.54 & 24.35 \\
\hline 35 & 13.97 & 16.36 & 21.48 & 14.47 & 16.94 & 22.24 & 15.47 & 18.10 & 23.77 \\
\hline 40 & 13.81 & 16.16 & 21.22 & 14.26 & 16.70 & 21.92 & 15.17 & 17.76 & 23.32 \\
\hline 45 & 13.67 & 16.01 & 21.02 & 14.10 & 16.50 & 21.67 & 14.94 & 17.49 & 22.97 \\
\hline 50 & 13.57 & 15.88 & 20.85 & 13.96 & 16.34 & 21.46 & 14.75 & 17.27 & 22.67 \\
\hline 60 & 13.40 & 15.68 & 20.59 & 13.75 & 16.10 & 21.14 & 14.45 & 16.92 & 22.22 \\
\hline 70 & 13.27 & 15.53 & 20.40 & 13.59 & 15.91 & 20.90 & 14.23 & 16.66 & 21.88 \\
\hline 80 & 13.17 & 15.42 & 20.25 & 13.47 & 15.77 & 20.71 & 14.06 & 16.46 & 21.61 \\
\hline 90 & 13.09 & 15.32 & 20.13 & 13.37 & 15.65 & 20.56 & 13.92 & 16.29 & 21.40 \\
\hline 100 & 13.03 & 15.25 & 20.02 & 13.29 & 15.56 & 20.43 & 13.80 & 16.16 & 21.11 \\
\hline 200 & 12.69 & 14.85 & 19.51 & 12.87 & 15.06 & 19.78 & 13.21 & 15.47 & 20.32 \\
\hline 500 & 12.42 & 14.54 & 19.10 & 12.53 & 14.67 & 19.26 & 12.74 & 14.91 & 19.59 \\
\hline$\infty$ & 12.02 & 14.07 & 18.48 & 12.02 & 14.07 & 18.48 & 12.02 & 14.07 & 18.48 \\
\hline
\end{tabular}


Table D-7

H VALUES $(C=8)$

\begin{tabular}{|c|c|c|c|c|c|c|c|c|c|}
\hline \multirow[b]{2}{*}{$N$} & \multicolumn{3}{|c|}{$\gamma=0.90$} & \multicolumn{3}{|c|}{$\gamma=0.95$} & \multicolumn{3}{|c|}{$\gamma=0.99$} \\
\hline & $P=0.90$ & $P=0.95$ & $P=0.99$ & $P=0.90$ & $P=0.95$ & $P=0.99$ & $\mathrm{P}=0.90$ & $P=0.95$ & $P=0.99$ \\
\hline 2 & 44.93 & 51.62 & 65.67 & 57.38 & 65.93 & 83.88 & 95.46 & 109.68 & 139.54 \\
\hline 3 & 30.24 & 34.90 & 44.72 & 35.37 & 40.82 & 52.31 & 48.49 & 55.95 & 71.71 \\
\hline 4 & 25.41 & 29.38 & 37.78 & 28.73 & 33.22 & 42.72 & 36.68 & 42.41 & 54.54 \\
\hline 5 & 22.92 & 26.53 & 34.19 & 25.43 & 29.44 & 37.94 & 31.23 & 36.14 & 46.58 . \\
\hline 6 & 21.38 & 24.76 & 31.96 & 23.43 & 27.14 & 35.03 & 28.06 & 32.50 & 41.94 \\
\hline 7 & 20.33 & 23.56 & 30.42 & 22.08 & 25.59 & 33.05 & 25.96 & 30.08 & 38.85 \\
\hline 8 & 19.56 & 22.67 & 29.30 & 21.10 & 24.46 & 31.61 & 24.47 & 28.36 & 36.65 \\
\hline 9 & 18.97 & 21.99 & 28.43 & 20.36 & 23.60 & 30.51 & 23.34 & 27.07 & 34.99 \\
\hline 10 & 18.50 & 21.45 & 27.75 & 19.76 & 22.92 & 29.64 & 22.47 & 26.05 & 33.70 \\
\hline 11 & 18.12 & 21.01 & 27.18 & 19.29 & 22.37 & 28.93 & 21.76 & 25.21 & 32.65 \\
\hline 12 & 17.80 & 20.65 & 26.71 & 18.89 & 21.91 & 28.35 & 21.18 & 24.56 & 31.78 \\
\hline 13 & 17.53 & 20.33 & 26.32 & 18.55 & 21.52 & 27.85 & 20.69 & 24.00 & 31.06 \\
\hline 14 & 17.30 & 20.07 & 25.97 & 18.26 & 21.18 & 2.7 .42 & 20.27 & 23.51 & 30.43 \\
\hline 15 & 17.10 & 19.83 & 26.67 & 18.01 & 20.83 & 27.05 & 19.91 & 23.09 & 29.89 \\
\hline 16 & 16.92 & 19.63 & $25: 41$ & 17.79 & 20.64 & 26.72 & 19.59 & 22.73 & 29.42 \\
\hline 17 & 16.76 & 19.45 & 25.18 & 17.59 & 20.41 & 26.43 & 19.31 & 22.40 & 29.01 \\
\hline 18 & 16.62 & 19.29 & 24.97 & 17.42 & 20.21 & 26.17 & 19.06 & 22.12 & 28.63 \\
\hline 19 & 16.50 & 19.14 & 24.78 & 17.26 & 20.03 & 25.94 & 18.84 & 21.86 & 28.30 \\
\hline 20 & 16.38 & 19.01 & 24.61 & 17.12 & 19.87 & 25.72 & 18.64 & 21.62 & 28.00 \\
\hline 21 & 16.28 & 18.89 & 24.46 & 16.99 & 19.72 & 25.53 & 18.45 & 21.41 & 27.73 \\
\hline 22 & 16.18 & 18.78 & 24.32 & 16.87 & 19.58 & 25.36 & 18.28 & 21.22 & 27.48 \\
\hline 23 & 16.09 & 18.67 & 24.19 & 16.77 & 19.45 & 25.19 & 18.13 & 21.04 & 27.25 \\
\hline 24 & 16.01 & 18.58 & 24.06 & 16.67 & 19.34 & 25.05 & 17.99 & 20.87 & 27.03 \\
\hline 25 & 15.94 & 18.49 & 23.95 & 16.57 & 19.23 & 24.91 & 17.86 & 20.72 & 26.84 \\
\hline 26 & 15.87 & 18.41 & 23.85 & 16.49 & 19.13 & 24.78 & 17.74 & 20.58 & 26.66 \\
\hline 27 & 15.80 & 18.34 & 23.75 & 16.41 & 19.04 & 24.66 & 17.62 & 20.45 & 26.49 \\
\hline 28 & 15.74 & 18.27 & 23.66 & 16.33 & 18.95 & 24.55 & 17.52 & 20.33 & 26.33 \\
\hline 29 & 15.69 & 18.20 & 23.58 & 16.26 & 18.87 & 24.44 & 17.42 & 20.21 & 26.18 \\
\hline 30 & 15.63 & 18.14 & 23.50 & 16.20 & 18.79 & 24.34 & 17.33 & 20.11 & 26.04 \\
\hline 35 & 15.41 & 17.88 & 23.16 & 15.92 & 18.47 & 23.93 & 16.94 & 19.65 & 25.46 \\
\hline 40 & 15.23 & 17.68 & 22.90 & 15.70 & 18.22 & 23.61 & 16.64 & 19.31 & 25.01 \\
\hline 45 & 15.10 & 17.52 & 22.69 & 15.53 & 18.02 & 23.35 & 16.40 & 19.03 & 24.65 \\
\hline 50 & 14.98 & 17.39 & 22.52 & 15.39 & 17.86 & 23.14 & 16.20 & 18.80 & 24.35 \\
\hline 60 & 14.80 & 17.18 & 22.26 & 15.17 & 17.61 & 22.81 & 15.89 & 18.44 & 23.89 \\
\hline 70 & 14.67 & 17.03 & 22.06 & 15.01 & 17.42 & 22.56 & 15.66 & 18.18 & 23.55 \\
\hline 80 & 14.57 & 16.91 & 21.90 & 14.88 & 17.27 & 22.37 & 15.48 & 17.97 & 23.28 \\
\hline 90 & 14.48 & 16.81 & 21.78 & 14.77 & 17.15 & 22.21 & 15.34 & 17.80 & 23.06 \\
\hline 100 & 14.42 & 16.73 & 21.67 & 14.69 & 17.05 & 22.08 & 15.22 & 17.66 & 22.88 \\
\hline 200 & 14.06 & 16.32 & 21.15 & 14.25 & 16.54 & 21.42 & 14.61 & 16.95 & 21.96 \\
\hline 500 & 13.78 & 16.00 & 20.72 & 13.90 & 16.13 & 20.89 & 14.11 & 16.38 & 21.22 \\
\hline$\infty$ & 13.36 & 15.51 & 20.09 & 13.36 & 15.51 & 20.09 & 13.36 & 15.51 & 20.09 \\
\hline
\end{tabular}


Table D.8

H VALUES $(C=9)$

\begin{tabular}{|c|c|c|c|c|c|c|c|c|c|}
\hline \multirow[b]{2}{*}{$N$} & \multicolumn{3}{|c|}{$\gamma=0.90$} & \multicolumn{3}{|c|}{$\gamma=0.95$} & \multicolumn{3}{|c|}{$\gamma=0.99$} \\
\hline & $P=0.90$ & $P=0.95$ & $P=0.99$ & $P=0.90$ & $P=0.95$ & $P=0.99$ & $P=0.90$ & $P=0.95$ & $P=0.99$ \\
\hline 2 & 46.53 & 53.11 & 66.85 & 58.34 & 66.59 & 83.81 & 92.96 & 106.10 & 133.55 \\
\hline 3 & 32.05 & 36.73 & 46.55 & 37.09 & 42.50 & 53.87 & 49.72 & 56.97 & 72.21 \\
\hline 4 & 27.16 & 31.18 & 39.65 & 30.46 & 34.97 & 44.47 & 38.23 & 43.89 & 55.81 \\
\hline 5 & 24.61 & 28.29 & 36.04 & 27.13 & 31.18 & 39.73 & 32.85 & 37.75 & 48.10 \\
\hline 6 & 23.03 & 26.48 & 33.78 & 25.09 & 28.85 & 36.81 & 29.68 & 34.13 & 43.55 \\
\hline 7 & 21.94 & 25.24 & 32.23 & 23.71 & 27.28 & 34.83 & 27.57 & 31.72 & 40.51 \\
\hline 8 & 21.14 & 24.33 & 31.09 & 22.70 & 26.13 & 33.38 & 26.07 & $30 ̉ .000$ & 38.33 \\
\hline 9 & 20.53 & 23.63 & 30.21 & 21.93 & 25.25 & 32.27 & 24.93 & 28.70 & 36.68 \\
\hline 10 & 20.04 & 23.08 & 29.50 & 21.33 & 24.55 & 31.39 & 24.04 & 27.68 & 35.39 \\
\hline 11 & 19.65 & 22.62 & 28.93 & 20.83 & 23.99 & 30.67 & 23.32 & 26.86 & 34.34 \\
\hline 12 & 19.31 & 22.24 & 28.45 & 20.42 & 23.51 & 30.08 & 22.73 & 26.17 & 33.48 \\
\hline 13 & 19.03 & 21.92 & 28.04 & 20.07 & 23.11 & 29.57 & 22.23 & 25.60 & 32.75 \\
\hline 14 & 18.79 & 21.64 & 27.69 & 19.77 & 22.77 & 29.14 & 21.80 & 25.11 & 32.13 \\
\hline 15 & 18.58 & 21.40 & 27.39 & 19.51 & 22.47 & 28.76 & 21.43 & 24.69 & 31.59 \\
\hline 16 & 18.40 & 21.19 & 27.12 & 19.28 & 22.21 & 28.42 & 21.11 & 24.31 & 31.11 \\
\hline 17 & 18.23 & 21.00 & 26.88 & 19.08 & $21.98^{\circ}$ & 28.13 & 20.82 & 23.98 & 30.69 \\
\hline 18 & 18.09 & 20.83 & 26.66 & 18.90 & 21.77 & 27.86 & 20.57 & 23.69 & 30.32 \\
\hline 1.9 & 17.95 & 20.68 & 26.47 & 18.74 & 21.59 & 27.63 & 20.34 & 23.43 & 29.98 \\
\hline 20 & 17.83 & 20.54 & 26.30 & 18.59 & 21.42 & 27.41 & 20.13 & 23.19 & 29.68 \\
\hline 21 & 17.73 & 20.42 & 26.14 & 18.46 & 21.26 & 27.22 & 19.94 & 22.97 & 29.40 \\
\hline 22 & 17.63 & 20.31 & 25.99 & 18.33 & 21.12 & 27.04 & 19.77 & 22.77 & 29.15 \\
\hline 23 & 17.53 & 20.20 & 25.86 & 18.22 & 20.99 & 26.87 & 19.61 & 22.59 & 28.92 \\
\hline 24 & 17.45 & 20.10 & 25.74 & 18.12 & 20.87 & 26.72 & 19.47 & 22.42 & 28.71 \\
\hline 25 & 17.37 & 20.01 & 25.62 & 18.02 & 20.76 & 26.58 & 19.33 & 22.27 & 28.51 \\
\hline 26 & 17.30 & 19.93 & 25.51 & 17.93 & 20.66 & 26.45 & 19.21 & 22.13 & 28.33 \\
\hline 27 & 17.23 & 19.85 & 25.42 & 17.85 & 20.56 & 26.33 & 19.09 & 21.99 & 28.16 \\
\hline 28 & 17.17 & 19.78 & 25.32 & 17.77 & 20.47 & 26.21 & 18.98 & 21.87 & 28.00 \\
\hline 29 & 17.11 & 19.71 & 25.24 & 17.70 & 20.39 & 26.11 & 18.88 & 21.75 & 27.85 \\
\hline 30 & 17.05 & 19.65 & 25.15 & 17.63 & 20.31 & 26.00 & 18.78 & 21.64 & 27.71 \\
\hline 35 & 16.82 & 19.38 & 24.81 & 17.34 & 19.98 & 25.58 & 18.38 & 21.18 & 27.12 \\
\hline 40 & 16.64 & 19.17 & 24.54 & 17.12 & 19.72 & 25.25 & 18.07 & 20.82 & 26.66 \\
\hline 45 & 16.49 & 19.00 & 24.33 & 16.94 & 19.52 & 24.99 & 17.82 & 20.53 & 26.29 \\
\hline 50 & 16.37 & 18.86 & 24.15 & 16.79 & 19.35 & 24.77 & 17.62 & 20.30 & 25.99 \\
\hline 60 & 16.19 & 18.65 & 23.88 & 16.56 & 19.08 & 24.44 & 17.30 & 19.94 & 25.53 \\
\hline 70 & 16.05 & 18.49 & 23.68 & 16.39 & 18.89 & 24.19 & 17.06 & 19.66 & 25.18 \\
\hline 80 & 15.94 & 18.37 & 23.52 & 16.26 & 18.73 & 23.99 & 16.88 & 19.45 & 24.90 \\
\hline 90 & 15.85 & 18.27 & 23.39 & 16.15 & 18.61 & 23.83 & 16.73 & 19.28 & 24.68 \\
\hline 100 & 15.78 & 18.18 & 23.28 & 16.06 & 18.51 & 23.70 & 16.61 & 19.13 & 24.50 \\
\hline 200 & 15.41 & 17.76 & 22.74 & 15.60 & 17.98 & 23.02 & 15.97 & 18.40 & 23.57 \\
\hline 500 & 15.12 & 17.42 & 22.31 & 15.24 & 17.56 & 22.48 & 15.46 & 17.82 & 22.81 \\
\hline$\infty$. & 14.68 & 16.92 & 21.67 & 14.68 & 16.92 & 21.67 & 14.68 & 16.92 & 21.67 \\
\hline
\end{tabular}


Table D-9

H VALUES $(C=10)$

\begin{tabular}{|c|c|c|c|c|c|c|c|c|c|}
\hline \multirow[b]{2}{*}{$\mathrm{N}$} & \multicolumn{3}{|c|}{$\gamma=0.90$} & \multicolumn{3}{|c|}{$\gamma=0.95$} & \multicolumn{3}{|c|}{$\gamma=0.99$} \\
\hline & $P=0.90$ & $P=0.95$ & $P=0.99$ & $P=0.90$ & $P=0.95$ & $P=0.99$ & $P=0.90$ & $P=0.95$ & $P=0.99$ \\
\hline 2 & 48.25 & 54.76 & 68.29 & 59.60 & 67.63 & 84.35 & 91.88 & 104.27 & 130.04 \\
\hline 3 & 33.87 & 38.58 & 48.43 & 38.84 & 44.24 & 55.54 & 51.06 & 58.17 & 73.02 \\
\hline 4 & 28.89 & 32.97 & 41.53 & 32.19 & 36.73 & 46.27 & 39.83 & 45.45 & 57.25 \\
\hline 5 & 26.28 & 30.02 & 37.88 & 28.80 & 32.90 & 41.52 & 34.49 & 39.40 & 49.71 \\
\hline 6 & 24.65 & 28.18 & 35.60 & 26.73 & 30.55 & 38.60 & 31.30 & 35.78 & 45.20 \\
\hline 7 & 23.53 & 26.91 & 34.02 & 25.31 & 28.95 & 36.60 & 29.18 & 33.37 & 42.19 \\
\hline 8 & 22.70 & 25.97 & 32.85 & 24.28 & 27.77 & 35.13 & 27.66 & 31.63 & 40.02 \\
\hline 9 & 22.07 & 25.25 & 31.95 & 23.49 & 26.87 & 34.01 & 26.50 & 30.32 & 38.37 \\
\hline 10 & 21.56 & 24.67 & 31.23 & 22.86 & 26.16 & 33.12 & 25.60 & 29.29 & 37.08 \\
\hline 11 & 21,15 & 24.20 & 30.65 & 22.35 & 25.58 & 32.39 & 24.87 & 28.46 & 36.03 \\
\hline 12 & 20.81 & 23.81 & 30.15 & 21.93 & 25.10 & 31.78 & 24.26 & 27.77 & 35.16 \\
\hline 13 & 20.51 & 23.48 & $29.74^{\circ}$ & 21.57 & 24.69 & 31.27 & 23.75 & 27.19 & 34.43 \\
\hline 14 & 20.26 & 23.19 & 29.38 & 21.26 & 24.33 & 30.82 & 23.31 & 26.69 & 33.80 \\
\hline 15 & 20.04 & 22.94 & 29.07 & 20.99 & 24.03 & 30.44 & 22.94 & 26.25 & 33.26 \\
\hline 16 & 19.85 & 22.72 & 28.79 & 20.75 & 23.76 & 30.10 & 22.60 & 25.88 & 32.78 \\
\hline 17 & 19.68 & 22.53 & 28.55 & 20.55 & 23.52 & 29.80 & 22.31 & 25.54 & 32.36 \\
\hline 18 & 19.53 & 22.36 & 28.33 & 20.36 & 23.31 & 29.53 & 22.05 & 25.24 & 31.98 \\
\hline 19 & 19.39 & 22.20 & 28.13 & 20.19 & 23.11 & 29.29 & 21.81 & 24.97 & 31.64 \\
\hline 20 & 19.27 & 22.06 & 27.95 & 20.04 & 22.94 & 29.07 & 21.60 & 24.73 & 31.34 \\
\hline 21 & 19.15 & 21.93 & 27.79 & 19.90 & 22.78 & 28.87 & 21.41 & 24.51 & 31.06 \\
\hline 22 & 19.05 & 21.81 & 27.64 & 19.77 & 22.64 & 28.69 & 21.23 & 24.31 & 30.80 \\
\hline 23 & 18.95 & 21.70 & 27.50 & 19.65 & 22.50 & 28.52 & 21.07 & 24.12 & 30.57 \\
\hline 24 & 18.86 & 21.60 & 27.37 & 19.55 & 22.38 & 28.36 & 20.92 & 23.95 & 30.35 \\
\hline 25 & 18.78 & 21.51 & 27.26 & 19.45 & 22.27 & 28.22 & 20.78 & 23.79 & 30.15 \\
\hline 26 & 18.71 & 21.42 & 27.15 & 19.36 & 22.16 & 28.09 & 20.65 & 23.65 & 29.97 \\
\hline 27 & 18.64 & 21.34 & 27.05 & 19.27 & 22.06 & 27.96 & 20.53 & 23.51 & 29.80 \\
\hline 28 & 18.57 & 21.26 & 26.95 & 19.19 & 21.97 & 27.85 & 20.42 & 23.38 & 29.64 \\
\hline 29 & 18.51 & 21.19 & 26.86 & 19.11 & 21.88 & 27.74 & 20.32 & 23.26 & 29.48 \\
\hline 30 & 18.45 & 21.13 & 26.78 & 19.04 & 21.80 & 27.64 & 20.22 & 23.15 & 29.31 \\
\hline 35 & 18.21 & 20.85 & 26.43 & 18.74 & 21.46 & 27.20 & 19.80 & 22.68 & 28.74 \\
\hline 40 & 18.02 & 20.63 & 26.15 & 18.51 & 21.20 & 26.87 & 19.48 & 22.31 & 28.28 \\
\hline 45 & 17.87 & 20.46 & 25.93 & 18.32 & 20.98 & 26.60 & 19.23 & 22.02 & 27.91 \\
\hline 50 & 17.74 & 20.32 & 25.75 & 18.17 & 20.81 & 26.38 & 19.02 & 2.1 .78 & 27.61 \\
\hline 60 & 17.55 & 20.09 & 25.47 & 17.94 & 20.54 & 26.04 & 18.69 & 21.40 & 27.13 \\
\hline 70 & 17.40 & 19.93 & 25.27 & 17.76 & 20.33 & 25.78 & 18.45 & 21.12 & 26.78 \\
\hline 80 & 17.29 & 19.80 & 25.10 & 17.62 & 20.18 & 25.58 & 18.26 & 20.90 & 26.50 \\
\hline 90 & 17.20 & 19.70 & 24.97 & 17.51 & 20.05 & 25.41 & 18.10 & 20.73 & 26.28 \\
\hline 100 & 17.13 & 19.61 & 24.86 & 17.41 & 19.94 & 25.28 & 17.97 & 20.58 & 26.09 \\
\hline 200 & 16.74 & 19.17 & 24.31 & 16.94 & 19.40 & 24.59 & 17.32 & 19.83 & 25.14 \\
\hline 500 & 16.44 & 18.82 & 23.87 & 16.56 & 18.96 & 24.04 & 16.79 & 19.23 & 24.38 \\
\hline$\infty$ & 15.99 & 18.31 & 23.21 & 15.99 & 18.31 & 23.21 & 15.99 & 18.31 & 23.21 \\
\hline
\end{tabular}


Table D.10

H VALUES $(C=11)$

\begin{tabular}{|c|c|c|c|c|c|c|c|c|c|}
\hline \multirow[b]{2}{*}{$N$} & \multicolumn{3}{|c|}{$\gamma=0.90$} & \multicolumn{3}{|c|}{$\gamma=0.95$} & \multicolumn{3}{|c|}{$\gamma=0.99$} \\
\hline & $P=0.90$ & $P=0.95$ & $P=0.99$ & $P=0.90$ & $P=0.95$ & $P=0.99$ & $P=0.90$ & $P=0.95$ & $P=0.99$ \\
\hline 2 & 50.05 & 56.52 & 69.92 & 61.02 & 68.91 & 85.24 & 91.60 & 103.43 & 127.95 \\
\hline 3 & 35.68 & 40.44 & 50.34 & 40.61 & 46.02 & 57.30 & 52.58 & 59.58 & 74.18 \\
\hline 4 & 30.62 & 34.76 & 43.41 & 33.91 & 38.50 & 48.07 & 41.48 & 47.09 & 58.81 \\
\hline 5 & 27.93 & 31.74 & 39.71 & 30.47 . & 34.62 & 43.32 & 36.13 & 41.05 & 51.36 \\
\hline 6 & 26.26 & 29.85 & 37.39 & 28.35 & 32.24 & 40.37 & 32.92 & 37.43 & 46.88 \\
\hline 7 & 25.10 & 28.55 & 35.78 & 26.90 & 30.60 & 38.35 & 30.78 & 35.01 & 43.88 \\
\hline 8 & 24.25 & 27.58 & 34.59 & 25.84 & 29.40 & 36.87 & 29.23 & 33.26 & 41.71 \\
\hline 9 & 23.59 & 26.84 & 33.67 & 25.03 & 28.48 & 35.73 & 28.06 & 31.93 & 40.06 \\
\hline 10 & 23.06 & 26.25 & 32.94 & 24.38 & 27.75 & 34.82 & 27.14 & 30.89 & 38.76 \\
\hline 11 & 22.64 & 25.76 & 32.34 & 23.86 & 27.15 & 34.08 & 26.40 & 30.04 & 37.71 \\
\hline 12 & 22.28 & 25.36 & 31.84 & 23.42 & 26.66 & 33.47 & 25.78 & 29.34 & 36.84 \\
\hline 13 & 21.97 & 25.02 & 31.41 & 23.05 & 26.24 & 32.94 & 25.26 & 28.75 & 36.10 \\
\hline 14 & 21.71 & 24.72 & 31.04 & 22.73 & 25.88 & 32.49 & 24.81 & 28.24 & 35.47 \\
\hline 15 & 21.49 & 24.46 & 30.72 & 22.45 & 25.56 & 32.10 & 24.42 & 27.80 & 34.92 \\
\hline 16 & 21.29 & 24.21 & 30.44 & 22.21 & 25.28 & 31.75 & 24.08 & 27.42 & 34.43 \\
\hline 17 & 21.11 & 24.04 & 30.19 & 21.99 & 25.04 & 31.45 & 23.78 & 27.08 & 34.01 \\
\hline 18 & 20.95 & 23.85 & 29.96 & 21.80 & 24.82 & 31.17 & 23.51 & 26.77 & 33.63 \\
\hline 19 & 20.81 & 23.69 & 29.76 & 21.62 & 24.62 & 30.93 & 23.27 & 26.50 & 33.28 \\
\hline 20 & 20.68 & 23.55 & 29.58 & 21.46 & 24.44 & 30.70 & 23.05 & 26.25 & 32.97 \\
\hline 21 & 20.56 & 23.41 & 29.41 & 21.32 & 24.28 & 30.50 & 22.85 & 26.02 & 32.69 \\
\hline 22 & 20.45 & 23.29 & 29.26 & 21.19 & 24.13 & 30.31 & 22.67 & 25.82 & 32.43 \\
\hline 23 & 20.35 & 23.18 & 29.12 & 21.07 & 23.99 & 30.14 & 22.51 & 25.63 & 32.20 \\
\hline 24 & 20.26 & 23.07 & 28.99 & 20.96 & 23.87 & 29.98 & 22.35 & 25.45 & 31.98 \\
\hline 25 & 20.18 & 22.98 & 28.87 & 20.85 & 23.75 & 29.81 & 22.21 & 25.29 & 31.78 \\
\hline 26 & 20.10 & 22.89 & 28.75 & 20.76 & 23.64 & 29.70 & 22.08 & 25.14 & 31.59 \\
\hline 27 & 20.02 & 22.80 & 28.65 & 20.67 & 23.54 & 29.57 & 21.96 & 25.00 & 31.41 \\
\hline 28 & 19.96 & 22.73 & 28.55 & 20.59 & 23.44 & 29.45 & 21.84 & 24.87 & 31.25 \\
\hline 29 & 19.89 & 22.65 & 28.46 & 20.51 & 23.35 & 29.34 & 21.73 & 24.75 & 31.10 \\
\hline 30 & 19.83 & 22.58 & 28.38 & 20.43 & 23.27 & 29.24 & 21.63 & 24.64 & 30.95 \\
\hline 35 & 19.58 & 22.30 & 28.01 & 20.12 & 22.92 & 28.80 & 21.21 & 24.15 & 30.35 \\
\hline 40 & 19.38 & 22.07 & 27.73 & 19.88 & 22.65 & 28.46 & 20.88 & 23.78 & 29.88 \\
\hline 45 & 19.22 & 21.89 & 27.51 & 19.69 & 22.43 & 28.18 & 20.61 & 23.48 & 29.50 \\
\hline 50 & 19.09 & 21.75 & 27.33 & 19.53 & 22.25 & 27.96 & 20.40 & 23.23 & 29.19 \\
\hline 60 & 18.89 & 21.52 & 27.04 & 19.29 & 21.97 & 27.61 & 20.06 & 22.85 & 28.71 \\
\hline 70 & 18.74 & 21.35 & 26.82 & 19.11 & 21.76 & 27.34 & 19.81 & 22.56 & 28.35 \\
\hline 80 & 18.63 & 21.21 & 26.66 & 18.96 & 21.60 & 27.14 & 19.61 & 22.34 & 28.07 \\
\hline 90 & 18.53 & 21.11 & 26.52 & 18.85 & 21.46 & 26.97 & 19.45 & 22.16 & 27.84 \\
\hline 100 & 18.45 & 21.02 & 26.41 & 18.75 & 21.35 & 26.83 & 19.32 & 22.01 & 27.65 \\
\hline 200 & 18.06 & 20.57 & 25.84 & 18.26 & 20.80 & 26.13 & 18.65 & 21.24 & 26.69 \\
\hline 500 & 17.74 & 20.21 & 25.39 & 17.87 & 20.35 & 25.57 & 18.10 & 20.62 & 25.91 \\
\hline$\infty$ & 17.28 & 19.68 & 24.72 & 17.28 & 19.68 & 24.72 & 17.28 & 19.68 & 24.72 \\
\hline
\end{tabular}


Table D-11

H VALUES $(C=12)$

\begin{tabular}{|c|c|c|c|c|c|c|c|c|c|}
\hline \multirow[b]{2}{*}{$N$} & \multicolumn{3}{|c|}{$\gamma=0.90$} & \multicolumn{3}{|c|}{$\gamma=0.95$} & \multicolumn{3}{|c|}{$\gamma=0.99$} \\
\hline & $P=0.90$ & $P=0.95$ & $P=0.99$ & $P=0.90$ & $P=0.95$ & $P=0.99$ & $P=0.90$ & $P=0.95$ & $P=0.99$ \\
\hline 2 & 51.89 & 58.34 & 71.65 & 62.61 & 70.38 & 86.45 & 91.69 & 103.08 & 126.60 \\
\hline 3 & 37.49 & 42.29 & 52.26 & 42.40 & 47.83 & 59.10 & 51.12 & 61.05 & 75.45 \\
\hline 4 & 32.32 & 36.53 & 45.27 & 35.63 & 40.26 & 49.90 & 43.14 & 48.74 & 60.42 \\
\hline 5 & 29.57 & 33.45 & 41.53 & 32.13 & 36.34 & 45.11 & 37.77 & 42.71 & 53.03 \\
\hline 6 & 27.85 & 31.51 & 39.17 & 29.96 & 33.90 & 42.14 & 34.54 & 39.08 & 48.58 \\
\hline 7 & 26.65 & 30.17 & 37.53 & 28.47 & 32.23 & 40.09 & 32.37 & 36.64 & 45.57 \\
\hline 8 & 25.77 & 29.18 & 36.31 & 27.38 & 31.01 & 38.59 & 30.80 & 34.88 & 43.40 \\
\hline 9 & 25.09 & 28.42 & 35.37 & 26.55 & 30.07 & 37.43 & 2961 & 3353 & 41.74 \\
\hline 10. & 24.55 & 27.81 & 34.62 & 25.88 & 29.32 & 36.51 & 28.67 & 32.47 & 40.44 \\
\hline 11 & 21.10 & 27.31 & 34.01 & 25.34 & 28.71 & 35.76 & 27.91 & 31.62 & 39.37 \\
\hline 12 & 23.73 & 26.89 & 33.49 & 24.89 & 28.20 & 35.13 & 27.28 & 30.90 & 38.49 \\
\hline 13 & 23.42 & 26.53 & 33.06 & 24.51 & 27.77 & 34.60 & 26.74 & 30.30 & 37.75 \\
\hline 14 & 23.15 & 26.23 & 32.68 & 24.18 & 27.40 & 34.14 & 26.29 & 29.79 & 37.11 \\
\hline 15 & 22.91 & 25.96 & 32.35 & 23.89 & 27.07 & 33.74 & 25.89 & 29.34 & 36.56 \\
\hline 16 & 22.71 & 25.73 & 32.06 & 23.64 & 26.79 & 33.38 & 25.54 & 28.94 & 36.07 \\
\hline 17 & 22.52 & 25.52 & 31.80 & 23.42 & 26.54 & 33.07 & 25.23 & 28.60 & 35.64 \\
\hline 18 & 22.36 & 25.34 & 31.57 & 23.22 & 26.31 & 32.79 & 24.96 & 28.29 & 35.25 \\
\hline 19 & 22.21 & 25.17 & 31.37 & 23.04 & 26.11 & 32.54 & 24.71 & 28.01 & 34.90 \\
\hline 20 & 22.07 & 25.02 & 31.18 & 22.88 & 25.93 & 32.31 & 24.49 & 27.75 & 34.59 \\
\hline 21 & 21.95 & 24.88 & 31.01 & 22.73 & 25.76 & 32.11 & 24.29 & 27.52 & 34.31 \\
\hline 22 & 21.84 & 24.75 & 30.85 & 22.59 & 25.60 & 31.91 & 24.10 & 27.31 & 34.04 \\
\hline 23 & 21.74 & 24.64 & 30.71 & 22.47 & 25.46 & 31.74 & 23.93 & 27.12 & 33.80 \\
\hline 24 & 21.64 & 24.53 & 30.57 & 22.35 & 25.33 & 31.58 & 23.77 & 26.94 & 33.58 \\
\hline 25 & 21.55 & 24.43 & 30.45 & 22.25 & 25.21 & 31.43 & 23.62 & 26.78 & 33.38 \\
\hline 26 & 21.47 & 24.34 & 30.34 & 22.15 & 25.10 & 31.29 & 23.49 & 26.62 & 33.19 \\
\hline 27 & 21.40 & 24.25 & 30.23 & 22.05 & 25.00 & 31.16 & 23.36 & 26.48 & 33.01 \\
\hline 28 & 21.32 & 24.17 & 30.13 & 21.97 & 24.90 & 31.04 & 23.25 & 26.35 & 32.84 \\
\hline 29 & 21.26 & 24.09 & . 30.04 & 21.89 & 24.81 & 30.93 & 23.13 & 26.22 & 32.69 \\
\hline 30 & 21.20 & 24.02 & 29.95 & 21.81 & 24.72 & 30.82 & 23.03 & 26.10 & 32.54 \\
\hline 35 & 20.93 & 23.72 & 29.58 & 21.49 & 24.36 & 30.37 & 22.59 & 25.61 & 31.93 \\
\hline 40 & 20.73 & 23.49 & 29.29 & 21.24 & 24.08 & 30.02 & 22.26 & 25.23 & 31.45 \\
\hline 45 & 20.56 & 23.31 & 29.06 & 21.04 & 23.85 & 29.74 & 21.99 & 24.92 & 31.07 \\
\hline 50 & 20.43 & 23.16 & 29.87 & 20.88 & 23.67 & 29.51 & 21.76 & 24.67 & 30.76 \\
\hline 60 & 20.22 & 22.92 & 29.58 & 20.63 & 23.38 & 29.15 & 21.42 & 24.28 & 30.27 \\
\hline 70 & 20.07 & 22.75 & 28.36 & 20.44 & 23.17 & 28.88 & 21.16 & 23.98 & 29.90 \\
\hline 80 & 19.95 & 22.61 & 28.19 & 20.29 & 23.00 & 28.67 & 20.95 & 23.75 & 29.62 \\
\hline 90 & 19.85 & 22.50 & 28.05 & 20.17 & 22.86 & 28.51 & 20.79 & 23.57 & 29.38 \\
\hline 100 & 19.77 & 22.41 & 27.94 & 20.07 & 22.75 & 28.36 & 20.65 & 23.41 & 29.19 \\
\hline 200 & 19.36 & 21.94 & 27.36 & 19.56 & 22.18 & 27.65 & 19.96 & 22.63 & 28.21 \\
\hline 500 & 19.03 & 21.57 & 26.90 & 19.16 & 21.72 & 27.08 & 19.40 & 21.99 & 27.42 \\
\hline$\infty$ & 18.55 & 21.03 & 26.22 & 18.55 & 21.03 & 26.22 & 18.55 & 21.03 & 26.22 \\
\hline
\end{tabular}


Table D-12

H VALUES $(C=13)$

\begin{tabular}{|c|c|c|c|c|c|c|c|c|c|}
\hline \multirow[b]{2}{*}{$N$} & \multicolumn{3}{|c|}{$\gamma=0.90$} & \multicolumn{3}{|c|}{$\gamma=0.95$} & \multicolumn{3}{|c|}{$\gamma=0.99$} \\
\hline & $P=0.90$ & $P=0.95$ & $P=0.99$ & $P=0.90$ & $P=0.95$ & $P=0.99$ & $P=0.90$ & $P=0.95$ & $P=0.99$ \\
\hline 2 & 53.78 & 60.22 & 73.49 & 64.29 & 71.99 & 87.85 & 92.31 & 103.37 & 126.14 \\
\hline 3 & 39.29 & 44.14 & 54.18 & 44.18 & 49.63 & 60.93 & 55.73 & 62.61 & 76.86 \\
\hline 4 & 34.02 & 38.28 & 47.13 & 37.33 & 42.01 & 51.72 & 44.80 & 50.42 & 62.07 \\
\hline 5 & 31.20 & 35.14 & 43.33 & 33.77 & 38.03 & 46.90 & 39.41 & 44.38 & 54.73 \\
\hline 6 & 29.42 & 33.16 & 40.93 & 31.55 & 35.56 & 43.89 & 36.14 & 40.73 & 50.28 \\
\hline 7 & 28.19 & 31.78 & 39.25 & 30.03 & 33.86 & 41.82 & 33.94 & 38.27 & 47.27 \\
\hline 8 & 27.28 & 30.76 & 38.01 & 28.91 & 32.60 & 40.29 & 32.35 & 36.48 & 45.08 \\
\hline 9 & 26.68 & 29.97 & 37.05 & 28.05 & 31.64 & 39.11 & 31.14 & 35.12 & 43.42 \\
\hline 10 & 26.02 & 29.34 & 36.29 & 27.37 & 30.87 & 38.18 & 30.18 & 34.05 & 42.10 \\
\hline 11 & 25.56 & 28.83 & 35.66 & 26.81 & 30.25 & 37.41 & 29.41 & 33.17 & 41.03 \\
\hline 12 & 25.17 & 28.40 & 35.13 & 26.35 & 29.73 & 36.77 & 28.76 & 32.45 & 40.14 \\
\hline 13 & 24.85 & 28.03 & 34.68 & 25.96 & 29.28 & 36.23 & 28.22 & 31.84 & 39.39 \\
\hline 14 & 24.57 & 27.72 & 34.30 & 25.62 & 28.90 & 35.76 & 27.75 & 31.31 & 38.74 \\
\hline 15 & 24.32 & 27.45 & 33.96 & $25: 32$ & 28.57 & 35.35 & 27.34 & 30.85 & 38.18 \\
\hline 16 & 24.11 & 27.20 & $33: 67$ & 25.06 & 28.28 & 36.00 & 36.88 & 30.16 & 37.68 \\
\hline 17 & 23.92 & 26.99 & 33.40 & 24.83 & 28.02 & 34.68 & 26.67 & 30.10 & 37.25 \\
\hline 18 & 23.75 & 26.80 & 33.17 & 24.63 & 27.79 & 34.39 & 26.39 & 29.78 & 36.86 \\
\hline 19 & 23.59 & 26.63 & 32.95 & 24.44 & 27.58 & 34.14 & 26.14 & 29.50 & 36.51 \\
\hline 20 & 23.46 & 26.47 & 32.76 & 24.27 & 27.39 & 33.90 & 25.91 & 29.24 & 36.19 \\
\hline 21 & 23.33 & 26.33 & 32.59 & 24.12 & 27.22 & 33.69 & 25.70 & 29.00 & 35.90 \\
\hline 22 & 23.21 & 26.20 & 32.43 & 23.98 & 27.06 & 33.50 & 25.51 & 28.79 & 35.64 \\
\hline 23 & 23.11 & 26.08 & 32.28 & 23.85 & 26.92 & 33.32 & 25.34 & 28.59 & 35.39 \\
\hline 24 & 23.01 & 25.97 & 32.14 & 23.73 & 26.78 & 33.15 & 25.17 & 28.41 & 35.17 \\
\hline 25 & 22.92 & 25.86 & 32.02 & 23.62 & 26.66 & 33.00 & 25.02 & 28.24 & 34.96 \\
\hline 26 & 22.83 & 25.77 & 31.90 & 23.52 & 26.54 & 32.86 & 24.89 & 28.08 & 34.77 \\
\hline 27 & 22.75 & 25.68 & 31.79 & 23.42 & 26.44 & 32.73 & 24.76 & 27.94 & 34.59 \\
\hline 28 & 22.68 & 25.60 & 31.69 & 23.34 & 26.34 & 32.60 & 24.63 & 27.80 & 34.42 \\
\hline 29 & 22.61 & 25.52 & 31.59 & 23.25 & 26.24 & 32.49 & 24.52 & 27.68 & 34.26 \\
\hline 30 & 22.55 & 25.45 & 31.50 & 23.17 & 26.15 & 32.38 & 24.41 & 27.56 & 34.11 \\
\hline 35 & 22.27 & 25.14 & 31.12 & 22.84 & 25.78 & 31.92 & 23.97 & 27.05 & 33.40 \\
\hline 40 & 22.06 & 24.90 & 30.83 & 22.59 & 25.49 & 31.56 & 23.62 & 26.66 & 33.00 \\
\hline 45 & 21.89 & 24.71 & 30.59 & 22.38 & 25.26 & 31.28 & 23.34 & 26.34 & 32.62 \\
\hline 50 & 21.75 & 24.55 & 30.40 & 22.21 & 25.07 & 31.04 & 23.11 & 26.09 & 32.30 \\
\hline 60 & 21.54 & 24.31 & 30.10 & 21.95 & 24.78 & 30.68 & 22.76 & 25.69 & 31.80 \\
\hline 70 & 21.38 & 24.13 & 29.87 & 21.76 & 24.56 & 30.40 & 22.49 & 25.39 & 31.43 \\
\hline 80 & 21.25 & 23.99 & 29.70 & 21.60 & 24.38 & 30.19 & 22.28 & 25.15 & 31.14 \\
\hline 90 & 21.15 & 23.87 & 29.56 & 21.48 & 24.24 & 30.02 & 22.11 & 24.96 & 30.91 \\
\hline 100 & 21.07 & 23.78 & 29.44 & 21.38 & 24.13 & .29 .87 & 21.97 & 24.80 & 30.71 \\
\hline 200 & 20.64 & 23.30 & 28.85 & 20.86 & 23.54 & 29.15 & 21.26 & 24.00 & 29.71 \\
\hline 500 & 20.31 & 22.92 & 28.38 & 20.44 & 23.07 & 28.56 & 20.69 & 23.35 & 28.91 \\
\hline$\infty$ & 19.81 & 22.36 & 27.69 & 19.81 & 22.36 & 27.69 & 19.81 & 22.36 & 27.69 \\
\hline
\end{tabular}


Table D-13

H VALUES $(C=14)$

\begin{tabular}{|c|c|c|c|c|c|c|c|c|c|}
\hline \multirow[b]{2}{*}{$\mathrm{N}$} & \multicolumn{3}{|c|}{$\gamma=0.90$} & \multicolumn{3}{|c|}{$\gamma=0.95$} & \multicolumn{3}{|c|}{$\gamma=0.99$} \\
\hline & $P=0.90$ & $\mathrm{P}=0.95$ & $P=0 . \overline{99}$ & $P=0.90$ & $P=0.95$ & $P=0.99$ & $P=0.90$ & $P=0.95$ & $P=0.99$ \\
\hline 2 & 55.69 & 62.14 & 75.39 & 66.04 & 73.69 & 89.40 & 93.22 & 104.01 & 126.19 \\
\hline 3 & 41.08 & 45.99 & 56.11 & 45.97 & 51.46 & 62.79 & 57.41 & 64.27 & 78.42 \\
\hline 4 & 35.70 & 40.02 & 48.97 & 39.03 & 43.76 & 53.54 & 46.49 & 52.12 & 63.78 \\
\hline 5 & 32.81 & 36.82 & 45.12 & 35.40 & 39.72 & 48.68 & 41.04 & 46.05 & 56.44 \\
\hline 6 & 30.98 & 34.78 & 42.67 & 33.14 & 37.20 & 45.64 & 37.74 & 42.37 & 51.98 \\
\hline 7 & 29.71 & 33.37 & 40.96 & 31.58 & 35.46 & 43.53 & 35.51 & 39.88 & 48.96 \\
\hline 8 & 28.77 & 32.32 & 39.70 & 30.43 & 34.18 & 41.98 & 33.89 & 38.07 & 46.76 \\
\hline 9 & 28.05 & 31.51 & 38.72 & 29.55 & 33.20 & 40.78 & 32.66 & 36.69 & 45.08 \\
\hline 10 & 27.47 & 30.87 & 37.93 & 28.85 & 32.41 & 39.83 & 31.68 & 35.60 & 43.75 \\
\hline 11 & 27.00 & 30.34 & 37.29 & 28.27 & 31.77 & 39.05 & 30.89 & 34.72 & 42.67 \\
\hline 12 & 26.60 & 29.90 & 36.75 & 27.79 & 31.24 & 38.40 & 30.23 & 33.98 & 41.77 \\
\hline 13 & 26.26 & 29.52 & 36.29 & 27.39 & 30.78 & 37.85 & 29.68 & 33.36 & 41.01 \\
\hline 14 & 25.97 & 29.20 & 35.90 & 27.04 & 30.39 & 37.37 & 29.20 & 32.82 & 40.36 \\
\hline 15 & 25.72 & 28.91 & 35.55 & 26.74 & 30.05 & 36.95 & 28.79 & 32.36 & 39.79 \\
\hline 16 & 25.50 & 28.67 & 35.25 & 26.47 & 29.75 & 36.59 & 28.42 & 31.95 & 39.29 \\
\hline 17 & 25.30 & 28.44 & 34.98 & 26.23 & 29.49 & 36.26 & 28.10 & 31.59 & 38.85 \\
\hline 18 & 25.13 & 28.25 & 34.74 & 26.02 & 29.25 & 35.97 & 27.81 & 31.26 & 38.45 \\
\hline 19 & 24.97 & 28.07 & 34.52 & 25.83 & 29.04 & 35.71 & 27.55 & 30.97 & 38.09 \\
\hline 20 & 24.82 & 27.91 & 34.32 & 25.66 & 28.84 & 35.47 & 27.32 & 30.71 & 37.77 \\
\hline 21 & 24.69 & 27.76 & 34.15 & 25.50 & 28.67 & 35.26 & 27.10 & 30.47 & 37.48 \\
\hline 22 & 24.57 & 27.63 & 33.98 & 25.35 & 28.50 & 35.06 & 26.91 & 30.25 & 37.21 \\
\hline 23 & 24.46 & 27.50 & 33.83 & 25.22 & 28.36 & 34.88 & 26.73 & 30.05 & 36.96 \\
\hline 24 & 24.36 & 27.39 & 33.69 & 25.10 & 28.22 & 34.71 & 26.56 & 29.86 & 36.73 \\
\hline 25 & 24.27 & 27.28 & 33.56 & 24.99 & 28.09 & 34.55 & 26.41 & 29.69 & 36.52 \\
\hline 26 & 24.18 & 27.19 & 33.44 & 24.88 & 27.97 & 34.41 & 26.27 & 29.53 & 36.33 \\
\hline 27 & 24.10 & 27.09 & 33.33 & 24.78 & 27.86 & 34.27 & 26.13 & 29.38 & 36.15 \\
\hline 28 & 24.02 & 27.01 & 33.22 & 24.69 & 27.76 & 34.15 & 26.01 & 29.24 & 35.97 \\
\hline 29 & 23.95 & 26.93 & 33.13 & 24.60 & 27.66 & 34.03 & 25.89 & 29.11 & 35.81 \\
\hline 30 & 23.88 & 26.85 & 33.03 & 24.52 & 27.57 & 33.92 & 25.79 & 28.99 & 35.66 \\
\hline 35 & 23.60 & 26.54 & 32.65 & 24.18 & 27.19 & 33.45 & 25.33 & 28.47 & 35.03 \\
\hline 40 & 23.38 & 26.29 & 32.34 & 23.92 & 26.89 & 33.09 & 24.97 & 28.07 & 34.54 \\
\hline 45 & 23.21 & 26.09 & 32.10 & 23.71 & 26.66 & 32.80 & 24.68 & 27.75 & 34.15 \\
\hline 50 & 23.06 & 25.93 & 31.91 & 23.53 & 26.46 & 32.56 & 24.45 & 27.49 & 33.82 \\
\hline 60 & 22.84 & 25.68 & 31.60 & 23.26 & 26.16 & 32.18 & 24.09 & 27.08 & 33.32 \\
\hline 70 & 22.68 & 25.50 & 31.37 & 23.06 & 25.93 & 31.90 & 23.81 & 26.77 & 32.94 \\
\hline 80 & 22.55 & 25.35 & 31.19 & 22.91 & 25.75 & 31.69 & 23.60 & 26.53 & 32.65 \\
\hline 90 & 22.44 & 25.23 & 31.05 & 22.78 & 25.61 & 31.51 & 23.43 & 26.34 & 32.41 \\
\hline 100 & 22.36 & 25.14 & 30.93 & 22.67 & 25.49 & 31.37 & 23.28 & 26.18 & 32.21 \\
\hline 200 & 21.92 & 24.65 & 30.32 & 22.14 & 24.89 & 30.62 & 22.55 & 25.36 & 31.20 \\
\hline 500 & 21.57 & 24.26 & 29.84 & 21.71 & 24.41 & 30.03 & 21.96 & 24.69 & 30.38 \\
\hline$\infty$ & 21.06 & 23.68 & 29.14 & 21.06 & 23.68 & 29.14 & 21.06 & 23.68 & 29.14 \\
\hline
\end{tabular}


Table D-14

H VALUES $(C=15)$

\begin{tabular}{|c|c|c|c|c|c|c|c|c|c|}
\hline \multirow[b]{2}{*}{$N$} & \multicolumn{3}{|c|}{$\gamma=0.90$} & \multicolumn{3}{|c|}{$\gamma=0.95$} & \multicolumn{3}{|c|}{$\gamma=0.99$} \\
\hline & $P=0.90$ & $P=0.95$ & $P=0.99$ & $P=0.90$ & $P=0.95$ & $P=0.99$ & $\mathrm{P}=0.90$ & $P=0.95$ & $P=0.99$ \\
\hline 2 & 57.61 & 64.08 & 77.34 & 67.82 & 75.43 & 91.03 & 94.22 & 104.80 & 126.47 \\
\hline 3 & 42.87 & 47.83 & 58.04 & 47.76 & 53.28 & 64.66 & 59.09 & 65.92 & 80.00 \\
\hline 4 & 37.37 & 41.76 & 50.81 & 40.72 & 45.50 & 55.36 & 48.17 & 53.82 & 65.49 \\
\hline 5 & 34.41 & 38.48 & 46.89 & 37.02 & 41.40 & 50.45 & 42.67 & 47.72 & 58.16 \\
\hline 6 & 32.53 & 36.40 & 44.40 & 34.71 & 38.83 & 47.37 & 39.33 & 44.01 & 53.68 \\
\hline 7 & 31.22 & 34.95 & 42.66 & 33.11 & 37.06 & 45.23 & 37.07 & 41.49 & 50.64 \\
\hline 8 & 30.26 & 33.87 & 41.36 & 31.93 & 35.75 & 43.65 & 35.42 & 39.66 & 48.43 \\
\hline 9 & 29.51 & 33.04 & 40.36 & 31.03 & 34.74 & 42.44 & 34.17 & 38.26 & 46.73 \\
\hline 10 & 28.91 & 32.38 & 39.56 & 30.31 & 33.94 & 41.47 & 33.17 & 37.15 & 45.39 \\
\hline 11 & 28.42 & 31.83 & 38.90 & 29.72 & 33.28 & 40.67 & 32.37 & 36.25 & 44.30 \\
\hline 12 & 28.02 & 31.38 & 38.35 & 29.23 & 32.74 & 40.01 & 31.69 & 35.50 & 43.39 \\
\hline 13 & 27.67 & 30.99 & 37.88 & 28.81 & 32.27 & 39.45 & 31.13 & 34.86 & 42.62 \\
\hline 14 & 27.37 & 30.66 & 37.48 & 28.45 & 31.87 & 38.96 & 30.64 & 34.32 & 41.96 \\
\hline 15 & 27.11 & 30.37 & 37.13 & 28.14 & 31.52 & 38.54 & 30.21 & 33.85 & 41.38 \\
\hline 16 & 26.88 & 30.11 & 36.82 & 27.86 & 31.21 & 38.16 & 29.84 & 33.43 & 40.88 \\
\hline 17 & 26.68 & 29.89 & 36.54 & 27.62 & 30.94 & 37.83 & 29.51 & 33.06 & 40.43 \\
\hline 18 & 26.49 & 29.68 & 36.30 & 27.40 & 30.70 & 37.54 & 29.22 & 32.73 & 40.03 \\
\hline 19 & 26.33 & 29.50 & 36.07 & 27.21 & 30.48 & 37.27 & 28.95 & 32.44 & 39.66 \\
\hline 20 & 26.18 & 29.33 & 35.87 & 27.03 & 30.28 & 37.03 & 28.71 & 32.17 & 39.34 \\
\hline 21 & 26.05 & 29.18 & 35.69 & 26.87 & 30.10 & 36.81 & 28.49 & 31.92 & 39.04 \\
\hline 22 & 25.92 & 29.04 & 35.52 & 26.72 & 29.93 & 36.61 & 28.29 & 31.70 & 38.77 \\
\hline 23 & 25.81 & 28.92 & 35.36 & 26.58 & 29.78 & 36.42 & 28.11 & 31.49 & 38.52 \\
\hline 24 & 125.70 & 28.80 & 35.22 & 26.45 & 29.64 & 36.25 & 27.94 & 31.30 & 38.29 \\
\hline 25 & 25.61 & 28.69 & 35.09 & 26.34 & 29.51 & 36.09 & 27.78 & 31.13 & 38.07 \\
\hline 26 & 25.52 & 28.59 & 34.97 & 26.23 & 29.39 & 35.94 & 27.64 & 30.97 & 37.87 \\
\hline 27 & $25.43^{\circ}$ & 28.50 & 34.85 & 26.13 & 29.27 & 35.81 & 27.50 & 30.81 & 37.69 \\
\hline 28 & 25.35 & 28.41 & 34.75 & 26.03 & 29.17 & 35.68 & 27.38 & 30.67 & 37.52 \\
\hline 29 & 25.28 & 28.33 & 34.64 & 25.95 & 29.07 & 35.56 & 27.26 & 30.54 & 37.35 \\
\hline 30 & 25.21 & 28.25 & 34.55 & 25.86 & 28.98 & 35.44 & 27.14 & 30.41 & 37.20 \\
\hline 35 & 24.92 & 27.92 & 34.15 & 25.51 & 28.58 & 34.96 & 26.67 & 29.89 & 36.56 \\
\hline 40 & 24.69 & 27.67 & 33.84 & 25.24 & 28.28 & 34.59 & 26.31 & 29.48 & 36.06 \\
\hline 45 & 24.51 & 27.47 & 33.60 & 25.02 & 28.04 & 34.30 & 26.02 & 29.15 & 35.66 \\
\hline 50 & 24.37 & 27.30 & 33.40 & 24.84 & 27.84 & 34.05 & 25.78 & 28.88 & 35.33 \\
\hline 60 & 24.14 & 27.04 & 33.08 & 24.57 & 27.53 & 33.67 & 25.40 & 28.46 & 34.82 \\
\hline 70 & 23.96 & 26.85 & 32.85 & 24.36 & 27.29 & 33.39 & 25.12 & 28.15 & 34.44 \\
\hline 80 & 23.83 & 26.70 & 32.67 & 24.20 & 27.11 & 33.17 & 24.90 & 27.90 & 34.14 \\
\hline 90 & 23.72 & 26.58 & 32.52 & 24.07 & 26.97 & 32.99 & 24.73 & 27.71 & 33.89 \\
\hline 100 & 23.63 & 26.48 & 32.40 & 23.96 & 26.84 & 32.84 & 24.68 & 27.64 & 33.69 \\
\hline 200 & 23.18 & 25.98 & 31.78 & 23.41 & 26.23 & 32.08 & 23.83 & 26.70 & 32.67 \\
\hline 500 & 22.83 & 25.58 & 31.29 & 22.97 & 25.73 & 31.48 & 23.23 & 26.03 & 31.84 \\
\hline$\infty$ & 22.31 & 25.00 & 30.58 & 22.31 & 25.00 & 30.58 & 22.31 & 25.00 & 30.58 \\
\hline
\end{tabular}


Table D-15

H VALUES $(C=16)$

\begin{tabular}{|c|c|c|c|c|c|c|c|c|c|}
\hline \multirow[b]{2}{*}{$\mathbf{N}$} & \multicolumn{3}{|c|}{$\gamma=0.90$} & \multicolumn{3}{|c|}{$\gamma=0.95$} & \multicolumn{3}{|c|}{$\gamma=0.99$} \\
\hline & $P=0.90$ & $P=0.95$ & $P=0.99$ & $P=0.90$ & $P=0.95$ & $P=0.99$ & $P=0.90$ & $P=0.95$ & $P=0.99$ \\
\hline 2 & 59.55 & 66.04 & 79.31 & 69.65 & 77.25 & 92.77 & 95.49 & 105.89 & 127.18 \\
\hline 3 & 44.64 & 49.66 & 59.96 & 49.53 & 55.10 & 66.53 & 60.82 & 67.65 & 81.68 \\
\hline 4 & 39.03 & 43.48 & 52.64 & 42.40 & 47.23 & 57.18 & 49.84 & 55.52 & 67.22 \\
\hline 5 & 36.00 & 40.13 & 48.66 & 38.63 & 43.07 & 52.21 & 44.30 & 49.39 & 59.88 \\
\hline 6 & 34.07 & 38.00 & 46.12 & 36.26 & 40.45 & 49.09 & 40.92 & 45.64 & 55.39 \\
\hline 7 & 32.73 & 36.51 & 44.34 & 34.63 & 38.64 & 46.92 & 38.62 & 43.09 & 52.32 \\
\hline 8 & 31,73 & 35.41 & 43.02 & 33.42 & 37.30 & 45.32 & 36.94 & 41.23 & 5ก.ก9 \\
\hline 9 & 30.06 & 31.66 & 11.80 & 32.60 & 36.37 & 11.08 & 36.67 & $30 ! 81$ & 18.38 \\
\hline 10 & 30.34 & 33.87 & 41.17 & 31.76 & 35.45 & 43.09 & 34.65 & 38.68 & 47.02 \\
\hline 11 & 29.84 & 33.32 & 40.50 & 31.15 & 34.78 & 42.28 & 33.83 & 37.77 & 45.91 \\
\hline 12 & 29.42 & 32.85 & 39.94 & 30.65 & 34.22 & 41.61 & 33.14 & 37.01 & 44.99 \\
\hline 13 & 29.06 & 32.45 & 39.46 & 30.22 & 33.74 & 41.03 & 32.56 & 36.36 & 44.21 \\
\hline 14 & 28.75 & 32.11 & 39.05 & 29.85 & 33.33 & 40.54 & 32.07 & 35.81 & 43.54 \\
\hline 15 & 28.49 & 31.81 & 38.69 & 29.53 & 32.98 & 40.11 & 31.63 & 35.32 & 42.96 \\
\hline 16 & 28.25 & 31.55 & 38.37 & 29.25 & 32.66 & 39.73 & 31.25 & 34.90 & 42.45 \\
\hline 17 & 28.04 & 31.31 & 38.09 & 29.00 & 32.38 & 39.39 & 30.92 & 34.52 & 41.99 \\
\hline 18 & 27.85 & 31.10 & 37.84 & 28.77 & 32.13 & 39.09 & 30.61 & 34.19 & 41.59 \\
\hline 19 & 27.68 & 30.92 & 37.61 & 28.57 & 31.91 & 38.82 & 30.34 & 33.89 & 41.22 \\
\hline 20 & 27.53 & 30.75 & 37.40 & 28.39 & 31.70 & 38.57 & 30.10 & 33.61 & 40.89 \\
\hline 21 & 27.39 & 30.59 & 37.21 & 28.22 & 31.52 & 38.34 & 29.87 & 33.36 & 40.59 \\
\hline 22 & 27.26 & 30.45 & 37.04 & 28.07 & 31.35 & 38.14 & 29.67 & 33.14 & 40.31 \\
\hline 23 & 27.15 & 30.32 & 36.88 & 27.93 & 31.19 & 37.95 & 29.48 & 32.93 & 40.06 \\
\hline 24 & 27.04 & 30.20 & 36.74 & 27.80 & 31.05 & 37.77 & 29.31 & 32,73 & 39.82 \\
\hline 25 & 36.94 & 30.00 & 36.60 & 37.68 & 30.01 & 37.61 & 20.16 & 32,66 & $30: 61$ \\
\hline 26 & 26.84 & 29.98 & 36.48 & 27.57 & 30.79 & 37.46 & 29.00 & 32.39 & 39.41 \\
\hline 27 & 26.76 & 29.88 & 36.36 & 27.46 & 30.67 & 37.32 & 28.86 & 32.23 & 39.22 \\
\hline 28 & 26.68 & 29.79 & 36.25 & 27.37 & 30.57 & 37.19 & 28.73 & 32.09 & 39.04 \\
\hline 29 & 26.60 & 29.71 & 36.15 & 27.28 & 30.47 & 37.07 & 28.61 & 31.95 & 38.88 \\
\hline 30 & 26.53 & 29.63 & 36.05 & 27.19 & 30.37 & 36.95 & 28.49 & 31.82 & 38.72 \\
\hline 35 & 26.23 & 29.29 & 35.64 & 26.83 & 29.97 & 36.46 & 28.01 & 31.29 & 38.07 \\
\hline 40 & 26.00 & 29.04 & 35.33 & 26.55 & 29.66 & 36.09 & 27.64 & 30.87 & 37.56 \\
\hline 45 & 25.81 & 28.83 & 35.08 & 26.33 & 29.41 & 35.78 & 27.34 & 30.54 & 37.16 \\
\hline 50 & 25.66 & 28.66 & 34.87 & 26.14 & 29.20 & 35.54 & 27.09 & 30.26 & 36.82 \\
\hline 60 & 25.42 & 28.39 & 34.55 & 25.86 & 28.88 & 35.15 & 26.71 & 29.83 & 36.30 \\
\hline 70 & 25.24 & 28.20 & 34.31 & 25.65 & 28.65 & 34.86 & 26.42 & 29.51 & 35.91 \\
\hline 80 & 25.11 & 28.04 & 34.13 & 25.48 & 28.46 & 34.63 & 26.20 & 29.26 & 35.61 \\
\hline 90 & 25.00 & 27.92 & 33.98 & 25.34 & 28.31 & 34.45 & 26.02 & 29.06 & 35.36 \\
\hline 100 & 24.90 & 27.82 & 33.85 & 25.23 & 28.19 & 34.30 & 25.87 & 28.89 & 35.16 \\
\hline 200 & 24.44 & 27.30 & 33.22 & 24.67 & 27.55 & 33.53 & 25.10 & 28.04 & 34.12 \\
\hline 500 & 24.08 & 26.89 & 32.73 & 24.22 & 27.05 & 32.92 & 24.48 & 27.35 & 33.28 \\
\hline$\infty$ & 23.54 & 26.30 & 32.00 & 23.54 & 26.30 & 32.00 & 23.54 & 26.30 & 32.00 \\
\hline
\end{tabular}


Table D-16

H VALUES $(C=17)$

\begin{tabular}{|c|c|c|c|c|c|c|c|c|c|}
\hline \multirow[b]{2}{*}{$N$} & \multicolumn{3}{|c|}{$\gamma=0.90$} & \multicolumn{3}{|c|}{$\gamma=0.95$} & \multicolumn{3}{|c|}{$\gamma=0.99$} \\
\hline & $P=0.90$ & $P=0.95$ & $P=0.99$ & $P=0.90$ & $P=0.95$ & $P=0.99$ & $\bar{P}:=0.90$ & $P=0.95$ & $P=0.99$ \\
\hline 2 & 61.49 & 68.01 & 81.32 & 71.52 & 79.10 & 94.57 & 96.88 & 107.16 & 128.12 \\
\hline 3 & 46.41 & 51.48 & 61.88 & 51.31 & 56.92 & 68.41 & 62.53 & 69.36 & 83.36 \\
\hline 4 & 40.68 & 45.19 & 54.45 & 44.07 & 48.96 & 58.99 & 51.52 & 57.23 & 68.96 \\
\hline 5 & 37.58 & 41.77 & 50.41 & 40.23 & 44.72 & 53.97 & 45.92 & 51.05 & 61.60 \\
\hline 6 & 35.60 & 39.59 & 47.82 & 37.81 & 42.06 & 50.79 & 42.49 & 47.26 & 57.08 \\
\hline 7 & 34.22 & 38.07 & 46.00 & 36.14 & 40.21 & 48.59 & 40.16 & 44.68 & 54.00 \\
\hline 8 & 33.19 & 36.94 & 44.66 & 34.91 & 38.84 & 46.96 & 38.46 & 42.80 & 51.74 \\
\hline 9 & 32.40 & 36.06 & 43.61 & 33.96 & 37.79 & 45.71 & 37.15 & 41.35 & 50.01 \\
\hline 10 & 31.77 & 35.36 & 42.77 & 33.20 & 36.95 & 44.70 & 36.12 & 40.21 & 48.64 \\
\hline 11 & 31.25 & 34.79 & 42.09 & 32.58 & 36.27 & 43.88 & 35.28 & 39.28 & 47.52 \\
\hline 12 & 30.82 & 34.31 & 41.51 & 32.06 & 35.69 & 43.19 & 34.58 & 38.50 & 46.59 \\
\hline 13 & 30.45 & 33.90 & 41.02 & 31.62 & 35.21 & 42.60 & 33.99 & 37.85 & 45.80 \\
\hline 14 & 30.13 & 33.55 & 40.60 & 31.24 & 34.79 & 42.10 & 33.48 & 37.28 & 45.12 \\
\hline 15 & 29.85 & 33.24 & 40.23 & 30.91 & 34.42 & 41.66 & 33.04 & 36.79 & 44.53 \\
\hline 16 & 29.61 & 32.97 & 39.91 & 30.62 & 34.10 & 41.27 & 32.65 & 36.36 & 44.01 \\
\hline 17 & 29.39 & 32.73 & 39.62 & 30.37 & 33.81 & 40.93 & 32.31 & 35.98 & 43.55 \\
\hline 18 & 29.20 & 32.52 & 39.36 & 30.14 & 33.56 & 40.62 & 32.00 & 35.63 & 43.14 \\
\hline 19 & 29.03 & 32.32 & 39.13 & 29.93 & 33.33 & 40.35 & 31.72 & 35.33 & 42.77 \\
\hline 20 & 28.87 & 32.15 & 38.92 & 29.74 & 33.12 & 40.09 & 31.47 & 35.05 & 42.43 \\
\hline 21 & $28 . \% 2$ & 31.99 & 38.73 & 29.57 & 32.93 & 39.87 & 31.24 & 34.79 & 42.12 \\
\hline 22 & 28.59 & 31.84 & 38.55 & 29.41 & 32.75 & 39.66 & 31.04 & 34.56 & 41.84 \\
\hline 23 & 28.47 & 31.71 & 38.39 & 29.27 & 32.59 & 39.46 & 30.84 & 34.35 & 41.59 \\
\hline 24 & 28.36 & 31.58 & 38.24 & 29.14 & 32.45 & 39.28 & 30.67 & 34.15 & 41.35 \\
\hline 25 & 28.26 & 31.47 & 38.10 & 29.01 & 32.31 & 39.12 & 30.50 & 33.97 & 41.13 \\
\hline 26 & 28.16 & 31.36 & 37.97 & 28.90 & 32.18 & 38.97 & 30.35 & 33.80 & 40.92 \\
\hline 27 & 28.07 & 31.26 & 37.85 & 28.79 & 32.06 & 38.82 & 30.21 & 33.64 & 40.73 \\
\hline 28 & 27.99 & 31.17 & 37.74 & 28.69 & 31.95 & 38.69 & 30.07 & 33.49 & 40.55 \\
\hline 29 & 27.91 & 31.08 & 37.64 & 28.60 & 31.85 & 38.56 & 29.95 & 33.35 & 40.39 \\
\hline 30 & 27.84 & 31.00 & 37.54 & 28.51 & 31.75 & 38.45 & 29.83 & 33.22 & 40.23 \\
\hline 35 & 27.53 & 30.66 & 37.12 & 28.14 & 31.34 & 37.95 & 29.34 & 32.68 & 39.57 \\
\hline 40 & 27.29 & 30.39 & 36.80 & 27.85 & 31.02 & 37.56 & 28.96 & 32.25 & 39.05 \\
\hline 45 & 27.10 & 30.18 & 36.54 & 27.62 & 30.77 & 37.26 & 28.65 & 31.91 & 38.64 \\
\hline 50 & 26.94 & 30.00 & 36.33 & 27.44 & 30.56 & 37.00 & 28.40 & 31.63 & 38.30 \\
\hline 60 & 26.70 & 29.73 & 36.01 & $27: 14$ & 30.23 & 36.61 & 28.01 & 31.19 & 37.78 \\
\hline 70 & 26.52 & 29.53 & 35.76 & 26.92 & 29.99 & 36.31 & 27.71 & 30.87 & 37.38 \\
\hline $8 \cap$ & 26.37 & 29.37 & .35 .57 & 26.75 & 29.80 & 3. & 27.49 & $3 \cap 61$ & 37.07 \\
\hline 90 & 26.26 & 29.25 & 35.42 & 26.62 & 29.64 & 35.90 & 27.30 & 30.41 & 36.82 \\
\hline 100 & 26.17 & 29.14 & 35.29 & 26.50 & 29.52 & 35.74 & 27.15 & 30.23 & 36.61 \\
\hline 200 & 25.69 & 28.61 & 34.65 & 25.92 & 28.87 & 34.96 & 26.36 & 29.36 & 35.56 \\
\hline 500 & 25.32 & 28.20 & 34.15 & 25.46 & 28.35 & 34.34 & 25.73 & 28.66 & 34.70 \\
\hline$\infty$ & 24.77 & 27.59 & 33.41 & 24.77 & 27.59 & 33.41 & 24.77 & 27.59 & 33.41 \\
\hline
\end{tabular}


Table D-17

HVALUES $(C=18)$

\begin{tabular}{|c|c|c|c|c|c|c|c|c|c|}
\hline \multirow[b]{2}{*}{$N$} & \multicolumn{3}{|c|}{$\gamma=0.90$} & \multicolumn{3}{|c|}{$\gamma=0.95$} & \multicolumn{3}{|c|}{$\gamma=0.99$} \\
\hline & $P=0.90$ & $P=0.95$ & $P=0.99$ & $P=0.90$ & $P=0.95$ & $P=0.99$ & $P=0.90$ & $P=0.95$ & $P=0.99$ \\
\hline 2 & 63.43 & 69.98 & 83.32 & 73.40 & 80.99 & 96.43 & 98.38 & 108.55 & 129.24 \\
\hline 3 & 48.17 & 53.30 & 63.78 & 53.09 & 58.74 & 70.30 & 64.28 & 71.12 & 85.12 \\
\hline 4 & 42.32 & 46.89 & 56.26 & 45.74 & 50.67 & 60.80 & 53.19 & 58.94 & 70.71 \\
\hline 5 & 39.14 & 43.40 & 52.14 & 41.82 & 46.37 & 55.71 & 47.54 & 52.71 & 63.32 \\
\hline 6 & 37.11 & 41.17 & 49.51 & 39.35 & 43.65 & 52.49 & 44.06 & 48.88 & 58.77 \\
\hline 7 & 35.70 & 39.61 & 47.66 & 37.64 & 41.77 & 50.26 & 41.69 & 46.26 & 55.66 \\
\hline 8 & 34.64 & 38.45 & 46.28 & 36.38 & 40.38 & 48.60 & 39.96 & 44.35 & 53.38 \\
\hline 9 & 33.83 & 37.55 & 45.22 & 35.41 & 39.30 & 47.32 & 38.63 & 42.89 & 51.63 \\
\hline 10 & 33.18 & 36.84 & 44.36 & 34.63 & 38.44 & 46.30 & 37.58 & 41.72 & 50.25 \\
\hline 11 & 32.65 & 36.25 & 43.66 & 33.99 & 37.74 & 45.46 & 36.73 & 40.78 & 49.11 \\
\hline 12 & 32.20 & 35.75 & 43.07 & 33.46 & 37.16 & 44.76 & 36.01 & 39.99 & 48.17 \\
\hline 13 & 31.82 & 35.34 & 42.57 & 33.01 & 36.66 & 44.16 & 35.41 & 39.32 & 47.37 \\
\hline 14 & 31.50 & 34.98 & 42.14 & 32.62 & 36.23 & 43.65 & 34.89 & 38.75 & 46.68 \\
\hline 15 & 31.21 & 34.66 & 41.76 & 32.29 & 35.85 & 43.20 & 34.44 & 38.25 & 46.09 \\
\hline 16 & 30.96 & 34.38 & 41.43 & 31.99 & 35.53 & 42.81 & 34.04 & 37.81 & 45.56 \\
\hline 17 & 30.74 & 34.14 & 41.14 & 31.73 & 35.23 & 42.46 & 33.69 & 37.42 & 45.09 \\
\hline 18 & 30.54 & 33.92 & 40.88 & 31.49 & 34.97 & 42.15 & 33.38 & 37.07 & 44.67 \\
\hline 19 & 30.36 & 33.72 & 40.64 & 31.28 & 34.74 & 41.86 & 33.09 & 36.76 & 44.30 \\
\hline 20 & 30.20 & 33.54 & 40.42 & 31.08 & 34.52 & 41.61 & 32.84 & 36.47 & 43.96 \\
\hline 21 & 30.05 & 33.38 & 40.23 & 30.91 & 34.33 & 41.37 & 32.61 & 36.21 & 43.65 \\
\hline 22 & 29.92 & 33.23 & 40.05 & 30.75 & 34.15 & 41.16 & 32.39 & 35.98 & 43.36 \\
\hline 23 & 29.79 & 33.09 & 39.88 & 30.60 & 33.99 & 40.96 & 32.20 & 35.76 & 43.10 \\
\hline 24 & 29.68 & 32.96 & 39.73 & 30.46 & 33.83 & 40.78 & 32.01 & 35.56 & 42.86 \\
\hline 25 & 29.57 & 32.84 & 39.59 & 30.34 & 33.69 & 40.61 & 31.85 & 35.37 & 42.64 \\
\hline 26 & 29.47 & 32.73 & 39.46 & 30.22 & 33.56 & 40.46 & 31.69 & 35.20 & 42.43 \\
\hline 27 & 29.38 & 32.63 & 39.33 & 30.11 & 33.44 & 40.31 & 31.55 & 35.04 & 42.23 \\
\hline 28 & 29.29 & 32.54 & 39.22 & 30.01 & 33.33 & 40.18 & 31.41 & 34.89 & 42.05 \\
\hline 29 & 29.21 & 32.45 & 39.11 & 29.91 & 33.22 & 40.05 & 31.28 & 34.75 & 41.88 \\
\hline 30 & 29.14 & 32.36 & 39.01 & 29.82 & 33.12 & 39.93 & 31.16 & 34.61 & 41.72 \\
\hline 35 & 28.82 & 32.01 & 38.59 & 29.44 & 32.70 & 39.42 & 30.66 & 34.05 & 41.05 \\
\hline 40 & 28.57 & 31.74 & 38.26 & 29.15 & 32.38 & 39.03 & 30.27 & 33.62 & 40.53 \\
\hline 45 & 28.38 & 31.52 & 38.00 & 28.91 & 32.12 & 38.72 & 29.96 & 33.27 & 40.11 \\
\hline 50 & 28.22 & 31.34 & 37.78 & 28.72 & 31.90 & 38.46 & 29.70 & 32.99 & 39.77 \\
\hline 60 & 27.97 & 31.06 & 37.45 & 28.42 & 31.57 & 38.06 & 29.30 & 32.54 & 39.23 \\
\hline 70 & 27.78 & 30.86 & 37.20 & 28.19 & 31.32 & 37.76 & 29.00 & 32.21 & 38.83 \\
\hline 80 & 27.63 & 30.69 & 37.01 & 28.02 & 31.12 & 37.52 & 28.76 & 31.95 & 38.52 \\
\hline 90 & 27.52 & 30.56 & 36.85 & 27.88 & 30.97 & 37.33 & 28.57 & 31.74 & 38.27 \\
\hline 100 & 27.42 & 30.46 & 36.72 & 27.76 & 30.84 & 37.18 & 28.42 & 31.57 & 38.06 \\
\hline 200 & 26.93 & 29.92 & 36.07 & 27.17 & 30.18 & 36.38 & 27.61 & 30.67 & 36.98 \\
\hline 500 & 26.55 & 29.49 & 35.55 & 26.69 & 29.65 & 35.75 & 26.97 & 29.96 & 36.12 \\
\hline$\infty$ & 25.99 & 28.87 & 34.81 & 25.99 & 28.87 & 34.81 & 25.99 & 28.87 & .34 .81 \\
\hline
\end{tabular}


Table D-18

H VALUES $(C=19)$

\begin{tabular}{|c|c|c|c|c|c|c|c|c|c|}
\hline \multirow[b]{2}{*}{$N$} & \multicolumn{3}{|c|}{$\gamma=0.90$} & \multicolumn{3}{|c|}{$\gamma=0.95$} & \multicolumn{3}{|c|}{$\gamma=0.99$} \\
\hline & $P=0.90$ & $P=0.95$ & $P=0.99$ & $P=0.90$ & $P=0.95$ & $P=0.99$ & $P=0.90$ & $P=0.95$ & $P=0.99$ \\
\hline 2 & 65.37 & 71.96 & 85.35 & 75.30 & 82.89 & 98.32 & 99.86 & 109.92 & 130.38 \\
\hline 3 & 49.92 & 55.10 & 65.69 & 54.86 & 60.56 & 72.19 & 66.01 & 72.87 & 86.86 \\
\hline 4 & 43.96 & 48.59 & 58.06 & 47.39 & 52.38 & 62.59 & 54.86 & 60.64 & 72.46 \\
\hline 5 & 40.70 & 45.02 & 53.87 & 43.40 & 48.01 & 57.44 & 49.14 & 54.36 & 65.04 \\
\hline 6 & 38.62 & 42.74 & 51.18 & 40.88 & 45.24 & 54.18 & 45.62 & 50.49 & 60.46 \\
\hline 7 & 37.17 & 41.14 & 49.30 & 39.13 & 43.32 & 51.91 & 43.21 & 47.84 & 57.32 \\
\hline 8 & 36.09 & 39.96 & 47.90 & 37.84 & 41.90 & 50.23 & 41.45 & 45.90 & 55.02 \\
\hline 9 & 35.25 & 39.04 & 46.81 & 36.85 & 40.80 & 48.92 & 40.10 & 44.41 & 53.25 \\
\hline 10 & 34.58 & 38.30 & 45.94 & 36.05 & 39.93 & 47.88 & 39.03 & 43.23 & 51.85 \\
\hline 11 & 34.04 & 37.70 & 45.22 & 35.40 & 39.21 & 47.03 & 38.16 & 42.27 & 50.70 \\
\hline 12 & 33.58 & 37.19 & 44.62 & 34.86 & 38.61 & 46.32 & 37.44 & 41.46 & 49.74 \\
\hline 13 & 33.19 & 36.76 & 44.11 & 34.40 & 38.10 & 45.71 & 36.82 & 40.79 & 48.93 \\
\hline 14 & 32.85 & 36.39 & 43.67 & 34.00 & 37.66 & 45.19 & 36.29 & 40.20 & 48.24 \\
\hline 15 & 32.56 & 36.07 & 43.29 & 33.65 & 37.28 & 44.73 & 35.83 & 39.69 & 47.63 \\
\hline 16 & 32.30 & 35.79 & 42.95 & 33.35 & 36.94 & 44.33 & 35.43 & 39.25 & 47.10 \\
\hline 17 & 32.08 & 35.54 & 42.65 & 33.08 & 36.64 & 43.98 & 35.07 & 38.85 & 46.62 \\
\hline 18 & 31.87 & 35.31 & 42.38 & 32.83 & 36.38 & 43.66 & 34.75 & 38.49 & 46.20 \\
\hline 19 & 31.69 & 35.11 & 42.13 & 32.62 & 36.13 & 43.37 & 34.46 & 38.18 & 45.82 \\
\hline 20 & 31.52 & 34.92 & 41.92 & 32.42 & 35.92 & 43.11 & 34.20 & 37.89 & 45.47 \\
\hline 21 & 31.37 & 34.75 & 41.71 & 32.24 & 35.72 & 42.87 & 33.96 & 37.62 & 45.16 \\
\hline 22 & 31.23 & 34.60 & 41.53 & 32.07 & 35.54 & 42.65 & 33.74 & 37.38 & 44.87 \\
\hline 23 & 31.10 & 34.46 & 41.36 & 31.92 & 35.37 & 42.45 & 33.54 & 37.16 & 44.60 \\
\hline 24 & 30.98 & 34.33 & 41.21 & 31.78 & 35.21 & 42.27 & 33.35 & 36.96 & 44.36 \\
\hline 25 & 30.88 & 34.21 & 41.06 & 31.65 & 35.07 & 42.10 & 33.18 & 36.77 & 44.13 \\
\hline 26 & 30.77 & 34.10 & 40.93 & 31.53 & 34.94 & 41.94 & 33.02 & 36.59 & 43.92 \\
\hline 27 & 30.68 & 33.99 & 40.80 & 31.42 & 34.81 & 41.79 & 32.88 & 36.43 & 43.73 \\
\hline 28 & 30.59 & 33.89 & 40.69 & 31.32 & 34.70 & 41.65 & 32.74 & 36.27 & 43.54 \\
\hline 29 & 30.51 & 33.80 & 40.58 & 31.22 & 34.59 & 41.52 & 32.61 & 36.13 & 43.37 \\
\hline 30 & 30.43 & 33.72 & 40.48 & 31.12 & 34.49 & 41.40 & 32.49 & 35.99 & 43.21 \\
\hline 35 & 30.10 & 33.35 & 40.04 & 30.74 & 34.06 & 40.88 & 31.97 & 35.42 & 42.53 \\
\hline 40 & 29.85 & 33.08 & 39.71 & 30.43 & 33.72 & 40.48 & 31.57 & 34.98 & 42.00 \\
\hline 45 & 29.65 & 32.85 & 39.44 & 30.19 & 33.46 & 40.16 & 31.25 & 34.63 & 41.57 \\
\hline 50 & 29.48 & 32.67 & 39.22 & 30.00 & 33.24 & 39.90 & 30.99 & 34.34 & 41.22 \\
\hline $6 \cap$ & 29.23 & 32.38 & 38.88 & 29.69 & 32.90 & 39.49 & 30.58 & 33.88 & 40.68 \\
\hline 70 & 29.03 & 32.17 & 38.63 & 29.46 & 32.64 & 39.19 & 30.27 & 33.55 & 40.27 \\
\hline 80 & 2889 & $32 \cap 1$ & $.38,4.3$ & 29.28 & 32.44 & 38.95 & 30.03 & 33.28 & 39.96 \\
\hline 90 & 28.77 & 31.87 & 38.27 & 29.13 & 32.28 & 38.76 & 29.84 & 33.07 & 39.70 \\
\hline 100 & 28.67 & 31.76 & 38.14 & 29.01 & 32.15 & 38.60 & 29.68 & 32.89 & 39.48 \\
\hline 200 & 28.17 & 31.21 & 37.47 & 28.41 & 31.48 & 37.79 & 28.86 & 31.98 & 38.40 \\
\hline 500 & 27.77 & 30.78 & 36.95 & 27.92 & 30.94 & 37.15 & 28.20 & 31.25 & 37.52 \\
\hline$\infty$ & 27.20 & 30.14 & 36.19 & 27.20 & 30.14 & 36.19 & 27.20 & 30.14 & 36.19 \\
\hline
\end{tabular}


Table D-19

H VALUES $(C=20)$

\begin{tabular}{|c|c|c|c|c|c|c|c|c|c|}
\hline \multirow[b]{2}{*}{$\mathrm{N}$} & \multicolumn{3}{|c|}{$\gamma=0.90$} & \multicolumn{3}{|c|}{$\boldsymbol{\gamma}=0.95$} & \multicolumn{3}{|c|}{$\gamma=0.99$} \\
\hline & $P=0.90$ & $P=0.95$ & $P=0.99$ & $P=0.90$ & $P=0.95$ & $P=0.99$ & $P=0.90$ & $P=0.95$ & $P=0.99$ \\
\hline 2 & 67.32 & 73.95 & 87.39 & 77.20 & 84.80 & 100.22 & 101.49 & 111.48 & 131.76 \\
\hline 3 & 51.65 & 56.89 & 67.57 & 56.62 & 62.36 & 74.06 & 67.79 & 74.66 & 88.67 \\
\hline 4 & 45.58 & 50.27 & 59.85 & 49.04 & 54.08 & 64.38 & 56.53 & 62.35 & 74.22 \\
\hline 5 & 42.25 & 46.63 & . $\quad 55.59$ & 44.98 & 49.64 & 59.17 & 50.75 & 56.01 & 66.76 \\
\hline 6 & 40.12 & 44.30 & $\therefore \quad 52.85$ & 42.40 & 46.82 & 55.86 & 47.17 & 52.09 & 62.14 \\
\hline 7 & 38.63 & 42.67 & 50.93 & 40.62 & 44.86 & 53.55 & 44.73 & 49.40 & 58.97 \\
\hline 8 & 37.52 & 41.45 & 49.50 & 39.30 & 43.41 & 51.84 & 42.94 & 47.43 & 56.64 \\
\hline 9 & 36.67 & 40.51 & 48.39 & 38.28 & 42.29 & 50.52 & 41.57 & 45.92 & 54.86 \\
\hline 10 & 35.48 & 39.76 & 47.50 & 37.47 & 41.40 & $49.4 \overline{6}$ & 40.48 & 44.73 & 53.43 \\
\hline 11 & 35.42 & 39.14 & 46.77 & 36.80 & 40.66 & 48.59 & 39.59 & 43.75 & 52.27 \\
\hline 12 & 34.95 & 38.62 & 46.16 & 36.24 & 40.05 & 47.87 & 38.85 & 42.93 & 51.31 \\
\hline 13 & 34.55 & 38.18 & 45.64 & 35.77 & 39.53 & 47.25 & 38.22 & 42.24 & 50.49 \\
\hline 14 & 34.20 & 37.80 & 45.19 & 35.36 & 39.08 & 46.72 & 37.68 & 41.65 & 49.78 \\
\hline .15 & 33.90 & 37.47 & 44.79 & 35.01 & 38.69 & 46.25 & 37.21 & 41.13 & 49.17 \\
\hline 16 & 33.64 & 37.18 & 44.45 & . $\quad 34.70$ & 38.35 & $45.85^{\circ}$ & 36.80 & 40.68 & 48.63 \\
\hline 17 & 33.41 & 36.92 & 44.14 & 34.42 & 38.04 & 45.48 & 36.43 & 40.27 & 48.14 \\
\hline 18 & 33.20 & 36.69 & 43.87 & 34.17 & 37.77 & 45.16 & 36.11 & .39 .91 & 47.72 \\
\hline 19 & 33.01 & 36.48 & 43.62 & 33.95 & 37.52 & 44.86 & 35.81 & 39.59 & 47.33 \\
\hline 20 & 32.84 & 36.30 & 43.40 & 33.75 & 37.30 & 44.60 & 35.55 & 39.29 & 46.98 \\
\hline 21 & 32.68 & 36.12 & 43.19 & 3356 & .37 .10 & 44.36 & $35.3 n$ & $39.0 ?$ & 46.66 \\
\hline 22 & 32.54 & 35.97 & 43.00 & 33.39 & 36.91 & 44.11 & 35.08 & 38.78 & 46.37 \\
\hline 23 & 32.41 & 35.82 & 42.83 & 33.24 & 36.74 & 43.93 & 34.88 & 38.55 & 46.10 \\
\hline 24 & 32.29 & 35.60 & 42.67 & 33.09 & 36.58 & 43.74 & 34.69 & 38.34 & 45.85 \\
\hline 25 & 32.17 & 35.56 & 42.53 & 32.96 & 36.44 & 43.57 & 3451 & 3815 & $456 ?$ \\
\hline 26 & 32.07 & 35.45 & 42.39 & 32.84 & 36.30 & 43.41 : & 34.35 & 37.97 & 46.41 \\
\hline 27 & $31.97^{\circ}$ & 35.34 & 42.26 & 32.72 & 36.17 & 43.26 & 34.20 & 37.80 & 45.21 \\
\hline 28 & 31.88 & 35.24 & 42.14 & 32.62 & 36.06 & 43.12 & 34.06 & 37.65 & 45.02 \\
\hline 29 & 31.80 & 35.15 & 42.03 & 32.52 & 35.94 & 42.98 & 33.92 & 37.50 & 11.86 \\
\hline 30 & 31.72 & 35.08 & 41.93 & 32.42 & 35.84 & 42.86 & 33.80 & 31.36 & 44.68 \\
\hline 35 & 31.38 & 34.69 & 41.49 & 32.02 & 35.40 & 42.33 & 33.27 & 36.78 & 43.99 \\
\hline 40 & 31.12 & 34.40 & 41.14 & 31.71 & 35.06 & 41.93 & 32.87 & 36.33 & 43.45 \\
\hline 45 & 30.91 & 34.18 & 40.87 & 31.47 & 34.79 & 41.60 & 32.54 & 35.97 & 43.02 \\
\hline 50 & 30.74 & 33.99 & 40.65 & 31.26 & 34.56 & 41.34 & 32.27 & 35.68 & 42.67 \\
\hline 60 & 30.40 & 33.70 & 40.30 & 30.95 & 34.22 & 40.92 & 31.86 & 35.22 & 42.12 \\
\hline 70 & 30.28 & 33.48 & 40.04 & 30.71 & 33.96 & 40.61 & 31.54 & 34.87 & 41.70 \\
\hline 80 & 30.13 & 33.31 & 39.84 & 30.53 & 33.75 & 40.37 & 31.30 & 34.60 & 41.38 \\
\hline 90 & 30.01 & 33.18 & 39.68 & 30.38 & 33.59 & 40.17 & 31.10 & 34.38 & 41.12 \\
\hline 100 & 29.91 & 33.06 & 39.54 & 30.26 & 33.45 & 40.01 & 30.94 & 34.20 & 40.90 \\
\hline 200 & 29.40 & 32.50 & 38.87 & 29.64 & 32.77 & 39.19 & 30.10 & 33.28 & 39.80 \\
\hline 500 & 28.99 & 32.05 & 38.34 & 29.14 & 32.22 & 38.53 & 29.43 & 32.54 & 38.91 \\
\hline$\infty$ & 28.41 & 31.41 & 37.57 & 28.41 & 31.41 & 37.57 & 28.41 & 31.41 & 37.57 \\
\hline
\end{tabular}


Table D-20

$H$ VALUES $(C=21)$

\begin{tabular}{|c|c|c|c|c|c|c|c|c|c|}
\hline \multirow[b]{2}{*}{$N$} & \multicolumn{3}{|c|}{$\gamma=0.90$} & \multicolumn{3}{|c|}{$\gamma=0.95$} & \multicolumn{3}{|c|}{$\gamma=0.99$} \\
\hline & $P=0.90$ & $P=0.95$ & $P=0.99$ & $P=0.90$ & $P=0.95$ & $P=0.99$ & $P=0.90$ & $P=0.95$ & $P=0.99$ \\
\hline 2 & 69.26 & 75.93 & 89.44 & 79.12 & 86.73 & 102.16 & 103.18 & 113.12 & 133.24 \\
\hline 3 & 53.39 & 58.68 & 69.45 & 58.37 & 64.16 & 75.94 & 69.53 & 76.43 & 90.46 \\
\hline 4 & 47.20 & 51.95 & 61.62 & 50.68 & 55.78 & 66.17 & 58.20 & 64.05 & 75.98 \\
\hline 5 & 43.80 & 48.23 & 57.29 & 46.54 & 51.26 & 60.88 & 52.34 & 57.65 & 68.47 \\
\hline 6 & 41.62 & 45.85 & 54.51 & 43.92 & 48.39 & 57.53 & 48.72 & 53.68 & 63.81 \\
\hline 7 & 40.09 & 44.18 & 52.55 & 42.10 & 46.39 & 55.18 & 46.24 & 50.96 & 60.61 \\
\hline 8 & 38.95 & 42.94 & 51.09 & 40.75 & 44.92 & 53.44 & 44.42 & 48.96 & 58.26 \\
\hline 9 & 38.07 & 41.98 & 49.96 & 39.70 & 43.77 & 52.10 & 43.02 & 47.43 & 56.45 \\
\hline 10 & 37.37 & 41.21 & 49.05 & 38.87 & 42.86 & 51.02 & 41.91 & 46.21 & 55.02 \\
\hline 11 & 36.79 & 40.57 & 48.31 & 38.19 & 42.11 & 50.14 & 41.01 & 45.22 & 53.84 \\
\hline 12 & 36.31 & 40.04 & 47.68 & 37.62 & 41.49 & 49.40 & 40.26 & 44.39 & 52.86 \\
\hline 13 & 35.90 & 39.59 & 47.15 & 37.14 & 40.96 & 48.78 & 39.62 & 43.69 & 52.03 \\
\hline 14 & 35.55 & 39.21 & 46.69 & 36.72 & 40.50 & 48.23 & 39.07 & 43.09 & 51.31 \\
\hline 15 & 35.24 & 38.87 & 46.29 & 36.36 & 40.10 & 47.76 & 38.59 & 42.56 & 50.69 \\
\hline 16 & 34.97 & 38.57 & 45.94 & 36.04 & 39.75 & 47.35 & 38.17 & 42.10 & 50.14 \\
\hline 17 & 34.73 & 38.30 & 45.63 & 35.76 & 39.44 & 46.98 & 37.80 & 41.69 & 49.66 \\
\hline 18 & 34.51 & 38.07 & 45.35 & 35.50 & 39.16 & 46.65 & 37.46 & 41.32 & 49.22 \\
\hline 19 & 34.32 & 37.85 & 45.10 & 35.27 & 38.91 & 46.35 & 37.16 & 40.99 & 48.83 \\
\hline 20 & 34.14 & 37.66 & 44.87 & 35.07 & 38.68 & 46.08 & 36.89 & 40.69 & 48.47 \\
\hline 21 & 33.98 & 37.49 & 44.66 & 34.88 & 38.47 & 45.83 & 36.64 & 40.42 & 48.15 \\
\hline 22 & 33.84 & 37.32 & 44.47 & 34.71 & 38.28 & 45.61 & 36.41 & 40.17 & 47.85 \\
\hline 23 & 33.70 & 37.18 & 44.29 & 34.55 & 38.11 & 45.40 & 36.21 & 39.94 & 47.58 \\
\hline 24 & 33.58 & 37.04 & 44.13 & 34.40 & 37.95 & 45.21 & 36.01 & 39.72 & 47.33 \\
\hline 25 & 33.46 & 36.91 & 43.98 & 34.26 & 37.80 & 45.03 & 35.84 & 39.53 & 47.10 \\
\hline 26 & 33.36 & 36.80 & 43.84 & 34.14 & 37.66 & 44.87 & 35.67 & 39.35 & 46.88 \\
\hline 27 & 33.26 & 36.69 & 43.71 & 34.02 & 37.53 & 44.71 & 35.52 & 39.18 & 46.68 \\
\hline 28 & 33.17 & 36.58 & 43.59 & 33.91 & 37.41 & 44.57 & 35.37 & 39.02 & 46.49 \\
\hline 29 & 33.08 & 36.49 & 43.48 & 33.81 & 37.29 & 44.43 & 35.24 & 38.87 & 46.31 \\
\hline 30 & 33.00 & 36.40 & 43.37 & 33.71 & 37.19 & 44.31 & 35.11 & 38.73 & 46.14 \\
\hline 35 & 32.65 & 36.02 & 42.92 & 33.30 & 36.74 & 43.77 & 34.57 & 38.14 & 45.44 \\
\hline 40 & 32.39 & 35.73 & 42.57 & 32.99 & 36.39 & 43.36 & 34.16 & 37.68 & 44.90 \\
\hline 45 & 32.17 & 35.49 & 12.29 & 32.74 & 36.11 & 43.03 & 33.82 & 37.31 & 44.46 \\
\hline 50 & 32.00 & 35.30 & 42.06 & 32.53 & 35.88 & 42.76 & 33.55 & 37.01 & 44.10 \\
\hline 60 & 31.73 & 35.00 & 41.71 & 32.21 & 35.53 & 42.34 & 33.12 & 36.54 & 43.54 \\
\hline 70 & 31.53 & 34.78 & 41.45 & 31.97 & 35.26 & 42.02 & 32.81 & 36.19 & 43.13 \\
\hline 80 & 31.37 & 34.61 & 41.24 & 31.78 & 35,06 & 41.77 & 32.56 & 35.92 & 42.80 \\
\hline 90 & 31.25 & 34.47 & 41.08 & 31.63 & 34.89 & 41.57 & 32.35 & 35.69 & 42.53 \\
\hline 100 & 31.14 & 34.35 & 40.94 & 31.50 & 34.75 & $41: 41$ & 32.19 & 35.51 & 42.31 \\
\hline 200 & 30.62 & 33.78 & 40.25 & 30.87 & 34.05 & 40.58 & 31.34 & 34.57 & 41.19 \\
\hline 500 & 30.21 & 33.32 & 39.71 & 30.36 & 33.49 & 39.91 & 30.65 & 33.81 & 40.29 \\
\hline$\infty$ & 29.62 & 32.67 & 38.93 & 29.62 & 32.67 & 38.93 & 29.62 & 32.67 & 38.93 \\
\hline
\end{tabular}


Table D-21

H VALUES $(C=22)$

\begin{tabular}{|c|c|c|c|c|c|c|c|c|c|}
\hline \multirow[b]{2}{*}{$N$} & \multicolumn{3}{|c|}{$\gamma=0.90$} & \multicolumn{3}{|c|}{$\gamma=0.95$} & \multicolumn{3}{|c|}{$\gamma=0.99$} \\
\hline & $P=0.90$ & $P=0.95$ & $P=0.99$ & $P=0.90$ & $P=0.95$ & $P=0.99$ & $\overline{\mathrm{P}}=0.90$ & $P=0.95$ & $P=0.99$ \\
\hline 2 & 71.21 & 77.92 & 91.49 & 81.04 & 88.68 & 104.13 & 104.92 & 114.81 & 134.81 \\
\hline 3. & 55.12 & 60.47 & 71.34 & 60.12 & 65.96 & 77.82 & 71.28 & 78.20 & 92.25 \\
\hline 4 & 48.81 & 53.61 & 63.39 & 52.32 & 57.46 & 67.95 & 59.85 & 65.74 & 77.74 \\
\hline 5 & 45.33 & 49.83 & 58.99 & 48.10 & 52.87 & 62.59 & 53.93 & 59.28 & 70.18 \\
\hline 6 & 43.10 & 47.39 & 56.15 & 45.43 & 49.95 & 59.18 & 50.26 & 55.27 & 65.48 \\
\hline 7 & 41.54 & 45.69 & 54.16 & 43.56 & 47.92 & 56.80 & 47.74 & 52.51 & 62.25 \\
\hline 8 & 40.38 & 44.42 & 52.68 & 42.19 & 46.41 & 55.04 & 45.89 & 50.49 & 59.87 \\
\hline 9 & 39.47 & 43.43 & 51.52 & 41.12 & 45.25 & 53.67 & 44.47 & 48.93 & 58.04 \\
\hline 10 & 38.75 & 42.65 & 50.60 & 40.27 & 44.32 & 52.58 & 43.34 & 47.69 & 56.59 \\
\hline 11 & 38.16 & 42.00 & 49.84 & 39.58 & 43.55 & 51.68 & 42.42 & 46.69 & 55.40 \\
\hline 12 & 37.67 & 41.46 & 49.20 & 38.99 & 42.92 & 50.93 & 41.65 & 45.84 & 54.41 \\
\hline 13 & 37.25 & 41.00 & 48.66 & 38.50 & 42.37 & 50.29 & 41.00 & 45.13 & 53.56 \\
\hline 14 & 36.89 & 40.60 & 48.19 & 38.07 & 41.91 & 49.74 & 40.44 & 44.52 & 52.84 \\
\hline 15 & 36.57 & 40.25 & 47.78 & 37.70 & 41.50 & 49.26 & 39.96 & 43.98 & 52.21 \\
\hline 16 & 36.29 & 39.95 & 47.42 & 37.38 & 41.14 & 48.84 & 39.53 & 43.51 & 51.65 \\
\hline 17 & 36.05 & 39.68 & 47.10 & 37.09 & 40.82 & 48.46 & 39.15 & 43.09 & 51.16 \\
\hline 18 & 35.83 & 39.44 & 46.82 & 36.83 & 40.54 & 48.13 & 38.81 & 42.72 & 50.72 \\
\hline 19 & 35.63 & 39.22 & 46.56 & 36.59 & 40.28 & 47.82 & 38.50 & 42.38 & 50.32 \\
\hline 20 & 35.45 & 39.02 & 46.33 & 36.38 & 40.05 & 47.55 & 38.23 & 42.08 & 49.96 \\
\hline 21 & 35.28 & 38.84 & 46.12 & 36.19 & 39.84 & 47.30 & 37.97 & 41.80 & 49.63 \\
\hline 22 & 35.13 & 38.68 & 45.92 & 36.01 & 39.64 & 47.07 & 37.74 & 41.55 & 49.33 \\
\hline 23 & 35.00 & 38.52 & 45.74 & 35.85 & 39.46 & 46.86 & 37.53 & 41.31 & 49.05 \\
\hline 24 & 34.87 & 38.38 & 45.58 & 35.70 & 39.30 & 46.66 & 37.33 & 41.10 & 48.80 \\
\hline 25 & 34.75 & 38.26 & 45.42 & 35.56 & 39.15 & 46.48 & $3 / .1 \mathrm{~b}$ & $4(1.90)$ & 48.56 \\
\hline 26 & 34.64 & 38.13 & 45.28 & 35.43 & 39.01 & 46.32 & 36.98 & 40.71 & 48.34 \\
\hline 27 & 34.54 & 38.02 & 45.15 & 35.31 & 38.87 & 46.16 & 36.82 & 40.54 & 48.14 \\
\hline 28 & 34.44 & 37.92 & 45.03 & 35.20 & 38.75 & 46.01 & 36.68 & 40.38 & 47.95 \\
\hline 29 & 34.35 & 37.82 & 44.91 & 35.09 & 38.63 & 45.88 & 36.54 & 40.23 & 47.77 \\
\hline 30 & 34.27 & 37.73 & 44.80 & 34.99 & 38.53 & 45.75 & 36.41 & 40.08 & 47.60 \\
\hline 35 & 33.92 & 37.34 & 44.34. & 34.58 & 38.07 & 45.20 & 35.86 & 39.48 & 46.89 \\
\hline 40 & 33.65 & 37.04 & 43.99 & 34.26 & 37.71 & 44.78 & 35.44 & 39.02 & 46.33 \\
\hline 45 & 33.43 & 36.80 & 43.70 & 34.00 & 37.43 & 44.45 & 35.10 & 38.64 & 45.89 \\
\hline 50 & 33.25 & 36.61 & 43.47 & 33.79 & 37.20 & 44.17 & 34.82 & 38.34 & 45.53 \\
\hline 60 & 32.97 & 36.30 & 43.11 & 33.46 & 36.83 & 43.74 & 34.39 & 37.86 & 44.96 \\
\hline 70 & 32.77 & 36.08 & 42.84 & 33.21 & 36.56 & 43.42 & 34.06 & 37.50 & 44.54 \\
\hline 80 & 32.61 & 35.90 & 42.63 & 33.02 . & 36.35 & 43.17 & 33.81 & 37.22 & 44.20 \\
\hline 90 & 32.48 & 35.76 & 42.47 & 32.86 & 36.18 & 42.97 & 33.60 & 37.00 & 43.94 \\
\hline 100 & 32.37 & 35.64 & 42.33 & 32.74 & 36.04 & 42.80 & 33.43 & 36.81 & 43.71 \\
\hline 200 & 31.84 & 35.05 & 41.63 & 32.09 & 35.33 & 41.95 & 32.56 & 35.85 & 42.58 \\
\hline 500 & 31.42 & 34.59 & 41.08 & 31.57 & 34.76 & 41.28 & 31.87 & 35.08 & 41.67 \\
\hline$\infty$ & 30.81 & 33.92 & 40.29 & 30.81 & 33.92 & 40.29 & 30.81 & 33.92 & 40.29 \\
\hline
\end{tabular}


Table D-22

$H$ VALUES $(C=23)$

\begin{tabular}{|c|c|c|c|c|c|c|c|c|c|}
\hline \multirow[b]{2}{*}{$N$} & \multicolumn{3}{|c|}{$\gamma=0.90$} & \multicolumn{3}{|c|}{$\gamma=0.95$} & \multicolumn{3}{|c|}{$\gamma=0.99$} \\
\hline & $P=0.90$ & $P=0.95$ & $P=0.99$ & $\mathbf{P}=0.90$ & $P=0.95$ & $P=0.99$ & $P=0.90$ & $P=0.95$ & $P=0.99$ \\
\hline 2 & 73.15 & 79.90 & 93.54 & 82.98 & 90.64 & 106.11 & 106.60 & 116.44 & 136.32 \\
\hline 3 & 56.84 & 62.25 & 73.21 & 61.87 & 67.75 & 79.69 & 73.03 & 79.98 & 94.06 \\
\hline 4 & 50.41 & 55.27 & 65.15 & 53.94 & 59.14 & 69.71 & 61.51 & 67.44 & 79.49 \\
\hline 5 & 46.86 & 51.41 & 60.68 & 49.65 & 54.18 & 64.29 & 55.52 & 60.91 & 71.89 \\
\hline 6 & 44.58 & 48.93 & 57.79 & 46.93 & 51.51 & 60.83 & 51.79 & 56.85 & 67.14 \\
\hline 7 & 42.98 & 47.19 & 55.76 & 45.03 & 49.44 & 58.42 & 49.23 & 54.05 & 63.88 \\
\hline 8 & $41,79^{\circ}$ & 45.89 & 54.25 & 43.62 & 47.90 & 56.63 & 47.36 & 52.00 & 61.47 \\
\hline .9 & 40.87 & 44.88 & 53.07 & 42.53 & 46.71 & 55.24 & 45.91 & 50.42 & 59.62 \\
\hline 10 & 40.13 & 44.08 & 52.13 & 41.67 & 45.76 & 54.12 & 44.76 & 49.17 & 58.15 \\
\hline 11 & 39.53 & 43.42 & 51.36 & 40.95 & 44.99 & 53.21 & 43.83 & 48.14 & 56.95 \\
\hline 12 & 39.02 & 42.86 & 50.71 & 40.36 & 44.34 & 52.45 & 43.05 & 47.29 & 55.94 \\
\hline 13 & 38.59 & 42.39 & 50.16 & 39.86 & 43.78 & 51.80 & 42.38 & 46.56 & 55.09 \\
\hline 14 & 38.22 & 41.99 & 49.68 & 39.42 & 43.31 & 51.24 & 41.82 & 45.94 & 54.35 \\
\hline 15 & 37.90 & 41.63 & 49.26 & 39.04 & 42.89 & 50.75 & 41.32 & 45.39 & 53.71 \\
\hline 16 & 37.61 & 41.32 & 48.90 & 38.71 & 42.53 & 50.32 & 40.88 & 44.92 & 53.15 \\
\hline 17 & 37.36 & 41.04 & 48.57 & 38.41 & 42.20 & 49.94 & 40.50 & 44.49 & 52.65 \\
\hline 18 & 37.13 & 40.80 & 48.28 & 38.15 & 41.91 & 49.60 & 40.15 & 44.11 & 52.20 \\
\hline 19 & 36.93 & 40.57 & 48.02 & 37.91 & 41.65 & 49.29 & 39.84 & 43.77 & 51.80 \\
\hline 20 & 36.74 & 40.37 & 47.78 & 37.69 & 41.41 & 49.01 & 39.55 & 43.46 & 51.44 \\
\hline 21 & 36.58 & 40.19 & 47.56 & 37.49 & 41.20 & 48.76 & 39.30 & 43.18 & 51.10 \\
\hline 22 & 36.42 & 40.02 & 47.37 & 37.31 & 41.00 & 48.52 & 39.06 & 42.92 & 50.80 \\
\hline 23 & 36.28 & 39.86 & 47.18 & 37.15 & 40.82 & 48.31 & 38.85 & 42.68 & 50.52 \\
\hline 24 & 36.15 & 39.72 & 47.02 & 36.99 & 40.65 & 48.11 & 38.65 & 42.46 & 50.26 \\
\hline 25 & 36.03 & 39.59 & 46.86 & 36.85 & 40.49 & 47.93 & 38.46 & 42.26 & 50.02 \\
\hline 26 & 35.92 & 39.47 & 46.71 & 36.72 & 40.35 & 47.76 & 38.29 & 42.07 & 49.80 \\
\hline 27 & 35.81 & 39.35 & 46.58 & 36.60 & 40.21 & 47.60 & 38.13 & 41.90 & 49.59 \\
\hline 28 & 35.72 & 39.25 & 46.45 & 36.48 & 40.09 & 47.45 & 37.98 & 41.73 & 49.40 \\
\hline 29 & 35.62 & 39.15 & 46.34 & 36.37 & 39.97 & 47.31 & 37.84 & 41.58 & 49.21 \\
\hline 30 & 35.54 & 39.05 & 46.22 & 36.27 & 39.86 & 47.18 & 37.71 & 41.43 & 49.04 \\
\hline 35 & 35.18 & 38.65 & 45.76 & 35.85 & 39.39 & 46.63 & 37.15 & 40.82 & 48.32 \\
\hline 10 & 34.90 & 38.35 & 45.40 & 35.52 & 39.03 & 46.20 & 36.72 & 40.35 & 47.76 \\
\hline 45 & 34.68 & 38.10 & 45.11 & 35.25 & 38.74 & 45.86 & 36.37 & 39.97 & 47.31 \\
\hline 50 & 34.49 & 37.90 & 44.87 & 35.04 & 38.50 & 45.58 & 36.09 & 39.66 & 46.94 \\
\hline 60 & 34.21 & 37.59 & 44.50 & 34.70 & 38.13 & 45.14 & 35.65 & 39.17 & 46.37 \\
\hline 70 & 34.00 & 37.36 & 44.23 & 34.45 & 37.86 & 44.82 & 35.31 & 38.81 & 45.94 \\
\hline 80 & 33.84 & $3 \% .18$ & 44.02 & 34.25 & 37.64 & 44.56 & 35.06 & 38.52 & 45.60 \\
\hline 90 & 33.70 & 37.04 & 43.85 & 34.10 & 37.47 & 44.35 & 34.85 & 38.29 & 45.33 \\
\hline 100 & 33.60 & 36.92 & 43.70 & 33.97 & 37.32 & 44.19 & 34.67 & 38.10 & 45.10 \\
\hline 200 & 33.05 & 36.32 & 42.99 & 33.30 & 36.60 & 43.33 & 33.79 & 37.13 & 43.96 \\
\hline 500 & 32.62 & 35.85 & 42.44 & 32.78 & 36.02 & 42.64 & 33.08 & 36.35 & 43.03 \\
\hline$\infty$ & 32.01 & 35.17 & 41.64 . & 32.01 & 35.17 & 41.64 & 32.01 & 35.17 & 41.64 \\
\hline
\end{tabular}


Table D-23

$H$ VALUES $(C=24)$

\begin{tabular}{|c|c|c|c|c|c|c|c|c|c|}
\hline \multirow[b]{2}{*}{$N$} & \multicolumn{3}{|c|}{$\gamma=0.90$} & \multicolumn{3}{|c|}{$\gamma=0.95$} & \multicolumn{3}{|c|}{$\gamma=0.99$} \\
\hline & $P=0.90$ & $P=0.95$ & $P=0.99$ & $P=0.90$ & $\mathrm{P}=0.95$ & $P=0.99$ & $P=0.90$ & $P=0.95$ & $P=0.99$ \\
\hline 2 & 75.09 & 81.88 & 95.60 & 84.91 & 92.60 & 108.11 & 108.39 & 118.20 & 138.00 \\
\hline 3 & 58.56 & 64.02 & 75.08 & 63.61 & 69.54 & 81.56 & 74.78 & 81.75 & 95.87 \\
\hline 4 & 52.01 & 56.92 & 66.90 & 55.56 & 60.82 & 71.48 & 63.16 & 69.13 & 81.25 \\
\hline 5 & 48.38 & 52.99 & 62.36 & 51.20 & 56.07 & 65.98 & 57.10 & 62.53 & 73.59 \\
\hline ' 6 & 46.05 & 50.46 & 59.42 & 48.42 & 53.05 & 62.48 & 53.32 & 58.42 & .68 .80 \\
\hline 7 & 44.42 & 48.68 & 57.35 & 46.48 & 50.95 & 60.02 & 50.72 & 55.59 & 65.50 \\
\hline 8 & 43.20 & 47.35 & 55.81 & 45.05 & 49.38 & 58.20 & 48.81 & 53.51 & 63.07 \\
\hline 9 & 42.26 & 46.33 & 54.62 & 43.94 & 48.17 & 56.79 & 47.35 & 51.91 & 61.20 \\
\hline 10 & 41.50 & 45.50 & 53.66 & 43.05 & 47.21 & 55.66 & 46.18 & 50.63 & 59.71 \\
\hline$i 1$ & $40.88^{\circ}$ & 44.83 & 52.87 & 42.33 & 46.41 & 54.74 & 45.23 & 49.59 & 58.49 \\
\hline 12 & 40.36 & 44.26 & 52.21 & 41.72 & 45.75 & 53.96 & 44.43 & 48.73 & 57.47 \\
\hline 13 & 39.92 & 43.78 & 51.64 & 41.20 & 45.19 & 53.30 & 43.76 & 47.99 & 56.61 \\
\hline 14 & 39.54 & 43.37 & 51.16 & 40.76 & 44.70 & 52.73 & 43.18 & 47.35 & 55.86 \\
\hline 15 & 39.21 & 43.01 & 50.74 & 40.37 & 44.28 & 52.24 & 42.68 & 46.80 & 55.21 \\
\hline 16 & 38.92 & 42.69 & 50.36 & 40.03 & 43.90 & 51.80 & 42.23 & 46.32 & 54.64 \\
\hline 17 & 38.66 & 42.40 & 50.03 & 39.73 & 43.57 & 51.41 & 41.84 & 45.88 & 54.14 \\
\hline 18 & 38.43 & 42.15 & 49.73 & 39.46 & 43.28 & 51.06 & 41.48 & 45.50 & 53.68 \\
\hline 19 & 38.22 & 41.92 & 49.47 & 39.21 & 43.01 & 50.75 & 41.17 & 45.15 & 53.28 \\
\hline 20 & 38.04 & 41.72 & 49.22 & 38.99 & 42.77 & 50.46 & 40.88 & 44.84 & 52.91 \\
\hline 21 & 37.88 & 41.53 & 49.00 & 38.79 & 42.55 & 50.21 & 40.62 & 44.55 & 52.57 \\
\hline 22 & 37.71 & 41.36 & 48.80 & 38.61 & 42.35 & 49.97 & 40.38 & 44.20 & 52.26 \\
\hline 23 & 37.56 & 41.20 & 48.692 & 38.44 & 42.16 & 49.75 & 40.16 & 44.0 .5 & 5198 \\
\hline 24 & 37.43 & 41.05 & 48.44 & 38.28 & 41.99 & 49.55 & 39.95 & 43.82 & 51.71 \\
\hline 25 & 37.30 & 40.92 & 48.29 & 38.14 & 41.83 & 49.36 & 39.76 & 43.62 & $51.4 \%$ \\
\hline 26 & 37.19 & 40.79 & 48.14 & 38.00 & 41.68 & $49.19^{\circ}$ & 39.59 & 43.42 & 51.24 \\
\hline 27 & 37.08 & 40.68 & 48.00 & 37.88 & 41.55 & 49.03 & 39.43 & 43.25 & 51.03 \\
\hline 28 & 36.98 & 40.57 & 47.87 & 37.76 & 41.42 & 48.88 & 39.27 & 43.08 & 50.84 \\
\hline 29 & 36.89 & 40.46 & 47.75 & 37.65 & 41.30 & 48.74 & 39.13 & 42.92 & 50.65 \\
\hline 30 & 36.80 & 40.37 & 47.64 & 37.55 & 41.18 & 48.60 & 39.00 & 42.77 & 50.48 \\
\hline 35 & 36.43 & 39.96 & 47.16 & 37.11 & 40.71 & 48.04 & 38.43 & 42.15 & 49.75 \\
\hline 40 & 36.15 & 39.65 & 46.80 & 36.77 & 40.34 & 47.61 & 37.99 & 41.67 & 49.18 \\
\hline 45 & 35.92 & 39.40 & 46.50 & 36.50 & 40.04 & 47.26 & 37.64 & 41.29 & 48.73 \\
\hline 50 & 35.73 & 39.20 & 46.26 & 36.28 & 39.80 & 46.97 & 37.35 & 40.97 & 48.35 \\
\hline 60 & 35.44 & 38.88 & 45.89 & 35.94 & 39.43 & 46.53 & 36.90 & 40.17 & 47.77 \\
\hline 70 & 35.23 & 38.64 & 45.61 & 35.68 & 39.14 & 46.20 & 36.56 & 40.10 & 47.33 \\
\hline 80 & 35.06 & 38.46 & 45.39 & 35.48 & 38.92 & 45.94 & 36.30 & 39.82 & 46.99 \\
\hline 90 & 34.93 & 38.31 & 45.22 & 35.32 & 38.75 & 45.73 & 36.08 & 39.58 & 46.72 \\
\hline 100 & 34.82 & 38.19 & 45.08 & 35.19 & 38.60 & 45.56 & 35.91 & 39.39 & 46.49 \\
\hline 200 & 34.26 & 37.58 & 44.35 & 34.52 & 37.86 & 44.69 & 35.01 & 38.40 & 45.32 \\
\hline 500 & 33.82 & 37.10 & 43.79 & 33.98 & 37.28 & 44.00 & 34.28 & 37.61 & 44.39 \\
\hline$\infty$ & 33.20 & 36.42 & 42.98 & 33.20 & 36.42 & 42.98 & 33.20 & 36.42 & 42.98 \\
\hline
\end{tabular}


Table D-24

H VALUES $(C=25)$

\begin{tabular}{|c|c|c|c|c|c|c|c|c|c|}
\hline \multirow[b]{2}{*}{$N$} & \multicolumn{3}{|c|}{$\gamma=0.90$} & \multicolumn{3}{|c|}{$\gamma=0.95$} & \multicolumn{3}{|c|}{$\gamma=0.99$} \\
\hline & $P=0.90$ & $P=0.95$ & $P=0.99$ & $P=0.90$ & $P=0.95$ & $P=0.99$ & $P=0.90$ & $P=0.95$ & $P=0.99$ \\
\hline 2 & 77.02 & 83.86 & 97.65 & 86.85 & 94.56 & 110.11 & 110.21 & 120.00 & 139.73 \\
\hline 3 & 60.27 & 65.78 & 76.94 & 65.35 & 71.33 & 83.42 & 76.53 & 83.53 & 97.69 \\
\hline 4 & 53.60 & 58.57 & 68.65 & 57.18 & 62.48 & 73.23 & 64.81 & 70.82 & 83.00 \\
\hline 5 & 49.90 & 54.56 & 64.03 & 52.74 & 57.66 & 67.67 & 58.67 & 64.15 & 75.28 \\
\hline 6 & 47.52 & 51.98 & 61.04 & 49.91 & 54.59 & 64.11 & 54.84 . & 59.99 & 70.45 \\
\hline 7 & 45.85 & 50.16 & 58.94 & 47.93 & 52.45 & 61.62 & 52.20 & 57.12 & 67.11 \\
\hline 8 & 44.60 & 48.81 & 57.37 & 46.47 & 50.86 & 59.77 & 50.27 & 55.01 & 64.66 \\
\hline 9 & 43.64 & 47.76 & 56.15 & 45.34 & 49.62 & 58.34 & 48.78 & 53.39 & 62.76 \\
\hline 10 & 42.87 & 46.92 & 55.17 & 44.44 & 48.64 & 57.19 & 47.59 & 52.09 & 61.25 \\
\hline 11 & 42.23 & 46.23 & 54.37 & 43.69 & 47.83 & 56.25 & 46.62 & 51.04 & 60.02 \\
\hline 12 & 41.70 & 45.66 & 53.70 & 43.08 & 47.16 & 55.46 & 45.81 & 50.16 & 58.99 \\
\hline 13 & 41.25 & 45.16 & 53.12 & 42.55 & 46.58 & 54.79 & 45.13 & 49.41 & 58.11 \\
\hline 14 & 40.87 & 44.74 & 52.63 & 42.10 & 46.09 & 54.21 & 44.54 & 48.76 & 57.36 \\
\hline 15 & 40.53 & 44.37 & 52.20 & 41.70 & 45.66 & 53.71 & 44.03 & 48.20 & 56.71 \\
\hline 16 & 40.23 & 44.05 & 51.82 & 41.35 & 45.28 & 53.27 & 43.57 & 47.71 & 56.13 \\
\hline 17 & 39.96 & 43.76 & 51.48 & 41.04 & 44.94 & 52.87 & 43.17 & 47.27 & 55.61 \\
\hline 18 & 39.73 & 43.50 & 51.18 & 40.77 & 44.64 & 52.52 & 42.81 & 46.88 & 55.15 \\
\hline 19 & 39.51 & 43.27 & 50.91 & 40.52 & 44.36 & 52.20 & 42.49 & 46.53 & 54.74 \\
\hline 20 & 39.32 & 43.06 & 50.66 & 40.29 & 44.12 & 51.91 & 42.20 & 46.21 & 54.37 \\
\hline 21 & 39.15 & 42.86 & 50.44 & 40.09 & 43.89 & 51.65 & 41.93 & 45.91 & 54.02 \\
\hline 22 & 38.99 & 42.69 & 50.23 & 39.90 & 43.69 & 51.41 & 41.69 & 45.65 & 53.71 \\
\hline 23 & 38.84 & 42.53 & 50.04 & 39.72 & 43.50 & 51.18 & 41.46 & 45.40 & 53.42 \\
\hline 24 & 38.70 & 42.38 & 49.87 & 39.56 & $43.32^{\circ}$ & 50.98 & 41.26 & 45.18 & 53.16 \\
\hline 25 & 38.57 & 42.24 & 49.71 & 39.42 & 43.16 & 50.79 & 41.06 & 44.97 & 52.91 \\
\hline 26 & 38.46 & 42.11 & 49.56 & 39.28 & 43.01 & 50.61 & 40.88 & 44.77 & 52.68 \\
\hline 27 & 38.35 & 41.99 & 49.42 & 39.15 & 42.87 & 50.45 & 40.72 & 44.59 & 52.47 \\
\hline 28 & 38.25 & 41.88 & 49.28 & 39.03 & 42.74 & 50.30 & 40.56 & 44.42 & 52.27 \\
\hline 29 & 38.15 & 41.78 & 49.16 & 38.92 & 42.62 & 50.15 & 40.42 & 44.26 & 52.08 \\
\hline 30 & 38.06 & 41.68 & 49.05 & 38.81 & 42.50 & 50.02 & 40.28 & 44.11 & 51.91 \\
\hline 35 & 37.68 & 41.27 & 48.56 & 38.37 & 42.02 & 49.45 & 39.70 & 43.48 & 51.17 \\
\hline 40 & 37.39 & 40.95 & 18.19 & 38.03 & 41.64 & $49.01^{\circ}$ & 39.26 & 42.99 & 50.59 \\
\hline 45 & 37.16 & 40.69 & 47.89 & 37.75 & 41.34 & 48.65 & 38.90 & 42.60 & 50.13 \\
\hline 50 & 36.97 & 40.48 & 47.64 & 37.53 & 41.10 & 48.36 & 38.60 & 42.27 & 49.75 \\
\hline 60 & 36.67 & 40.16 & 47.27 & 37.18 & 40.71 & 47.91 & 38.14 & 41.7 .7 & 49.16 \\
\hline 70 & 36.45 & 39.92 & 46.98 & 36.91 & 40.43 & 47.58 & 37.80 & 41.40 & 48.72 \\
\hline 80 & 36.28 & 38.73 & 16.76 & 36.71 & 40.20 & 47.32 & 37.53 & 41.10 & 48.38 \\
\hline 90 & 36.14 & 39.58 & 46.59 & 36.55 & 40.02 & 47.10 & 37.32 & 40.87 & 48.10 \\
\hline 100 & 36.03 & 39.46 & 46.44 & 36.41 & 39.87 & 46.93 & 37.14 & 40.67 & 47.86 \\
\hline 200 & 35.46 & 38.81 & 45.71 & 35.72 & 39.12 & 46.04 & 36.22 & 39.67 & 46.69 \\
\hline 500 & 35.02 & 38.35 & 45.13 & 35.18 & 38.53 & 45.34 & 35.49 & 38.86 & 45.74 \\
\hline$\infty$ & 34.38 & 37.65 & 44.31 & 34.38 & 37.65 & 44.31 & 34.38 & 37.65 & 44.31 \\
\hline
\end{tabular}


Table D-25

H VALUES $(C=26)$

\begin{tabular}{|c|c|c|c|c|c|c|c|c|c|}
\hline \multirow[b]{2}{*}{$\mathrm{N}$} & \multicolumn{3}{|c|}{$\gamma=0.90$} & \multicolumn{3}{|c|}{$\gamma=0.95$} & \multicolumn{3}{|c|}{$\gamma=0.99$} \\
\hline & $P=0.90$ & $P=0.95$ & $P=0.99$ & $P=0.90$ & $P=0.95$ & $P=0.99$ & $\mathrm{P}=0.90$ & $P=0.95$ & $\mathrm{P}=0.99$ \\
\hline 2 & 78.94 & 85.83 & 99.69 & 88.77 & 96.51 & 112.10 & 111.98 & 121.75 & 141.41 \\
\hline 3 & 61.97 & 67.54 & 78.79 & 67.08 & 73.10 & 85.28 & 78.28 & 85.31 & 99.52 \\
\hline 4 & 55.18 & 60.21 & 70.38 & 58.79 & 64.14 & 74.98 & 66.45 & 72.50 & 84.75 \\
\hline 5 & 51.41 & 56.13 & 65.69 & 54.27 & 59.25 & 69.34 & 60.24 & 65.76 & 76.97 \\
\hline 6 & 48.98 & 53.49 & 62.65 & 51.39 & 56.13 & 65.74 & 56.36 & 61.55 & 72.09 \\
\hline 7 & 47.27 & 51.64 & 60.51 & 49.38 & 53.94 & 63.21 & 53.68 & 58.65 & 68.72 \\
\hline 8 & 46.00 & 50.26 & 58.92 & 47.89 & 52.33 & 61.34 & 51.71 & 56.51 & 66.24 \\
\hline 9 & 45.02 & 49.19 & 57.68 & 46.73 & 51.07 & 59.88 & 50.20 & 54.86 & 64.32 \\
\hline 10 & 44.23 & 48.34 & 56.68 & 45.81 & 50.07 & 58.71 & 49.00 & 53.55 & 62.79 \\
\hline 11 & 43.58 & 47.63 & 55.87 & 45.06 & 49.25 & 57.76 & 48.01 & 52.48 & 61.55 \\
\hline 12 & 43.04 & 47.04 & 55.18 & 44.42 & 48.56 & 56.96 & 47.19 & 51.58 & 60.50 \\
\hline 13 & 42.58 & 46.54 & 54.60 & 43.89 & 47.97 & 56.28 & 46.49 & 50.82 & 59.62 \\
\hline 14 & 42.18 & 46.11 & 54.09 & 43.42 & 47.47 & 55.69 & 45.89 & 50.17 & 58.85 \\
\hline 15 & 41.84 & 45.73 & 53.66 & 43.02 & 47.03 & 55.18 & 45.37 & 49.60 & 58.19 \\
\hline 16 & 41.53 & 45.40 & 53.27 & 42.67 & 46.64 & 54.73 & 44.91 & 49.10 & 57.60 \\
\hline 17 & 41.26 & 45.11 & 52.93 & 42.35 & 46.30 & 54.32 & 44.50 & 48.65 & 57.08 \\
\hline 18 & 41.02 & 44.84 & 52.62 & 42.07 & 45.99 & 53.97 & 44.14 & 48.25 & 56.62 \\
\hline 19 & 40.80 & 44.61 & 52.34 & 41.81 & 45.71 & 53.64 & 43.81 & 47.89 & 56.20 \\
\hline 20 & 40.60 & 44.39 & 52.09 & 41.58 & 45.46 & 53.35 & 43.51 & 47.57 & 55.82 \\
\hline 21 & 40.42 & 44.19 & 51.86 & 41.37 & 45.23 & 53.08 & 43.24 & 47.27 & 55.47 \\
\hline 22 & 40.26 & 44.02 & 51.65 & 41.18 & 45.02 & 52.84 & 42.93 & 47.00 & 55.16 \\
\hline 23 & 40.11 & 43.85 & 51.46 & 41.01 & 44.83 & 52.61 & 42.76 & 46.75 & 54.87 \\
\hline 24 & 39.97 & 43.70 & 51.28 & 40.84 & 44.65 . & 52.40 & 42.55 & 46.52 & 54.60 \\
\hline 25 & 39.84 & 43.56 & 51.12 & 40.69 & 44.49 & 52.21 & 42.36 & 46.31 & 54.35 \\
\hline 26 & 39.72 & 43.43 & 50.96 & 40.55 & 44.34 & 52.03 & 42.18 & 46.11 & 54.11 \\
\hline 27 & 39.61 & 43.31 & 50.82 & 40.42 & 44.19 & 51.87 & 42.01 & 45.93 & 53.90 \\
\hline 28 & 39.50 & 43.19 & 50.69 & 40.30 & 44.06 & 51.71 & 41.85 & 45.75 & 53.70 \\
\hline 29 & 39.41 & 43.08 & 50.56 & 40.18 & 43.94 & 51.56 & 41.70 & 45.59 & 53.51 \\
\hline 30 & 39.31 & 42.98 & 50.45 & 40.08 & 43.82 & 51.43 & 41.56 & 45.44 & 53.33 \\
\hline 35 & 38.93 & 42.56 & 49.95 & 39.62 & 43.32 & 50.85 & 40.97 & 44.80 & 52.58 \\
\hline 40 & 38.63 & 42.24 & 49.57 & 39.27 & 42.94 & 50.40 & 40.52 & 44.30 & 51.99 \\
\hline 45 & 39.39 & 41.98 & 49.27 & 38.99 & 42.63 & 50.04 & 40.15 & 43.90 & 51.53 \\
\hline 50 & 38.20 & 41.77 & 49.02 & 38.76 & 42.38 & 49.75 & 39.85 & 43.58 & 51.15 \\
\hline 60 & 37.90 & 41.44 & 48.63 & 38.41 & 41.99 & 49.29 & 39.39 & 43.07 & 50.55 \\
\hline 70 & 37.67 & 41.19 & 48.35 & 38.14 & 41.70 & 48.95 & 39.04 & 42.68 & 50.10 \\
\hline 80 & 37.50 & 41.00 & 48.12 & 37.93 & 41.48 & 48.68 & 38.77 & 42.39 & 49.75 \\
\hline 90 & 37.36 & 40.85 & 47.94 & 37.77 & 41.29 & 48.47 & 38.54 & 42.15 & 49.47 \\
\hline 100 & 37.24 & 40.72 & 47.80 & 37.63 & 41.14 & 48.29 & 38.36 & 41.95 & 49.23 \\
\hline 200. & 36.66 & 40.09 & 47.05 & 36.93 & 40.38 & 47.39 & 37.43 & 40.93 & 48.04 \\
\hline 500 & 36.21 & 39.59 & 46.47 & 36.37 & 39.77 & 46.68 & 36.69 & 40.11 & 47.08 \\
\hline$\infty$ & 35.56 & 38.89 & 45.64 & 35.56 & 38.89 & 45.64 & 35.56 & 38.89 & 45.64 \\
\hline
\end{tabular}


Table D-26

H VALUES $(C=27)$

\begin{tabular}{|c|c|c|c|c|c|c|c|c|c|}
\hline \multirow[b]{2}{*}{$N$} & \multicolumn{3}{|c|}{$\gamma=0.90$} & \multicolumn{3}{|c|}{$\gamma=0.95$} & \multicolumn{3}{|c|}{$\gamma=0.99$} \\
\hline & $P=0.90$ & $P=0.95$ & $P=0.99$ & $P=0.90$ & $P=0.95$ & $P=0.99$ & $P=0.90$ & $P=0.95$ & $P=0.99$ \\
\hline 2 & 80.87 & 87.80 & 101.74 & 90.70 & 98.48 & 114.11 & 113.83 & 123.59 & 143.21 \\
\hline 3 & 63.67 & 69.29 & 80.64 & 68.80 & 74.88 & 87.14 & 80.02 & 87.09 & 101.34 \\
\hline 4 & 56.76 & 61.84 & 72.11 & 60.39 & 65.80 & 76.72 & 68.08 & 74.18 & 86.50 \\
\hline 5 & 52.91 & 57.68 & 67.34 & 55.80 & 60.83 & 71.01 & 61.80 & 67.37 & 78.65 \\
\hline 6 & 50.43 & 55.00 & 64.26 & 52.87 & 57.65 & 67.36 & 57.87 & 63.11 & 73.73 \\
\hline 7 & 48.69 & 53.12 & 62.08 & 50.82 & 55.44 & 64.79 & 55.15 & 60.16 & 70.32 \\
\hline 8 & 47.39 & 51.71 & 60.46 & 49.30 & 53.79 & 62.89 & 53.16 & 58.00 & 67.81 \\
\hline 9 & 46.39 & 50.62 & 59.20 & 48.12 & 52.51 & 61.41 & 51.62 & 56.33 & 65.87 \\
\hline 10 & 45.58 & 49.74 & 58.19 & 47.18 & 51.49 & 60.23 & 50.39 & 54.99 & 64.33 \\
\hline 11 & 44.92 & 49.03 & 57.35 & 46.41 & 50.65 & 59.26 & 49.39 & 53.91 & 63.06 \\
\hline 12 & 44.37 & 48.42 & 56.66 & 45.77 & 49.95 & 58.45 & 48.56 & 53.00 & 62.01 \\
\hline 13 & 43.90 & 47.91 & 56.06 & 45.22 & 49.36 & 57.75 & 47.85 & 52.23 & 61.11 \\
\hline 14 & 43.49 & 47.47 & 55.55 & 44.75 & 48.84 & 57.16 & 47.24 & 51.56 & 60.34 \\
\hline 15 & 43.14 & 47.09 & 55.10 & 44.34 & 48.40 & 56.64 & 46.71 & 50.99 & 59.67 \\
\hline 16 & 42.83 & 46.75 & 54.71 & 43.98 & 48.00 & 56.18 & 46.24 & 50.48 & 59.07 \\
\hline 17 & 42.55 & 46.45 & 54.36 & 43.65 & 47.65 & 55.77 & 45.83 & 50.03 & 58.55 \\
\hline 18 & 42.30 & 46.18 & 54.05 & 43.37 & 47.34 & 55.41 & 45.46 & 49.62 & 58.08 \\
\hline 19 & 42.08 & 45.94 & 53.77 & 43.11 & 47.06 & 55.08 & 45.12 & 49.26 & 57.65 \\
\hline 20 & 41.88 & 45.72 & 53.51 & 42.87 & 46.80 & 54.78 & 44.82 & 48.93 & 57.27 \\
\hline 21 & 41.70 & 45.52 & 53.28 & 42.66 & 46.57 & 54.51 & 44.54 & 48.63 & 56.92 \\
\hline 22 & 41.53 & 45.34 & 53.07 & 42.46 & 46.36 & 54.26 & 44.29 & 48.35 & 56.59 \\
\hline 23 & 41.38 & 45.17 & 52.87 & 42.28 & 46.16 & 54.03 & 44.06 & 48.10 & 56.30 \\
\hline 24 & 41.23 & 45.01 & 52.69 & 42.12 & 45.98 & 53.82 & 43.84 & 47.86 & 56.03 \\
\hline 25 & 41.10 & 44.87 & 52.52 & 41.96 & 45.81 & 53.62 & 43.65 & 47.65 & 55.77 \\
\hline 26 & 40.98 & 44.74 & 52.37 & 41.82 & 45.65 & 53.44 & 43.46 & 47.45 & 55.54 \\
\hline 27 & 40.86 & 44.61 & 52.22 & 41.69 & 45.51 & 53.27 & 43.29 & 47.26 & 55.32 \\
\hline 28 & 40.76 & 44.50 & 52.09 & 41.56 & 45.37 & 53.11 & 43.13 & 47.08 & 55.12 \\
\hline 29 & 40.66 & 44.39 & 51.96 & 41.45 & 45.25 & 52.97 & 42.98 & 46.92 & 54.92 \\
\hline 30 & 40.56 & 44.29 & 51.84 & 41.34 & 45.13 & 52.83 & 42.84 & 46.76 & 54.74 \\
\hline 35 & 40.17 & 43.86 & 51.34 & 40.87 & 44.62 & 52.24 & 42.24 & 46.11 & 53.98 \\
\hline 10 & 39.87 & 43.62 & 50.95 & 40.52 & 44.23 & 51.78 & 41.78 & 45.61 & 53.39 \\
\hline 45 & 39.62 & 43.26 & 50.64 & 40.23 & 43.92 & 51.42 & 41.40 & 45.20 & 52.92 \\
\hline 50 & 39.43 & 43.04 & 50.39 & 40.00 & 43.67 & 51.12 & 41.10 & 44.87 & 52.53 \\
\hline 60 & 39.12 & 42.71 & 50.00 & 39.63 & 43.27 & 50.66 & 40.63 & 44.35 & 51.93 \\
\hline 70 & 38.89 & 42.46 & 49.71 & 39.36 & 42.97 & 50.31 & 40.27 & 43.97 & 51.47 \\
\hline 80 & 38.71 & 42.26 & 49.48 & 39.15 & 42.74 & 50.04 & 39.99 & 43.66 & 51.12 \\
\hline 90 & 38.57 & 42.11 & 49.30 & 38.98 & 42.56 & 49.82 & 39.77 & 43.42 & 50.83 \\
\hline 100 & 38.45 & 41.98 & 49.15 & 38.84 & 42.40 & 49.64 & 39.58 & 43.22 & 50.60 \\
\hline 200 & 37.86 & 41.33 & 48.39 & 38.13 & 41.63 & 48.73 & 38.64 & 42.18 & 49.39 \\
\hline 500 & 37.40 & 40.83 & 47.80 & 37.56 & 41.01 & 48.01 & 37.88 & 41.36 & 48.42 \\
\hline$\infty$ & 36.74 & 40.11 & 46.96 & 36.74 & 40.11 & 46.96 & 36.74 & 40.11 & 46.96 \\
\hline
\end{tabular}


Table D-27

H VALUES $(C=28)$

\begin{tabular}{|c|c|c|c|c|c|c|c|c|c|}
\hline \multirow[b]{2}{*}{$\mathrm{N}$} & \multicolumn{3}{|c|}{$\gamma=0.90$} & \multicolumn{3}{|c|}{$\gamma=0.95$} & \multicolumn{3}{|c|}{$\gamma=0.99$} \\
\hline & $P=0.90$ & $P=0.95$ & $P=0.99$ & $P=0.90$ & $P=0.95$ & $P=0.99$ & $P=0.90$ & $P=0.95$ & $P=0.99$ \\
\hline 2 & 82.79 & 89.77 & 103.79 & 92.64 & 100.45 & 116.13 & 115.70 & 125.45 & 145.04 \\
\hline 3 & 65.36 & 71.04 & 82.48 & 70.52 & 76.64 & 88.99 & 81.76 & 88.86 & 103.17 \\
\hline 4 & 58.33 & 63.46 & 73.83 & 61.99 & 67.44 & 78.46 & 69.72 & 75.85 & 88.24 \\
\hline 5 & 54.41 & 59.24 & 68.99 & 57.32 & 62.40 & 72.68 & 63.36 & 68.97 & 80.33 \\
\hline 6 & 51.88 & 56.51 & 65.86 & 54.34 & 59.18 & 68.97 & 59.37 & 64.66 & 75.36 \\
\hline 7 & 50.11 & 54.58 & 63.65 & 52.25 & 56.92 & 66.37 & 56.62 & 61.68 & 71.92 \\
\hline 8 & 48.78 & 53.15 & 61.99 & 50.71 & 55.24 & 64.44 & 54.59 & 59.48 & 69.38 \\
\hline 9 & 47.76 & 52.04 & 60.71 & 19.61 & 53.95 & 62.94 & $53.03^{\circ}$ & 57.79 & 67.42 \\
\hline 10 & 46.93 & 51.15 & 59.68 & 48.55 & 52.91 & 61.74 & 51.79 & 56.44 & 65.86 \\
\hline 11 & 46.26 & 50.41 & 58.83 & 47.76 & 52.06 & 60.75 & 50.77 & 55.33 & 64.58 \\
\hline 12 & 45.69 & 49.80 & 58.13 & 47.11 & 51.34 & 59.93 & 49.92 & 54.41 & 63.51 \\
\hline 13 & 45.21 & 49.28 & 57.52 & 46.55 & 50.74 & 59.22 & 49.20 & 53.63 & 62.60 \\
\hline 14 & 44.80 & 48.83 & 57.00 & 46.07 & 50.21 & 58.62 & 48.58 & 52.96 & 61.82 \\
\hline 15 & 44.44 & 48.44 & 56.55 & 45.65 & 49.76 & 58.09 & 48.04 & 52.37 & 61.14 \\
\hline 16 & 44.12 & 48.09 & 56.15 & 45.28 & 49.36 & 57.62 & 47.57 & 51.85 & 60.54 \\
\hline 17 & 43.84 & 47.79 & 55.79 & 44.95 & 49.00 & 57.21 & 47.15 & 51.39 & 60.00 \\
\hline 18 & 43.59 & 47.51 & 55.47 & 44.66 & 48.68 & 56.84 & 46.77 & 50.98 & 59.53 \\
\hline 19 & 43.36 & 47.27 & 55.19 & 44.40 & 48.40 & 56.51 & 46.43 & 50.61 & 59.10 \\
\hline 20 & 43.15 & 47.04 & 54.93 & 44.16 & 48.13 & 56.20 & 46.12 & 50.28 & 58.71 \\
\hline 21 & 42.97 & 46.84 & 54.69 & 43.94 & 47.90 & 55.93 & 45.84 & 49.97 & 58.35 \\
\hline 22 & 42.80 & 46.65 & 54.47 & 43.74 & 47.68 & 56.68 & $4 b .6 y$ & 49.69 & b8.U'3 \\
\hline 23 & 42.64 & 46.48 & 54.27 & 43.56 & 47.48 & 55.44 & 45.35 & 49.44 & 57.73 \\
\hline 24 & 42.49 & 46.32 & 54.09 & 43.39 & 47.30 & 55.23 & 45.13 & 49.20 & 57.45 \\
\hline 25 & 42.30 & 48.18 & 53.92 & 43.23 & $\because \quad 47.13$ & 5.03 & 44.90 & 48.90 & 57.20 \\
\hline 26 & 42.23 & 46.04 & 53.76 & 43.08 & 46.97 & 54.85 & 44.74 & 48.78 & 56.96 \\
\hline 27 & 42.12 & 45.91 & 53.62 & 42.95 & 46.82 & 54.67 & 44.57 & 48.59 & 56.74 \\
\hline 28 & 42.01 & 45.80 & 53.48 & 42.82 & 46.68 & 54.51 & 44.40 & 48.41 & 56.53 \\
\hline 29 & 41.91 & 45.68 & 53.35 & 42.70 & 46.55 & 54.36 & 44.25 & 48.24 & 56.33 \\
\hline 30 & 41.81 & 45.58 & 53.23 & 42.59 & 46.43 & 54.22 & 44.11 & 48.08 & 56.15 \\
\hline 35 & 41.41 & 45.14 & 52.72 & 42.12 & 45.92 & 53.62 & 43.50 & 47.42 & 55.38 \\
\hline 40 & 41.10 & 44.80 & 52.32 & 41.76 & 45.52 & 53.16 & 43.03 & 46.91 & 54.78 \\
\hline 45 & 40.85 & 44.54 & 52.01 & 41.47 & 45.21 & 52.79 & 42.65 & 46.50 & 54.30 \\
\hline 50 & 40.65 & 44.31 & 51.75 & 41.23 & 44.95 & 52.49 & 42.34 & 46.16 & 53.91 \\
\hline 60 & 40.33 & 43.97 & 51.36 & 40.86 & 44.54 & $52.0 ?$ & 41.86 & 45.64 & 53.30 \\
\hline 70 & 40.10 & 43.72 & 51.06 & 40.58 & 44.24 & 51.67 & 41.50 & 45.24 & 52.84 \\
\hline 80 & 39.92 & 43.52 & 50.83 & 40.36 & 44.01 & 51.39 & 41.22 & 44.94 & 52.48 \\
\hline 90 & 39.77 & 43.36 & 50.64 & 40.19 & 43.82 & 51.17 & 40.99 & 44.69 & 52.19 \\
\hline 100 & 39.65 & 43.23 & 50.49 & 40.05 & 43.66 & 50.99 & 40.80 & 44.48 & 51.95 \\
\hline 200 & 39.05 & 42.57 & 49.72 & 39.32 & 42.87 & 50.07 & 39.84 & 43.44 & 50.73 \\
\hline 500 & 38.58 & 42.06 & 49.13 & 38.75 & 42.25 & 49.34 & 39.07 & 42.60 & 49.75 \\
\hline$\infty$ & 37.92 & 41.34 & 48.28 & 37.92 & 41.34 & 48.28 & 37.92 & 41.34 & 48.28 \\
\hline
\end{tabular}


Tàble D-28

H VALUES $(C=29)$

\begin{tabular}{|c|c|c|c|c|c|c|c|c|c|}
\hline \multirow[b]{2}{*}{$N$} & \multicolumn{3}{|c|}{$\gamma=0.90$} & \multicolumn{3}{|c|}{$\gamma=0.95$} & \multicolumn{3}{|c|}{$\gamma=0.99$} \\
\hline & $P=0.90$ & $P=0.95$ & $P=0.99$ & $P=0.90$ & $P=0.95$ & $P=0.99$ & $P=0.90$ & $P=0.95$ & $P=0.99$ \\
\hline 2 & 84.71 & 91.74 & 105.83 & 94.57 & 102.42 & 118.15 & 117.58 & 127.34 & 146.90 \\
\hline 3 & 67.05 & 72.78 & 84.31 & 72.24 & 78.41 & 90.83 & 83.51 & 90.64 & 105.00 \\
\hline 4 & 59.90 & 65.08 & 75.55 & $63: 58$ & 69.08 & 80.19 & 71.34 & 77.52 & 89.98 \\
\hline 5 & 55.91 & 60.78 & 70.63 & 58.84 & 63.97 & 74.33 & 64.91 & 70.57 & 82.00 \\
\hline 6 & 53.33 & 58.00 & 67.45 & 55.80 & 60.69 & 70.58 & 60.87 & 66.20 & 76.99 \\
\hline 7 & 51.52 & 56.04 & 65.20 & 53.68 & 58.40 & 67.94 & 58.08 & 63.18 & 73.51 \\
\hline 8 & 50.17 & 54.58 & 63.52 & 52.11 & 56.70 & 65.98 & 56.02 & 60.96 & 70.94 \\
\hline 9 & 49.12 & 53.45 & 62.22 & 50.89 & 55.37 & 64.46 & 54.44 & 59.24 & 68.96 \\
\hline 10 & 48.28 & 52.54 & 61.17 & 49.91 & 54.32 & 63.24 & 53.18 & 57.87 & 67.38 \\
\hline 11 & 47.59 & 51.80 & 60.31 & 49.11 & 53.45 & 62.24 & 52.15 & 56.75 & 66.08 \\
\hline 12 & 47.01 & 51.17 & 59.59 & 48.44 & 52.73 & 61.40 & 51.28 & 55.82 & 65.00 \\
\hline 13 & 46.52 & 50.64 & 58.97 & 47.88 & 52.11 & 60.69 & 50.55 & 55.03 & 64.08 \\
\hline 14 & 46.10 & 50.18 & 58.45 & 47.39 & 51.58 & 60.07 & 49.92 & 54.34 & 63.29 \\
\hline 15 & 45.73 & 49.78 & 5.7 .98 & 46.96 & 51.12 & 59.54 & 49.38 & 53.75 & 62.60 \\
\hline 16 & $45.4 ?$ & 49.43 & 57.58 & 46.58 & 50.71 & 59.06 & 48.89 & 53.22 & 61.99 \\
\hline 17 & 45.12 & 49.12 & 57.22 & 46.25 & 50.35 & 58.64 & 48.46 & 52.76 & 61.45 \\
\hline 18 & 44.86 & 48.84 & 56.89 . & 45.95 & 50.02 & 58.27 & 48.08 & 52.34 & 60.97 \\
\hline 19 & 44.63 & 48.59 & 56.60 & 45.68 & 49.73 & 57.93 & 47.74 & 51.97 & 60.53 \\
\hline 20 & 44.42 & 48.36 & 56.34 & 45.44 & 49.46 & 57.62 & 47.42 & 51.63 & 60.14 \\
\hline 21 & 44.23 & 48.15 & 56.10 & 45.21 & 49.22 & 57.34 & 47.14 & 51.32 & 59.78 \\
\hline 22 & 44.06 & 47.96 & 55.88 & 45.01 & 49.00 & 57.09 & 46.88 & 51.03 & 59.45 \\
\hline 23 & 43.90 & 47.79 & 55.67 & 44.82 & 48.80 & 56.85 & 46.64 & 50.77 & 59.15 \\
\hline 24 & 43.75 & 47.63 & 55.49 & 44.65 & 48.61 & 56.63 & 46.42 & $50.53^{\bullet}$ & $58: 87$ \\
\hline 25 & 43.61 & 47.48 & 55.31 & 44.49 & 48.44 & 56.43 & 46.21 & 50.31 & 58.61 \\
\hline 26 & 43.48 & 47.34 & 55.15 & 44.34 & 48.28 & 56.24 & 46.02 & 50.10 & 58.37 \\
\hline 27 & 43.36 & 47.21 & 55.00 & 44.21 & 48.13 & 56.07 & 45.84 & 49.91 & 58.14 \\
\hline 28 & 43.25 & 47.09 & 54.86 & 44.08 & 47.99 & 55.91 & 45.68 & 49.73 & 57.93 \\
\hline 29 & 43.15 & 46.98 & 54.73 & 43.95 & 47.85 & 55.75 & 45.52 & 49.56 & 57.74 \\
\hline 30 & 43.05 & 46.87 & 54.61 & 43.84 & 47.73 & 55.61 & 45.37 & 49.40 & 57.55 \\
\hline 35 & 42.64 & 46.43 & 54.09 & 43.36 & 47.21 & 55.00 & 44.76 & 48.73 & 56.77 \\
\hline 40 & 42.33 & 46.08 & 53.69 & 42.99 & 16.81 & 54.54 & 44.28 & 48.21 & 56.17 \\
\hline 45 & 42.07 & 45.81 & 53.37 & 42.70 & 46.48 & 54.16 & 43.90 & 47.79 & 55.68 \\
\hline 50 & 41.87 & 45.58 & 53.11 & 42.45 & 46.22 & 53.85 & 43.58 & 47.45 & 55.28 \\
\hline 60 & 41.55 & 45.23 & 52.71 & 42.08 & 45.81 & 53.38 & 43.09 & 46.91 & 54.66 \\
\hline 70 & 41.31 & 44.98 & 52.41 & 41.79 & 45.50 & 53.02 & 42.72 & 46.52 & 54.20 \\
\hline 80 & 41.12 & 44.77 & 52.17 & $41.5 \%$ & 45.26 & 52.74 & 12.11 & 16.20 & 53.84 \\
\hline 90 & 40.98 & 44.61 & 51.98 & 41.40 & 45.07 & 52.52 & 41.21 & 45.95 & 53.54 \\
\hline 100 & 40.86 & 44.48 & 51.83 & 41.25 & 44.91 & 52.33 & 42.01 & 45.74 & 53.30 \\
\hline 200 & 40.24 & 43.81 & 51.05 & 40.52 & 44.11 & 51.40 & 41.04 & 44.68 & 52.06 \\
\hline 500 & 39.76 & 43.29 & 50.45 & 39.93 & 43.48 & 50.66 & 40.26 & 43.83 & 51.07 \\
\hline$\infty$ & 39.09 & 42.56 & 49.59 & 39.09 & 42.56 & 49.59 & 39.09 & 42.56 & 49.59 \\
\hline
\end{tabular}


Table D-29

H VALUES $(C=30)$

\begin{tabular}{|c|c|c|c|c|c|c|c|c|c|}
\hline \multirow[b]{2}{*}{$N$} & \multicolumn{3}{|c|}{$\gamma=0.90$} & \multicolumn{3}{|c|}{$\gamma=0.95$} & \multicolumn{3}{|c|}{$\gamma=0.99$} \\
\hline & $\bar{P}=0.90$ & $P=0.95$ & $P=0.99$ & $P=0.90$ & $P=0.95$ & $P=0.99$ & $\mathbf{P}=0.90$ & $P=0.95$ & $P=0.99$ \\
\hline 2 & 86.63 & 93.70 & 107.87 & 96.51 & 104.39 & 120.18 & 119.41 & 129.15 & 148.70 \\
\hline 3 & 68.73 & 74.51 & 86.14 & 73.95 & 80.16 & 92.67 & 85.24 & 92.41 & 106.83 \\
\hline 4 & 61.46 & 66.70 & 77.25 & 65.17 & 70.72 & 81.91 & 72.97 & 79.18 & 91.72 \\
\hline 5 & 57.40 & 62.32 & 72.27 & 60.35 & 65.53 & 75.98 & 66.46 & 72.16 & 83.67 \\
\hline 6 & 54.77 & 59.49 & 69.03 & 57.26 & 62.20 & 72.18 & 62.37 & 67.74 & 78.61 \\
\hline 7 & 52.92 & 57.50 & 66.75 & 55.11 & 59.87 & 69.50 & 59.54 & 64.69 & 75.09 \\
\hline 8 & 51.55 & 56.01 & 65.04 & 53.50 & 58.14 & 67.51 & 57.45 & 62.43 & 72.49 \\
\hline 9 & 50.48 & 54.86 & 63.72 & 52.26 & 56.80 & 65.97 & 55.84 & 60.69 & 70.49 \\
\hline 10 & 49.62 & 53.93 & 62.65 & 51.27 & 55.72 & 64.73 & 54.56 & 59.30 & 68.89 \\
\hline 11 & 48.92 & 53.17 & 61.78 & 50.46 & 54.84 & 63.72 & 53.52 & 58.17 & 67.58 \\
\hline 12 & 48.33 & 52.54 & 61.05 & 49.77 & 54.11 & 62.87 & 52.64 & 57.22 & 66.49 \\
\hline 13. & 47.83 & 52.00 & 60.42 & 49.20 & 53.48 & 62.14 & 51.90 & 56.42 & 65.56 \\
\hline 14 & 47.40 & 51.53 & 59.88 & 48.70 & 52.94 & 61.52 & 51.26 & 55.72 & 64.76 \\
\hline 15 & 47.03 & 51.12 & 59.41 & 48.26 & $52.4 \%$ & 60.98 & 50.70 & 55.12 & 64.06 \\
\hline 16 & 46.69 & 50.77 & 59.00 & 47.88 & 52.05 & 60.50 & 50.21 & 54.59 & 63.44 \\
\hline 17 & 46.40 & 50.45 & 58.63 & 47.54 & 51.68 & 60.07 & 49.78 & 54.12 & 62.90 \\
\hline 18 & 16.14 & 50.16 & 58.30 & 47.24 & 51.35 & 59.69 & 49.39 & 53.69 & 62.41 \\
\hline 19 & 45.90 & 49.91 & 58.01 & 46.96 & 51.06 & 59.35 & 49.04 & 53.31 & 61.97 \\
\hline 20 & 45.69 & 49.67 & 57.74 & 46.71 & 50.79 & 59.03 & 48.72 & 52.97 & 61.57 \\
\hline 21 & 45.49 & 49.46 & 57.49 & 16.19 & 50.54 & 58.75 & 48.43 & 52.65 & 61.20 \\
\hline 22 & 45.32 & 49.27 & 57.27 & 46.28 & 60.32 & 58.49 & 48.16 & 52.37 & 60.87 \\
\hline 23 & 45.15 & 49.09 & 57.07 & 46.09 & 50.11 & 58.25 & 47.92 & 52.10 & 60.56 \\
\hline 24 & 45.00 & 48.93 & 56.88 & 45.91 & 49.92 & 58.03 & 47.69 & 51.86 & 60.28 \\
\hline 25 & 44.86 & 48.78 & 56.70 & 45.75 & 49.74 & 57.83 & 47.49 & 51.63 & 60.02 \\
\hline 26 & 44.73 & 48.63 & 56.54 & 45.60 & $=49.58$ & 57.64 & 47.29 & 51.42 & 59.77 \\
\hline 27 & 44.61 & 48.50 & 56.38 & 45.46 & 49.43 & 57.46 & $4 \% .11$ & 51.22 & 59.55 \\
\hline 28 & 44.50 & 48.38 & 56.24 & 45.33 & 49.28 & 57.29 & 46.94 & 51.04 & 59.33 \\
\hline 29 & 44.39 & 48.27 & 56.11 & 45.20 & 49.15 & 57.14 & 46.78 & 50.87 & 59.14 \\
\hline 30 & 44.29 & 48.16 & 55.98 & 45.09 & 49.02 & 56.99 & 46.64 & 50.71 & 58.95 \\
\hline 35 & 43.87 & 47.70 & 55.46 & 44.60 & 48.49 & 56.38 & 46.01 & 50.03 & 58.16 \\
\hline 40 & 43.55 & 47.35 & 55.05 & 44.22 & 48.09 & 55.90 & 45.52 & 49.50 & 57.55 \\
\hline 45 & 43.29 & 47.07 & 54.73 & 43.92 & 47.76 & 55.52 & 45.13 & 49.08 & 57.06 \\
\hline 50 & 43.08 & 46.85 & 54.46 & 43.67 & 47.49 & 55.21 & 44.81 & 48.73 & 56.65 \\
\hline 60 & 42.76 & 46.49 & 54.05 & 43.29 & 47.07 & 54.73 & 44.32 & 48.19 & 56.02 \\
\hline 70 & 42.51 & 46.23 & 53.75 & 43.00 & 46.76 & 54.37 & 43.95 & 47.78 & 55.55 \\
\hline 80 & 42.33 & 46.02 & 53.51 & 42.78 & 46.52 & 54.08 & 43.65 & 47.47 & 55.19 \\
\hline 90 & 42.18 & 45.86 & 53.32 & 42.60 & 46.32 & 53.86 & 43.42 & 47.21 & 54.89 \\
\hline 100 & 42.05 & 45.72 & 53.16 & 42.45 & 46.16 & 53.67 & 43.22 & 47.00 & 54.64 \\
\hline 200 & 41.43 & 45.04 & 52.37 & 41.70 & 45.35 & 52.72 & 42.23 & 45.92 & 53.39 \\
\hline 500 & 40.94 & 44.52 & 51.76 & 41.12 & 44.71 & 51.98 & 41.44 & 45.06 & 52.39 \\
\hline$\infty$ & 40.26 & 43.77 & 50.89 & 40.26 & 43.77 & 50.89 & 40.26 & 43.77 & 50.89 \\
\hline
\end{tabular}




\section{APPENDIX E}

PROGRAM FOR DETERMINING IF THE TOLERANCE ELLIPSOID IS WITHIN THE SPECIFICATION ELLIPSOID

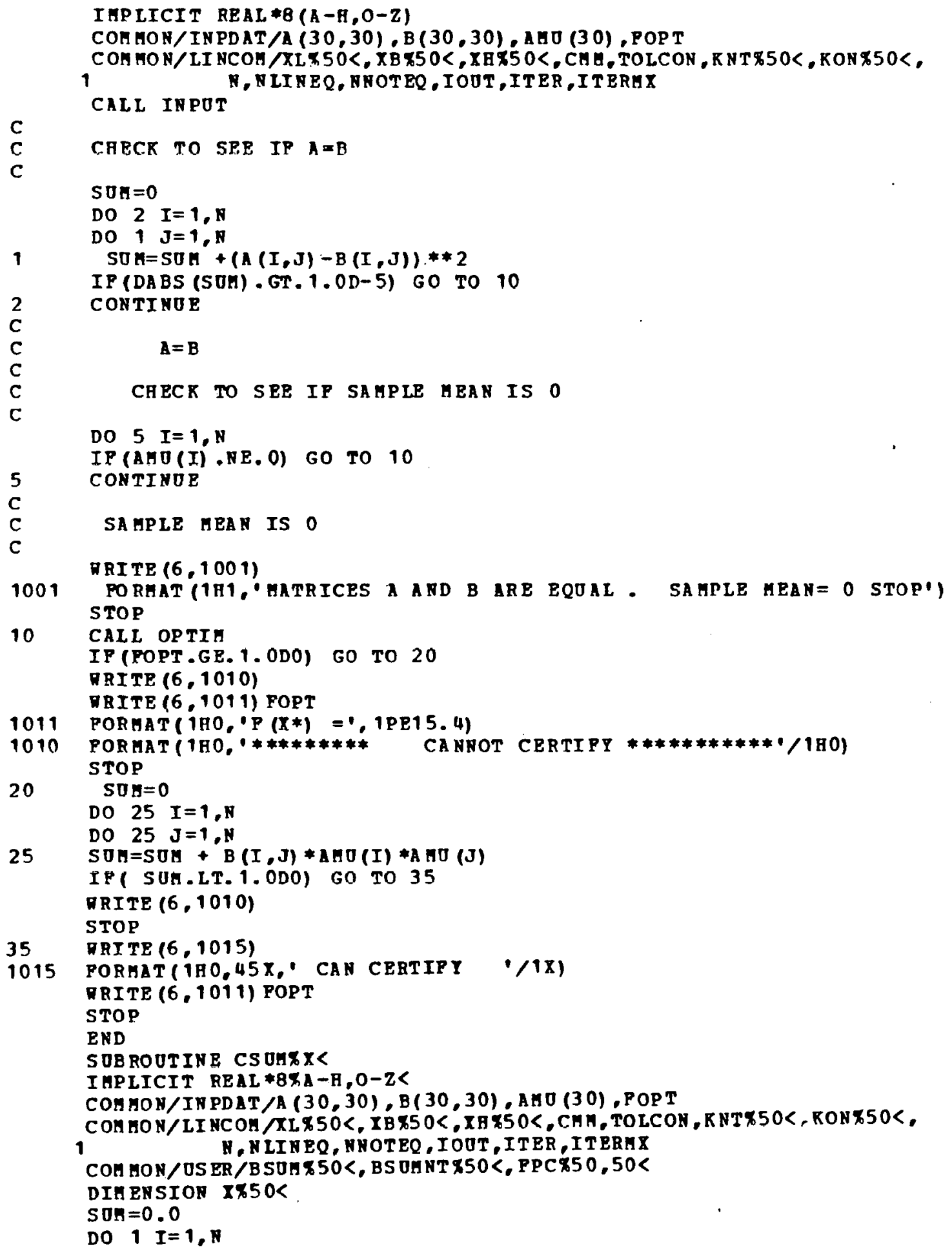


DO $1: J=1, N$

$5 \quad \operatorname{PPC}(R, 1)=2.0 * 50 \mathrm{R}$

RET OR N

END

S OBROOTINE EVALXI, Y, IOUTS

IHPLICIT REAL $\$ 8 \% A-H, U-Z<$ DIEENSION $\times \$ 50<, D \% 4<, \times D \times 4<$

CONHON/LIRCOH $X I \$ 50<$, XB\$50<, XH\$50<,CHA, TOLCON, KNT\$50<, KON\$50<, 1 N, NITHEQ, NNOT EQ, IOTT, ITER, ITERHX COHHON/IR PDAT/A $(30,30), B(30,30), A$ A $(30)$, POPT

$Y=0$

DO $5 \quad I=1, R$

952 PORMAT(1X,I3, 1P1OE12.4)

20 CORTINOE DO $30 \quad I=1, N$

$\operatorname{READ}(5,910)(B(I, J), J=1, N)$ DO $25 \mathrm{~J}=1, \mathrm{~N}$

$25 B(I, J)=B(I, J) / B N O R A$

30 CONTINOE

READ $(5,910)$ (A MU (I) $, I=1, N)$

NBITE $(6,953)$ ( ANO (I), I= $1, N$ )

953 PORAAT (1HO. MEANS=?, IP 10 E 12.4) HETURE

END 


\section{ACKNOWLEDGEMENTS}

Appreciation is expressed to Professor Robert A. McLean of The University of Tennessee who directed this study. Also, thanks go to R. R. Coveyou of the Oak Ridge National Laboratory for his helpful advice concerning some of the numerical analysis problems encountered in the study. A special thanks goes to Wayne Morrison of the Oak Ridge National Laboratory who performed a large portion of the computer programming. Appreciation is also extended to the Oak Ridge Y-12 Plant for its cooperation in all phases of my classroom work. 


\section{DISTRIBUTION}

Atomic Energy Commission - Oak Ridge

Hickman, H. D.

Leed, R. E.

Zachry, D. S., Jr

Los Alamos Scientific Laboratory

Zeigler, R. K.

Oak Ridge Gaseous Diffusion Plant

Handley, B. J.

Reavis, J. P.

Wilcox, W. J., Jr

Winkel, R. A.

Oak Ridge National Laboratory

Gardiner, D. A.

Morrison, G. W.
Smith, J. H.

Smith, R. D.

Stoner, H. H.

Tewes, W. E.

Weathersby, W. E.

Whitson, W. K.

Yaggi, W. J./Googin, J. M.

$Y-12$ Central Files (5)

$Y-12$ Central Files (master copy)

$Y-12$ Central Files (route copy)

$Y-12$ Central Files ( $Y-12 R C$ )

Zerby, C. D.

Paducah Gasenıs Diffusion Plant

Levin, R. W.

Sandia - Livermore

De Carli, C. J.

Oak Ridge Y-12 Plant

Alvey, H. E.

Bernander, N. K.

Briscoe, O. W.

Burditt, R. B.

Burkhart, L. E.

Denny, A.

Ellingson, R. D.

Foulk, D. L.

Fraser, R. J.

Holland, C. W. (20)

Jackson, V. C.

Jones, F. W.

Kahl, K. G.

Keith, A.

Kite, H. T.

Lundin, M. I.

McLendon, J. D.

Oliphant, G. W.

Phillips, L. R.

In addition, this report is distributed in accordance with the category UC-32, Mathematics and Computers, as given in the USAEC Standard Distribution Lists for Unclassified Scientific and Technical Reports, TID-4500. 